\title{
Seismic scattering and absorption mapping from intermediate-depth earthquakes reveals complex tectonic interactions acting in the Vrancea region and surroundings (Romania)
}

\author{
F. Borleanu ${ }^{(1,2)}$, L. De Siena ${ }^{(1,3)}$, C. Thomas ${ }^{(1)}$, M. Popa $^{(2)}$, M. Radulian ${ }^{(2)}$ \\ ${ }^{1}$ Institute for Geophysics, University of Munster (Germany); ${ }^{2}$ National Institute for Earth Physics (Romania); ${ }^{3}$ School of \\ Geosciences, University of Aberdeen (Scotland)
}

\section{Abstract}

The Vrancea region, located at the southeastern edge of the Carpathians arc bend, is a region of intense seismicity, whose major earthquakes produce hazard in southeastern Europe. Despite the consequent focus of the geophysical and geological community on providing accurate structural and dynamical models of Vrancea, these are still subject to numerous controversies and debates. In the present study, we use intermediate-depth seismicity recorded by the broadband stations of the Romanian Seismic Network between 2009 and 2011 to measure S-wave peak delay times and late-time coda quality factors. After mapping these two quantities in space, a cluster analysis provides a quantitative structural interpretation of the region in terms of different attenuation mechanisms affecting the seismic wave field, i.e. seismic scattering and seismic absorption. The results show that scattering is higher west and northwest of Vrancea, while absorption dominates in the Focsani Basin, located in the forearc region. In general, we obtain higher absorption in stable regions, with patterns emphasized at high-frequency affected by the presence of hydrocarbons and natural gas reservoirs in the upper crustal layers. Regions characterized by active seismicity and structural heterogeneity show higher scattering, spatially correlated with the highest velocity contrasts and the lowest density. The high-frequency scattering/absorption contrasts obtained using the cluster analysis depict a southwest-to-northeast lithospheric contrast, following the epicentral trend of Vrancea earthquakes, and characteristic of either lithospheric subduction or delamination. Low-frequency cluster analysis results, sampling deeper Earth layers, mark a unique high-absorption trend perpendicular to the epicentral trend, feasibly linked to Neogene volcanism, and induced by the back-arc mantle upwelling. Its most recent expression is Ciomadul volcano, located at the northwestern limit of the absorption trend.

Key words: Seismic attenuation, Vrancea region, intermediate depth earthquakes, peak delay times, coda quality factor, cluster analysis 


\section{INTRODUCTION}

The Vrancea region, located at the southeastern edge of the Carpathians arc bend in Romania (Figure 1a), represents one of the most seismically-active areas in Europe. Crustal- and intermediate-depth earthquakes overlay within the area. The intermediate-depth earthquakes are located in a small lithospheric volume going down in the mantle and cause important seismic hazard over large distances. Up to 4 - 5 events per century with magnitudes up to 7.9 (according to the Romplus catalog, Oncescu et al. 1999) are generated here. The earthquakes occurred in the shallower crust are characterized by moderate magnitudes (below 6) and spread over an extended area.

The competing effects of absorption, scattering, and geometrical spreading in 3-D structures cause the loss of seismic wave energy while travelling through the Earth. The study and 2D mapping of (1) anelastic absorption, related to temperature, chemical composition, melt or fluid content and (2) scattering of seismic waves on heterogeneities affecting different frequency ranges is an ideal complement to velocity tomography measurements, improving hazard assessment for regions exposed to strong ground motion. Nevertheless, the complex pattern of seismic radiation generated by an earthquake generally corrupts both the estimation of total seismic attenuation and the separation of specific attenuation mechanisms using direct waves (Del Pezzo et al. 2011). Subcrustal earthquakes in the Vrancea region near the Carpathians Arc in Romania (Figure 1) exhibit such complex ground motion patterns, with significant differences between the areas inside and outside of the Carpathians Arc. These differences are mainly attributed to attenuation properties (Popa et al. 2005; Russo et al. 2005; Oth et al. 2008) and the region is thus an ideal setting to apply methodologies that separate and map different attenuation mechanisms, in particular seismic scattering from seismic absorption (Takahashi et al. 2007; Calvet et al. 2013a). Oancea et al. (1991) were the first to measure $Q$ values of the order of $700-800$ for the region of maximum seismicity using Vrancea intermediate-depth earthquakes and coda wave analysis. Spatial variations of the attenuation patterns have been obtained by the comparison of waveforms produced by small- and moderate-magnitude Vrancea subcrustal earthquakes (Popa et al. 2003; 2005). Seismic amplitudes decrease by a factor of 10 to 100 for events occurring at the back-side part with respect to those occurring at the fore-side part. Sudhaus et al. (2005) used teleseismic waveforms from a seismic refraction experiment (VRANCEA99) to study seismic attenuation, and found relatively high-attenuation anomalies in the Carpathian Mountains as well as in the sedimentary basins. Russo et al. (2005) estimated S-wave quality factors for intermediate-depth earthquakes; their results show low attenuation east and north of Vrancea (Figure 1) and high attenuation in both the epicentral area and the Transylvanian Basin. Similar results were obtained by Ivan (2007) from 
teleseismic recordings of $\mathrm{P}$ and $\mathrm{pP}$ waves, while Radulian et al. (2006) show that attenuation is strongly frequency-dependent especially toward NW of Vrancea, at least with respect to SE. Oth et al. (2008) analysed the attenuation characteristics of $S$-wave spectra and found that attenuation is roughly homogeneous in the low frequency range $(<4-5 \mathrm{~Hz})$ for any propagation path, while at higher frequencies the attenuation in the Carpathian Mountains arc is over ten times stronger than that in the foreland area. The authors attribute this difference to the intrusion of hot asthenosphere beneath the Carpathians back-arc region. An overview of these studies is given in Table 1 and shown schematically in Figure $1 \mathrm{~b}$. While all these studies focus on seismic attenuation in the region, they do not distinguish between two different attenuation mechanisms, namely scattering attenuation and absorption.

Table 1. An overview of the attenuation effects for Vrancea subcrustal earthquakes within Romania according to various studies

\begin{tabular}{|c|c|c|}
\hline Study & low-attenuation & high-attenuation \\
\hline Oancea et al. (1991) & $\begin{array}{l}\text { High Qc (700- } 800) \text { within } \\
\text { the Carpathians bend }\end{array}$ & - \\
\hline Sudhaus et al. (2005) & & $\begin{array}{l}\text { Revealed in the Carpathian Mountains as well } \\
\text { as in the sedimentary basins }\end{array}$ \\
\hline Russo et al. (2005) & $\begin{array}{l}\text { Pointed out high Qs (low } \\
\text { attenuation) in Platform } \\
\text { regions and stable } \\
\text { Precambrian craton areas }\end{array}$ & $\begin{array}{l}\text { In tectonically active regions - especially } \\
\text { where asthenosphere lies at shallow levels }\end{array}$ \\
\hline $\begin{array}{l}\text { Popa et al. (2003; } \\
2005)\end{array}$ & $\begin{array}{l}\text { Shown in the foreland } \\
\text { platform }\end{array}$ & $\begin{array}{l}\text { Affects mostly high frequencies; the } \\
\text { amplitudes are reduced by a factor of } 20 \text { in } \\
\text { the Transylvanian Basin and the Eastern } \\
\text { Carpathians }\end{array}$ \\
\hline Radulian et al. (2006) & $\begin{array}{l}\text { Low attenuation in the } \\
\text { extra-Carpathians areas }\end{array}$ & $\begin{array}{l}\text { Strong attenuation at high frequencies } \\
\text { explains the low damage to structures in the } \\
\text { intra-arc region }\end{array}$ \\
\hline Ivan (2007) & $\begin{array}{l}\text { The volume is limited to } \\
\text { the East by the } 26^{\circ} 30^{\prime} \\
\text { meridian }\end{array}$ & $\begin{array}{l}\text { Has been observed for stations located in the } \\
\text { northwestern part of the Vrancea seismogenic } \\
\text { volume; no clear spatial correlation exists } \\
\text { between attenuation values and shallow } \\
\text { geological settings }\end{array}$ \\
\hline Oth et al. (2008) & $\begin{array}{l}\text { Was shown in the } \\
\text { foreland, variability } \\
\text { strongly increases with } \\
\text { increasing frequency }\end{array}$ & $\begin{array}{l}\text { Characterizes the Vrancea area; and the inner } \\
\text { sideof the mountain arc in the Transylvanian } \\
\text { Basin }\end{array}$ \\
\hline
\end{tabular}

87

The goal of the present study is to measure and map these two mechanisms in the Vrancea region and adjacent areas, i.e., to interpret them in terms of crustal and mantle structures and tectonic processes. We apply a set of techniques, namely peak delay time and coda quality factor mapping and 2D K-means cluster analysis, which have been widely used to 
image the heterogeneous crust in regions such as Japan (Sato, 1989; Obara and Sato, 1995; Petukhin and Gusev, 2003; Saito et al. 2002, 2005; Takahashi et al. 2007, 2009; Tripathi et al. 2010), the Pyrenean range (Calvet et al. 2013a), and local volcanoes (De Siena et al. 2011; Prudencio et al. 2013; De Siena et al. 2016). After presenting both the data used in our analysis and the limitations of the methods in terms of effective sensitivity of seismic waves to Earth structures, we discuss the results focusing on the novel insight they provide on the main seismo-tectonics and geological structures in the region.

\section{SEISMOTECTONIC OVERVIEW}

The SE Carpathian arc formation is related to the Alpine orogeny as a result of the collision of the Tisza-Dacia microplate in the West, the stable cratonic East European Platform in the East (Sandulescu, 1984, 1988) and Moesian Platform in the south east. Many studies showed that the Carpathian unit collided with the W-SW part of Moesia in Mid-Cretaceous times, rotated subsequently around its corner and since the Paleogene moved towards their present position (Săndulescu, 1988; Schmid et al. 1998; Hippolyte et al. 1999; Maţenco and Schmid, 1999). During the Tertiary, an oceanic or thinned continental lithosphere was subducted below the East-Carpathians (e.g. Săndulescu, 1988; Wortel and Spakman, 2000). The active shortening process stopped during the late Oligocene-Early Miocene periods (about 20 MA) when all the oceanic-type basins were closed (Ellouz and Roca, 1994; Linzer et al. 1998). Different studies explained the time difference between the end of the shortening process and lithospheric subduction and the beginning of the volcanic activity in the Eastern Transylvanian Basin characterized by calc-alkaline and alkali basaltic eruptions of magmas (Szakacs, 1993; Seghedi and Szakacs, 1994; Downes et al. 1995; Seghedi et al. 1998) by various geodynamic processes like roll-back, detachment and/or break-off of the subducted lithospheric slab (Csontos, 1995; Mason et al. 1998; Seghedi et al. 1998; Linzer et al. 1998), or delamination of the lower part of the lithospheric mantle from the lower plate (Gîrbacea, 1997; Gîrbacea and Frisch, 1998; Chalot-Prat and Gîrbacea, 2000). In this setting the Vrancea region, located at the limit of the SE Carpathian arc (Figure 1) is a region with notable crustal- and intermediate-depth seismicity with magnitudes up to 7.9, which can be used to illuminate the entire area. Earthquakes are generally located beneath the external thin-skinned thrust belt of the SE Carpathians at depths down to $220 \mathrm{~km}$ (Oncescu and Bonjer, 1997; Bala et al. 2003). Martin et al. (2005) have shown that the SE Carpathians area has a complex lithospheric structure because of its young and intense tectonic evolution. At least three distinct lithospheric blocks are in contact and responsible for the seismicity in Vrancea (Figure 1): (1) toward NE the East European Platform, (2) the 

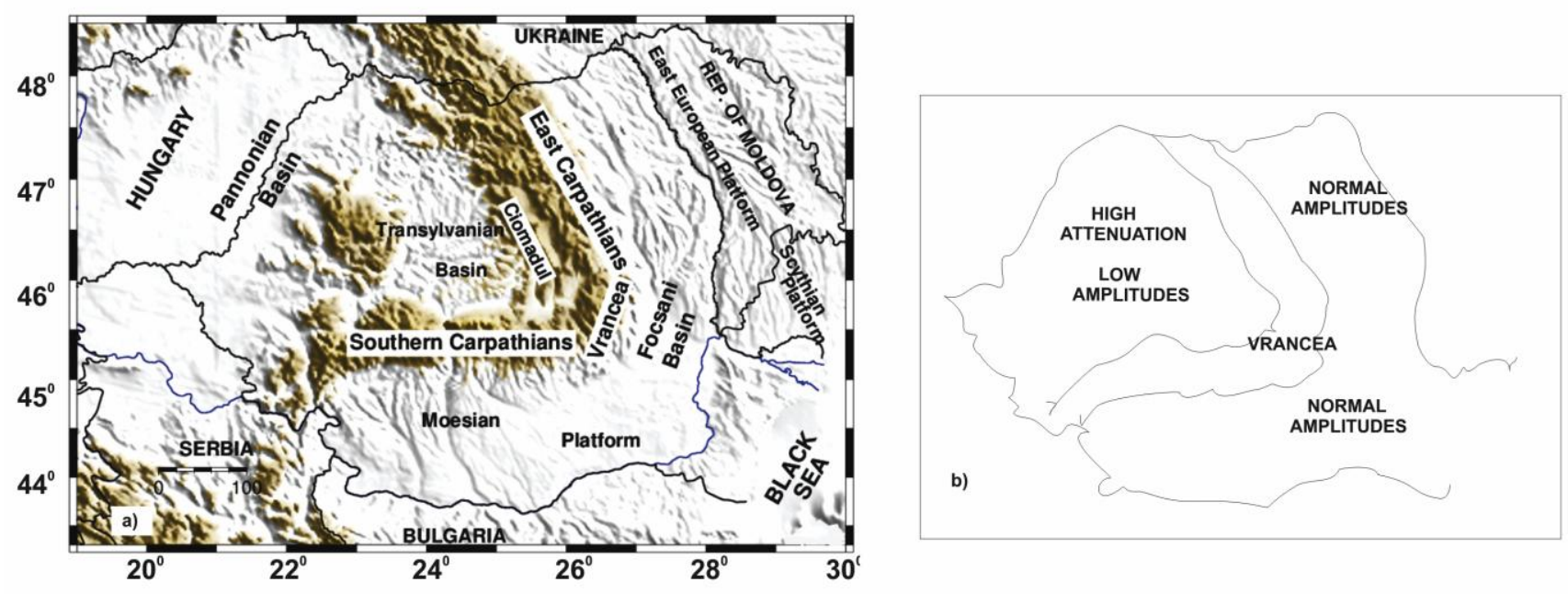

Figure 1 Simplified tectonic map of Romania (a) and sketch representing the attenuation mechanism (b) for the study area according to researches given in Table 1.

\section{DATA}

Velocity waveforms of local earthquakes in the Vrancea region recorded by 3-component broadband stations belonging to Romanian Seismic Network (RSN) of the National Institute for Earth Physics (NIEP) were used in the present study. The hypocentral distance of the selected earthquakes is in the range of 100 to $250 \mathrm{~km}$. The study region is characterised by good ray coverage due to the excellent aperture and station spacing of RSN, which has been constantly growing during the last decade (Neagoe and lonescu, 2009, Popa et al. 2015). A data set of 204 intermediate-depth earthquakes (depths between 50 and $168 \mathrm{~km}$ ) occurring mostly between 2009 and 2011 with magnitudes ranging from 2.9 to 5.0, was selected for the analysis. The Romanian Data Centre (RONDC) of NIEP (Romplus catalogue, Oncescu et al. 1999, which is constantly updated) provided earthquake parameters as well as P- and S-wave travel times. The distribution of hypocentres, the seismic station coverage, and the ray density are shown in Figure 2. 

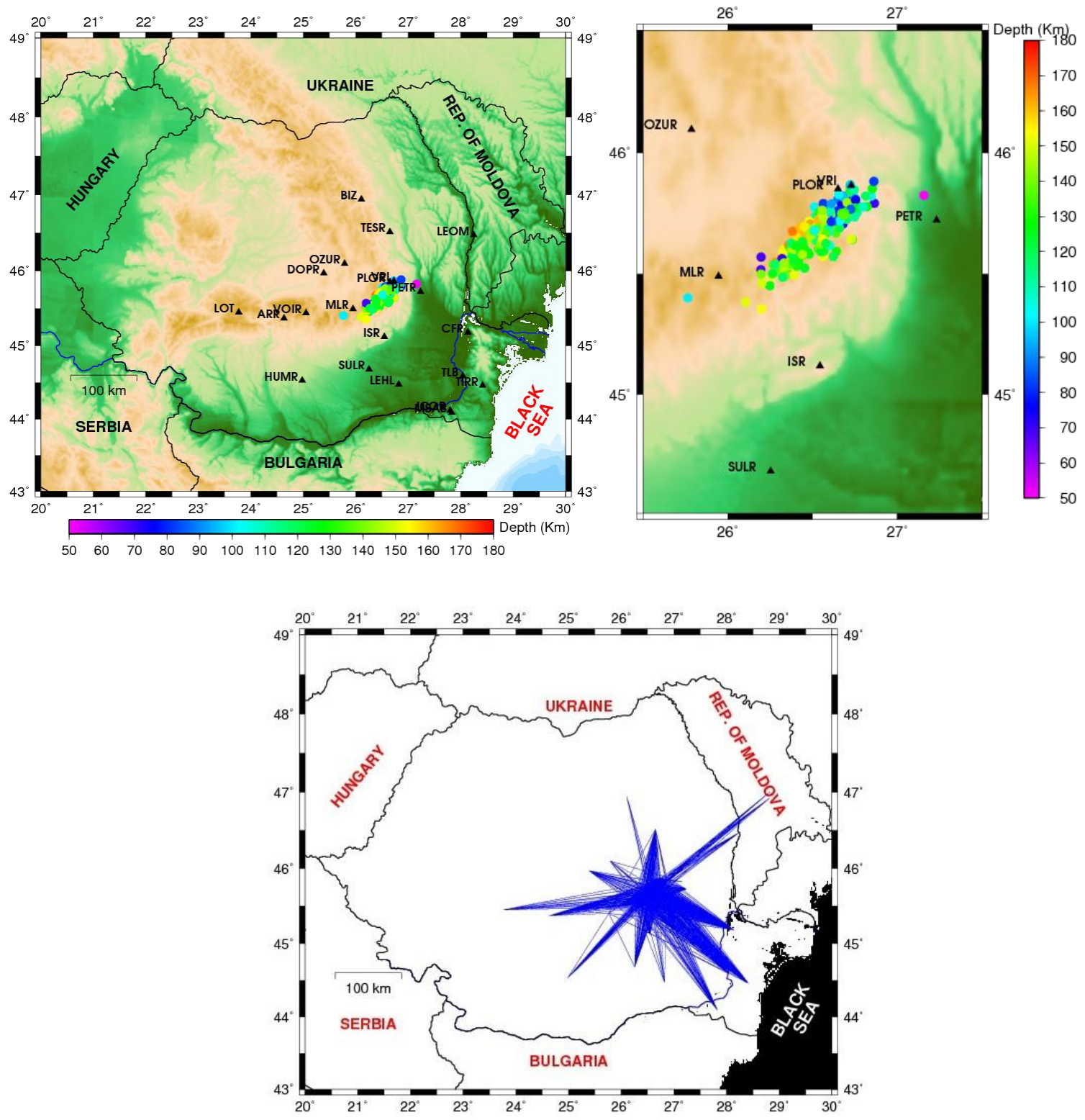

Figure 2 Epicenters (colored dots show depth) and stations distribution (black triangles) used in this study (top-left); a zoom on the seismicity, located in a SSW-NNE-trending vertical volume (top-right); the seismic ray paths density (bottom).

After the deconvolution of the instrument response, a fourth-order Butterworth bandpass filter was applied to each seismogram in forward and backward directions to obtain waveforms in 4 frequency bands $(2-4 \mathrm{~Hz}, 4-8 \mathrm{~Hz}, 8-16 \mathrm{~Hz}$ and 12-24 Hz). Envelopes for each frequency band were then computed as the root-mean-square (RMS - a direct measurement of seismic intensity) of each horizontal velocity seismograms (Figure 3). Finally, we applied smoothing using a moving time window whose typical duration is twice the central period of each frequency band. 


\section{METHODS}

\subsection{PEAK DELAY TIME (SCATTERING) MAPPING}

The peak delay time (Tpd) is defined as the time-difference between the S-wave onset and the maximum amplitude of the envelope, a well-known measurement of forward scattering (Takahashi et al. 2007, 2009; Tripathy et al. 2010; Calvet et al. 2013a). For each frequency band (central frequencies $3 \mathrm{~Hz}, 6 \mathrm{~Hz}, 12 \mathrm{~Hz}$, and $18 \mathrm{~Hz}$ ) the maximum was picked on the $\mathrm{EW}$ and NS components at each station in a time-window of $30 \mathrm{~s}$ duration, starting at the Swave onset. After averaging the two component measurements, we obtain $1540 \mathrm{Tpd}$ measurements for each frequency band. Figure 3 shows the data processing for two station recordings of the same earthquake $(25 / 02 / 2010,15: 51: 28, M w=4.3$, depth $h=110 \mathrm{~km})$.
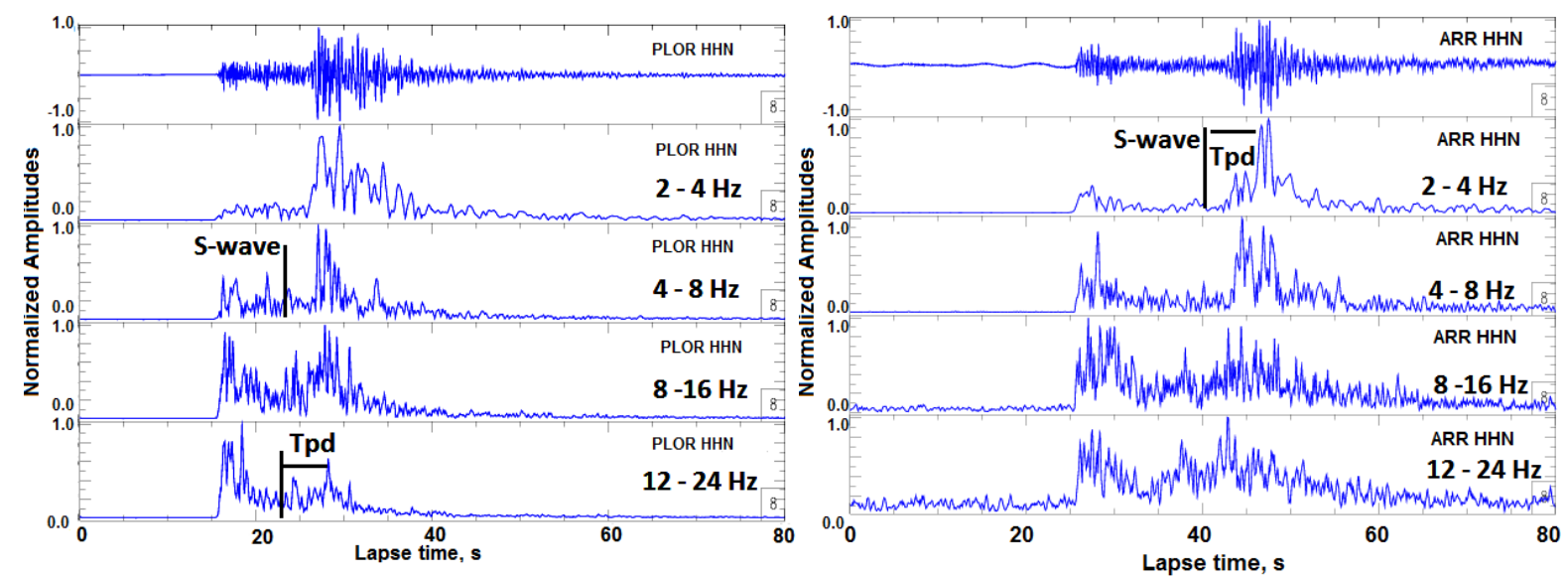

Figure 3 Examples of observed seismograms and their filtered envelopes at two stations: (left) PLOR situated around $140 \mathrm{~km}$ hypocentral distance and (right) ARR situated around $250 \mathrm{~km}$ (west relative to Vrancea) hypocentral distance. Top to bottom: velocity seismograms recorded by NS-components, filtered between 1 and $50 \mathrm{~Hz}$ after the deconvolution of the recording system response, and root mean square (RMS) envelopes in the 2-4 Hz, 4-8 Hz, 8-16 Hz, and 12-24 Hz frequency bands. The amplitudes were normalized to the maximum amplitude of each trace. The arrival of the S-wave and measurements of Tpd are shown in each panel.

\section{Correction of travel distance and frequency dependence of peak delay times}

We follow the selection criteria for distance of Sato (1989) and Takahashi et al. (2007) and consider source-station hypocentral distances in the range of 100 to $250 \mathrm{~km}$. This ensures that envelope broadening due to scattering does dominate over the source duration time (contrary to what happens at shorter distances), and that the travel distance dependence of the envelope broadening has the same characteristics along the entire hypocentral range (contrary to longer distances). The linear dependence of the logarithm of peak-delay times against hypocentral distances is shown in Figure 4 (red lines) and is characteristic for the selected frequency ranges at lithospheric scale (Takahashi et al. 2007; Tripathi et al. 2010). 
The linear fit corresponds to the following equation and is used to correct for the hypocentral distance $(\mathrm{R})$ dependence:

$$
\log _{10} T p d(f)=A_{r}(f)+B_{r}(f) \log _{10} R
$$

Both the regression coefficients $\left(A_{r}\right.$ and $\left.B_{r}\right)$ and the root mean square errors (RMSE) are given in Table 2.

Table 2. Estimated coefficients from peak delay time distance corrections, obtained by leastsquare regression for each frequency band. The right hand column shows the root mean square values (RMSE)

\begin{tabular}{|l|l|l|l|}
\hline Frequency (HZ) & Ar & Br & RMSE \\
\hline $\mathbf{2}-\mathbf{4 ~ H z}$ & 0.9803 & -0.1976 & 0.0875 \\
\hline $\mathbf{4}-\mathbf{8 ~ H z}$ & 0.4018 & -0.0327 & 0.1250 \\
\hline $\mathbf{8}-\mathbf{1 6 ~ H z}$ & -0.0835 & 0.1490 & 0.1577 \\
\hline $\mathbf{1 2}-\mathbf{2 4 ~ H z}$ & -0.5725 & 0.3526 & 0.1747 \\
\hline
\end{tabular}

Figure 4 reveals three important features of the regression trends with increasing frequency: (i) the slope of the regression trends increases, (ii) measurements are increasingly spread around the regression trend, and (iii) the slopes change from negative (3-6 Hz) to positive $(12-18 \mathrm{~Hz})$. Feature (i) is typical of upper-crustal measurements, especially at $3 \mathrm{~Hz}$, while features (ii) and (iii) are different with respect to what is generally observed at lithospheric scale (Takahashi et al. 2007; Calvet et al. 2013a).

Several studies (Popa et al. 2005; Oth et al. 2008) have previously highlighted that attenuation is frequency-dependent, with attenuation variability strongly increasing with increasing frequency. In particular, Oth et al. (2008) have shown that, at high frequencies (> 4-5 Hz), there is approximately one order of magnitude difference in attenuation between the recordings in the Carpathians and the foreland areas, whereas, at lower frequencies, the attenuation characteristics in both regions are similar. Possible physical explanations for this frequency-dependent behaviour of attenuation involve the degree of coupling between the slab and the overlying crust (Sperner et al. 2005), strong temperature effects (Zadeh et al. 2005), as well as scattering phenomena within the subducted lithosphere (Furumura and Kennett, 2005). We rely on the results of Saito et al. (2002), who showed that envelope broadening strongly increases with frequency if the content of short-wavelength (strong velocity fluctuations) in random media increases. This and the aforementioned results all agree with higher variation of high-frequency peak-delay measurements and indicate a dominance of small-scale heterogeneities in Vrancea and surrounding areas (feature ii). 
229 It has been shown by several authors that coda-waves at $3 \mathrm{~Hz}$ comprise surface waves 230 (Obermann et al. 2013; Popelliers et al. 2014; Galluzzo et al. 2015; De Siena et al. 2015). 231 Nevertheless, while surface-wave components could affect Qc measurements, this is no 232 feasible explanation for the lowering of the peak-delay times with hypocentral distance at low 233 frequencies (feature iii, Figure 4): if we would pick surface waves instead of S-waves we 234 would observe a time dispersion, i.e., peak-delays increasing with hypocentral distance. 235 Takahashi et al. (2007), who analysed data in a similar depth range similar but with a more 236 extended lateral coverage, did not observe noticeable changes in the behaviour of the linear 237 hypocentral-correction fit among different frequency ranges. Calvet et al. (2013a) noticed 238 changes of the slope of the regression line for different frequencies using seismicity located 239 in the upper crustal layers with less extended network coverage. However, they did not measure a negative slope. Our preferred explanation for feature (iii) is thus related (a) to the particular geometry of the hypocenters in our dataset and (b) to the different sensitivity of peak-delay measurements to depth in different frequencies. Seismic events are clustered inside a relatively-small lithospheric volume with respect to the extension of the seismic network. At larger hypocentral distances, $3 \mathrm{~Hz}$ and $6 \mathrm{~Hz}$ waves progressively sample deeper, more-compact/lower-scattering Earth layers, thus consistently showing a decrease in peak-delay time with distance. $12 \mathrm{~Hz}$ and $18 \mathrm{~Hz}$ waves sample instead shallower and more inhomogeneous layers, presenting stronger scattering that increases peak-delay times at larger hypocentral distances. This difference in sensitivity is the main cause for the lowfrequency negative slopes in the peak-delay times. If our interpretation is correct, we can safely assume that (1) the linear dependence of peak delay times versus distance and (2) the increase of peak-delay slopes versus distance with increasing frequency (Figure 4) are sufficient to ensure the validity of the linear peak-delay time distance correction.
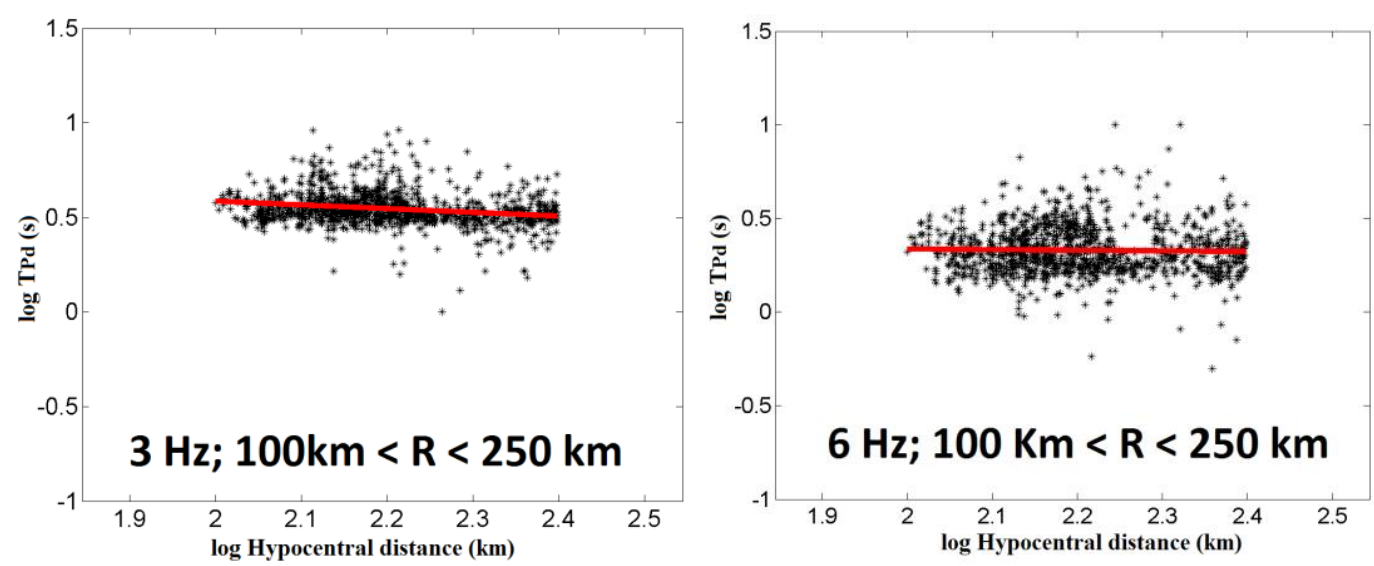

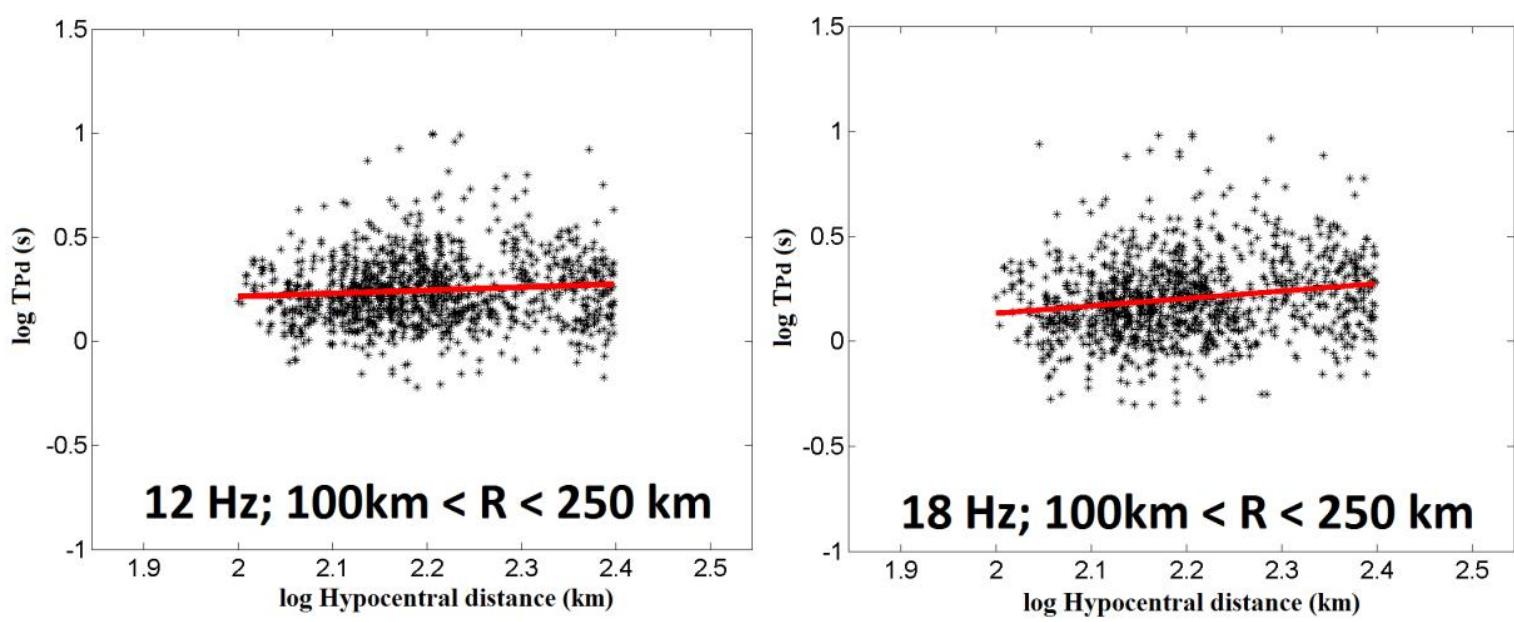

Figure 4 The logarithm of peak delay times (Tpd) against the logarithm of the hypocentral distance. Central frequency and distance range $(R)$ are shown in each panel.

\section{Spatial distribution of peak delay times in the Vrancea region and adjacent areas}

The 2-D spatial distribution of peak delay times (Tpd) was obtained following the approach of Takahashi et al. (2007) and Calvet et al. (2013a). The hypocentral distance dependence was removed for each frequency range computing Tpd differences following the equation:

$$
\Delta \log _{10} T_{p d}=\log _{10} T_{p d}(f)-\left(A_{r}(f)+B_{r}(f) \log _{10} R\right)
$$

where $\Delta \log _{10} T_{p d}$ are the mapped measurements and represent, in our interpretation, the strength of the scattering due to heterogeneities along the source-station path. The study region has been divided into squares of $0.25^{\circ} \times 0.25^{0}$. The average value of $\Delta \log _{10} T_{p d}$ from all rays crossing the square is allocated in space to the centre of the square and results are then interpolated. Figure 5 shows the $\Delta \log _{10} T_{p d}$, maps in the four frequency bands. We took into account only squares crossed by a minimum of 4 rays. Red regions are characterized by low $\Delta \log _{10} T_{p d}$ values (low scattering), while blue regions are characterized by high $\Delta \log _{10} T_{p d}$ values (strong scattering). 

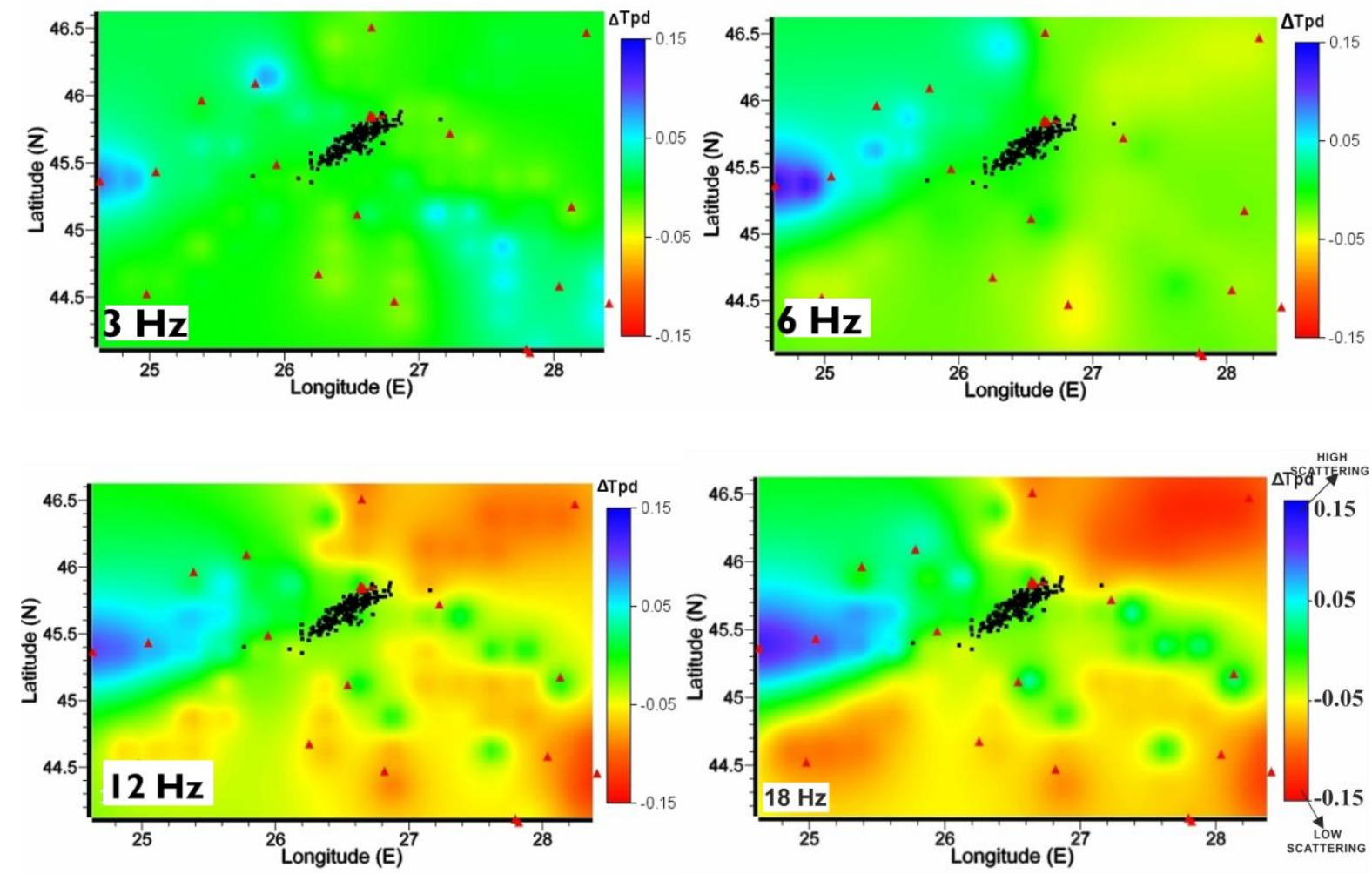

Figure 5 Maps of logarithmic peak delay times differences for the selected frequency ranges. Red triangles represent seismic stations and black dots earthquake epicenters. Blue regions are characterized by strong scattering; red denotes areas of low scattering.

From a smooth spatial distribution of scattering heterogeneity at low frequencies $(3 \mathrm{~Hz})$ we pass to strongly variable scattering strengths for higher frequencies $(18 \mathrm{~Hz})$. Anomalies in the high-frequency range show spatial correlation with the S-waves seismic velocity patterns obtained by Ren et al. (2013) from ambient noise tomography at a depth of $4 \mathrm{~km}$ (Figure 6). These are also associated with the three major tectonic units, intersecting in the Vrancea region.

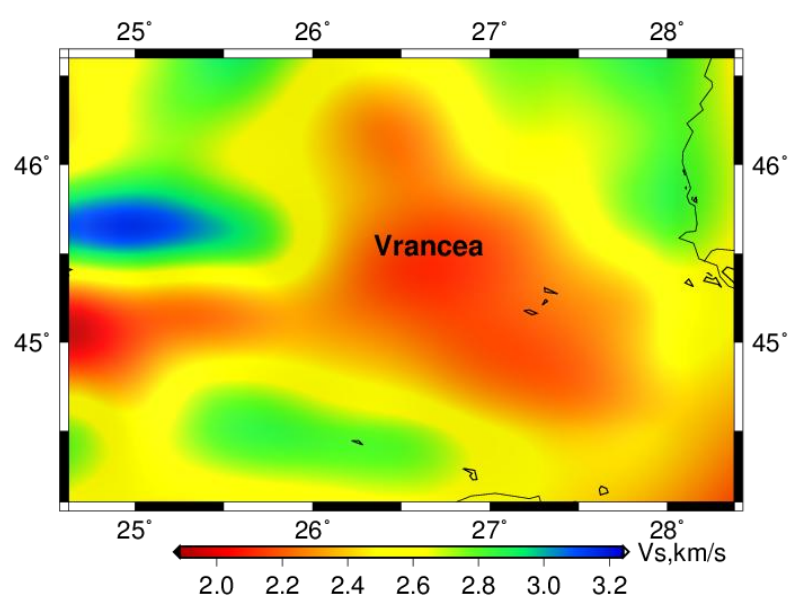

Figure 6 Horizontal section of $S$-waves velocity at a depth of $4 \mathrm{~km}$ according to Ren et al. 2013. 
300 In particular, the highest peak-delay time differences are distributed $\mathrm{W}$ and NW relative to 301 the Vrancea region, in the Transylvanian Basin, and are associated with the Carpathian Mountains roots, while the transition to the East European Platform to the Moesian Platform, east and northeast of Vrancea, produces low-/average-scattering anomalies (compare with Figure 1).

\subsection{CODA QUALITY FACTOR (ABSORPTION) MAPPING}

307

The quality factor $(Q)$ is a non-dimensional parameter (Knopoff, 1964) measuring the decrease in amplitude of a seismic wave travelling through a heterogeneous medium, thus used to quantify different media characteristics. The inverse coda quality factor $\left(Q_{c}{ }^{-1}\right.$, also called the coda attenuation factor) represents a direct measurement of seismic attenuation. According to Sato et al. (2012), $Q_{c}^{-1}$ is a linear combination of the inverse intrinsic quality factor $Q_{i}^{-1}$ (measuring intrinsic absorption) and the inverse scattering quality factor $Q_{s}^{-1}$ (measuring the energy scattered by the medium that can be recovered in seismic coda). Starting from Aki (1969), the $Q c^{-1}$ dependence from scattering and absorption as well as its connection to to tectonic stress has been the focus of several studies (e.g. Aki and Chouet 1975; Sato, 1977; Rautian and Khalturin, 1978; Hermann, 1980; Oancea et al. 1989b, 1991; Calvet et al. 2013a, b). In the present study, the single backscattering approach proposed first by Aki and Chouet (1975) is applied. It measures the coda attenuation factor from the decay of the energy envelope as a function of time $t$, according to the following equation:

where $A(f, t)$ represents the power spectral density, $A_{0}(f)$ is a source-dependent term, $t$ is the lapse time from the earthquake origin time, $f$ is the frequency, and $\alpha$ is the positive exponent (assumed equal to 1.5 following Calvet et al. 2013a). $Q_{c}^{-1}$ for a single station component was computed by a least-squares linear fit of $\log \left(A(f, t) t^{1.5}\right)$ versus $t$ in the four frequency bands used to measure peak delay times. The average over the two components was then taken as the source-station $Q_{c}^{-1}$. The envelope decay was measured (i) using a time window starting at the highest possible lapse-time from the origin of the earthquake, (ii) selecting those seismograms who had a signal-to-noise ratio higher than 1.5 and (iii) for which the correlation coefficient of the linear regression was greater than 0.5 . We obtain 1540 measurements for each frequency band. Figure 7 shows example-measurements for two different source-station pairs, using the same earthquake described in Figure 3. 
According to Calvet et al. (2013a, 2013b), the highest achievable lapse-time is selected (70 $\mathrm{s})$, so that the $Q_{c}^{-1}$ dependence on anisotropy and scattering attenuation is low, and the quantity can be considered a direct measurement of absorption. This assumption is not valid for shorter lapse times and higher levels of heterogeneity, where topography and different coherent effects might still affect the coda waves (Saito, 2010; Calvet et al. 2013a; De Siena et al., 2014). The signal-to-noise ratio after $90 \mathrm{~s}$ always drops below 1.5 for most sourcestation recordings, thus the coda time window $\left(t_{w}\right)$ is set at $20 \mathrm{~s}$.
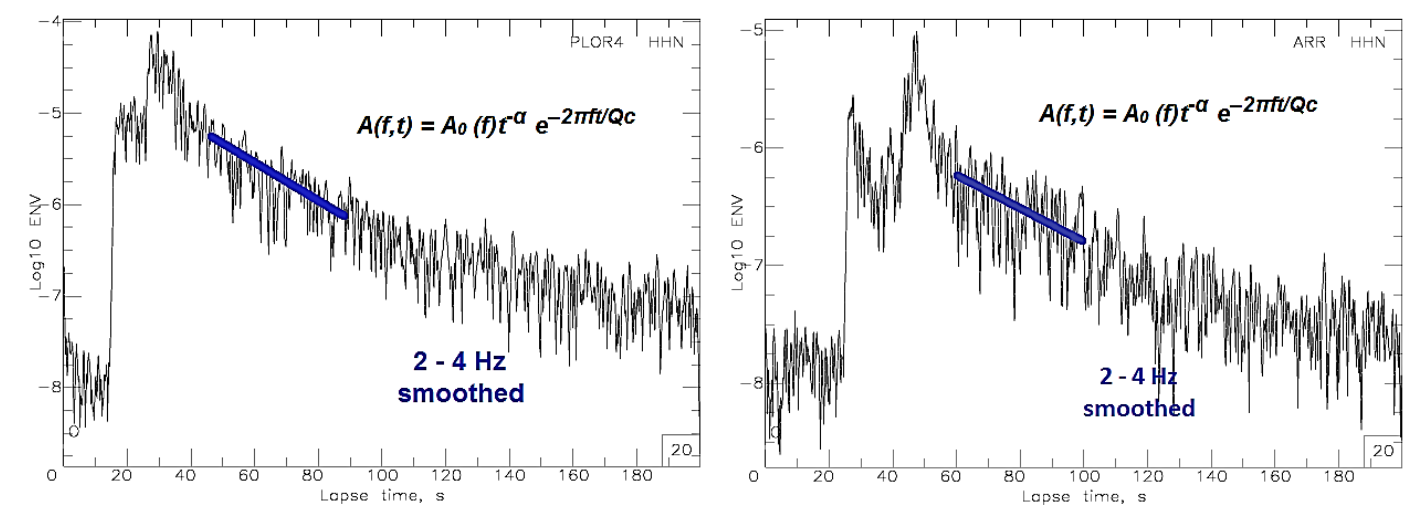

Figure 7 Examples of observed envelopes obtained from the NS components filtered between 2 and $4 \mathrm{~Hz}$ for station PLOR (left) situated at $140 \mathrm{~km}$ hypocentral distance and (right) for station ARR with a $250 \mathrm{~km}$ hypocentral distance. The two stations show different slopes for the envelope decay.

\section{Spatial distribution of $Q_{c}$ in the Vrancea region and adjacent areas.}

We adopt the same mapping strategy for both peak-delay times and coda quality factors, dividing the region into squares of $0.25^{0} \times 0.25^{\circ}$, allocating the average over ray values of $Q_{c}^{-1}$ to the centre of each square, and keeping only those crossed by at least 4 rays. The ray-dependent $Q_{c}{ }^{-1}$ values were finally divided by the average over the entire dataset $\left(Q_{m}{ }^{-1}\right)$. In Figure 8, red regions are associated with low $Q_{c}$ values (high absorption) whereas blue colors correspond to high $Q_{c}$ values (low absorption).

No clear correlation exists between the absorption maps and the three main tectonic units of the area. On the other hand, the absorption measurements are frequency dependent, with contrasts in absorption properties clearly enhanced at higher frequencies (Figure 8). At $3 \mathrm{~Hz}$, we observe secondary high-absorption anomalies crossing Vrancea from west to southeast, while at higher frequencies we observe a south-to-northeast absorption contrast, located between the outer and inner Carpathians, dominates the maps. 

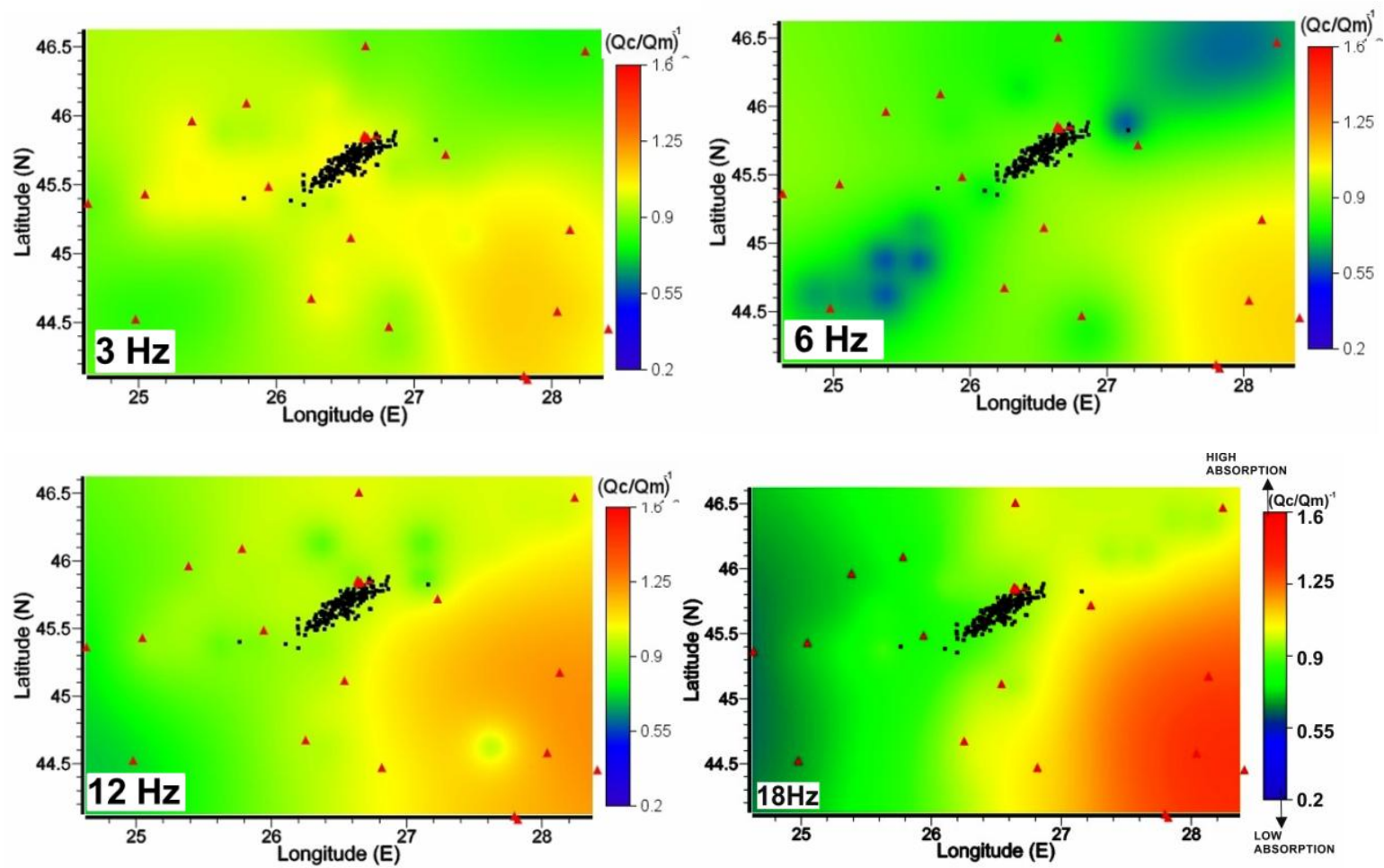

Figure 8 Maps of inverse coda quality factor divided by the mean of all measurements $\left(Q_{d} / Q_{m}\right)^{-1}$ for the selected frequency ranges. Red triangles represent seismic stations and black dots earthquake epicenters. Red colours show high absorption, blue colours low absorption.

Although the exact frequency-dependent sensitivity of coda waves to depth is still debated (e.g. Aki and Chouet, 1975; Shearer and Earle, 2004), it has been theoretically and experimentally shown that $3 \mathrm{~Hz}$ coda measurements are consisting of surface waves, making them particularly sensitive to surface structures (Calvet et al 2013a, Obermann et al. 2013; Mayor et al. 2014; Galluzzo et al. 2015; De Siena et al. 2016). Attenuation by absorption is more important in the upper crust than in the upper mantle (Sato et al. 2012). In a volcanic medium, the high heterogeneity and quick onset of the diffusion regime makes $Q_{c}$ particularly sensitive to shallow volcanic structures, as debris flows (Popelliers et al. 2015; De Siena et al. 2016). In a lithospheric setting however, different frequency-dependent behaviours are suggested by other studies (Calvet et al. 2013a, De Siena et al. 2014), with $Q_{c}$ measurements sampling deeper structures at lower frequencies: the results of the mapping at Vrancea agrees with this last interpretation, as higher spatial correlation with superficial lithospheric structures is found at higher frequencies.

\subsection{CLUSTER ANALYSIS}

To separate scattering and absorption patterns quantitatively using the maps of $\Delta \log _{10} T p d$

(Figure 5) and $\left(\mathrm{Qc}^{-} / \mathrm{Qm}\right)^{-1}$ (Figure 8) obtained in previous sections we have applied a non- 
hierarchical selection analysis known as K-means clustering (Hartigan, 1975) with Euclidean distance. Cluster analysis is a widely used method to separate data into groups depending on their physical characteristics. The main challenge this method presents is the estimation of an optimal number of clusters $(\mathrm{K})$, each cluster comprising objects with similar characteristics. According to Cornish (2007), the main disadvantage of cluster analysis is that there is no mechanism to differentiate between relevant and irrelevant variables when choosing the number of clusters. Therefore, the choice of variables included in a cluster analysis must be underpinned by conceptual considerations.

Our dataset comprises couples of peak-delay and $\left(\mathrm{Qc}^{-} / \mathrm{Qm}^{-1}\right.$ measurements, each couple corresponding to the centre of a square in space (De Siena et al., 2011). To compute the optimal number of clusters, we used the elbow method (Hartigan, 1975 - Figure 9 shows the curve obtained at $3 \mathrm{~Hz}$ ) and the Bayesian Information criterion (BIC - Schwartz, 1978). At all frequencies the number of clusters selected is two (see De Siena et al. 2011 for a similar analysis). A 2-mean cluster analysis was thus performed separately for all frequency ranges, with results (Figure 10) showing areas of either stronger absorption (orange) or stronger scattering (cyan). At all frequencies, absorption dominates south-east of Vrancea while scattering attenuation is stronger north and north-west of Vrancea.

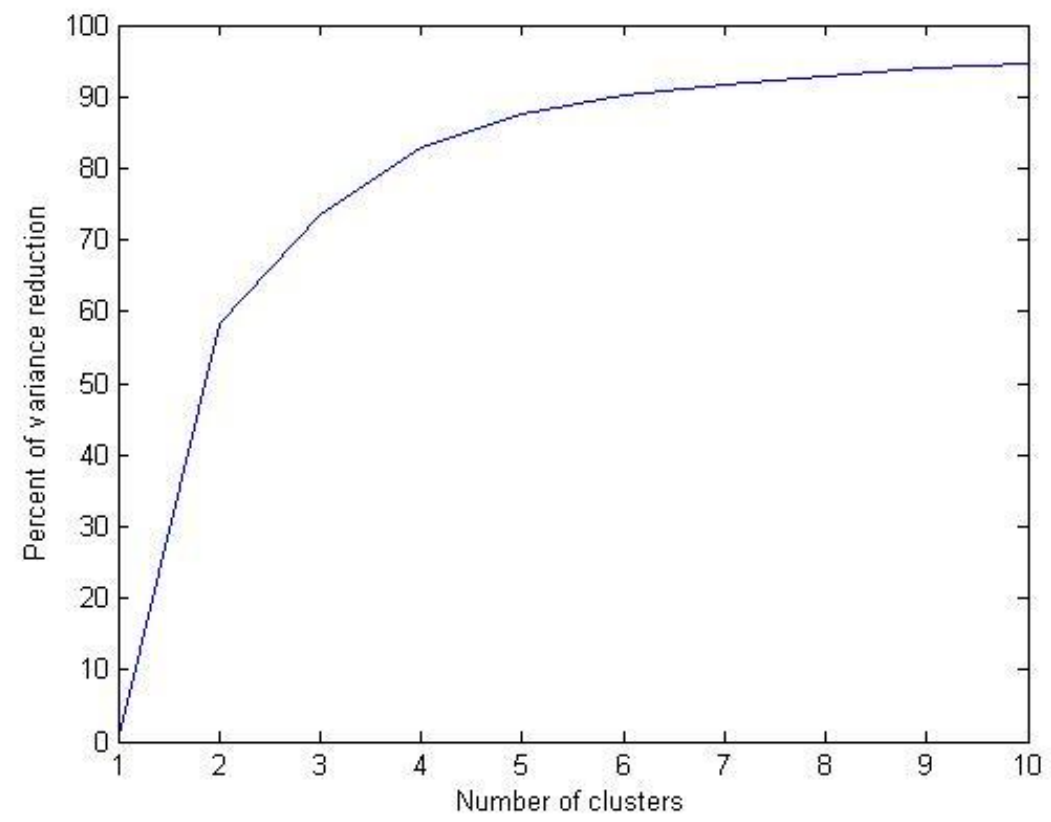

405

406

407

408
Figure 9 The percentage of variance reduction versus the number of clusters at $3 \mathrm{~Hz}$. The number of cluster chosen is 2 . 

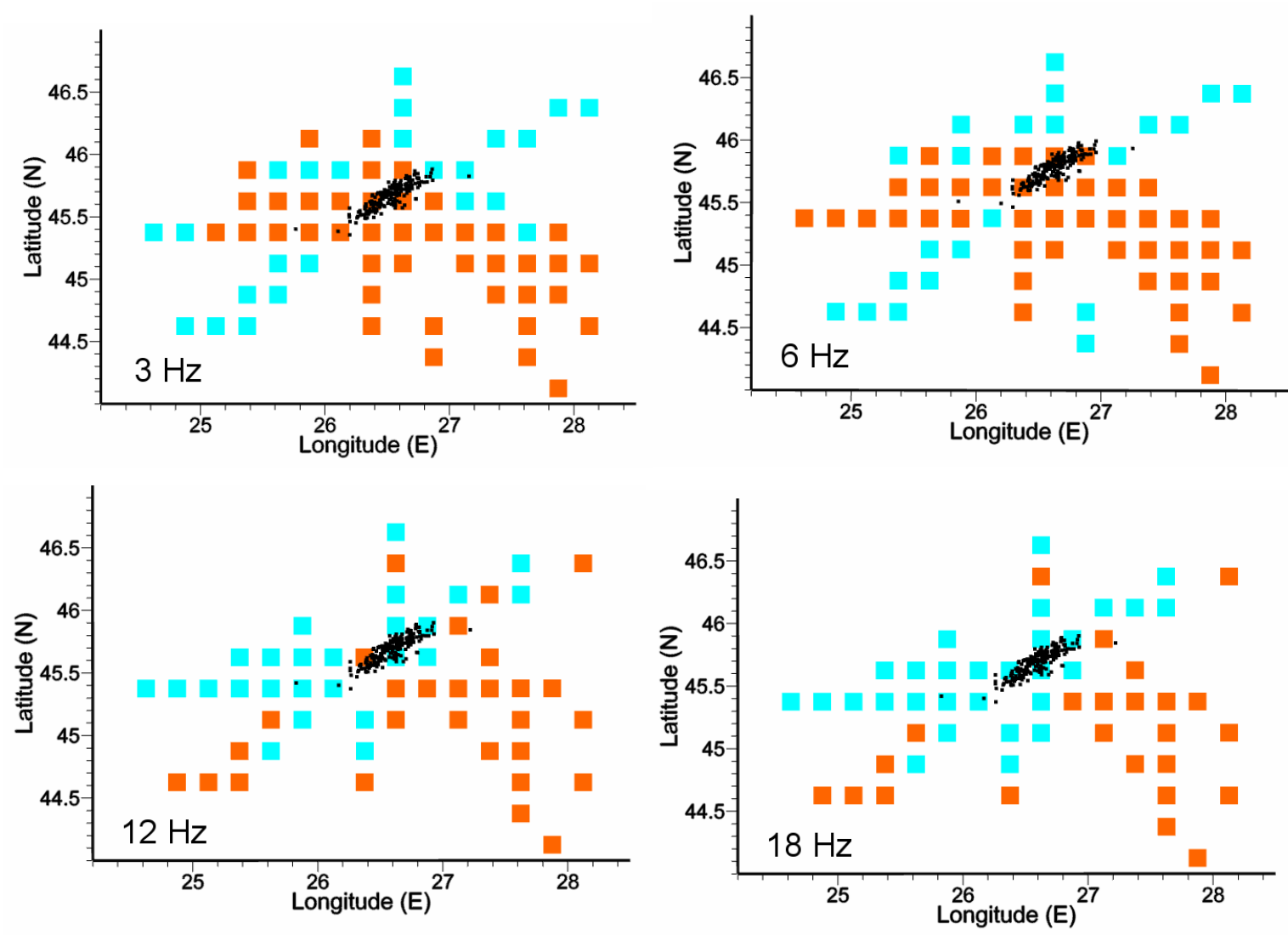

410

411

412

413

414

415

416

417

418

419

420

421

422

423

424

425

426

427

428

429

430

431

Figure 10 Maps showing results of cluster analysis obtained using the $\Delta \log _{10} T p d$ and the inverse of $\left(Q_{d} / Q_{m}\right)^{-1}$ spatial measurements. Black dots represent earthquake epicentres. Orange squares denote higher absorption while cyan squares represent higher scattering

\section{DISCUSSIONS}

The goals of the present study are (1) to investigate the two mechanisms producing seismic wave attenuation in the Vrancea region and adjacent areas and (2) to interpret the patterns in terms of seismotectonic structures. In this section, we take into account the interdisciplinary literature relative to the geophysical and geodynamical characteristics of the area, and discuss the limitations of the methodology. Scattering is dominant in the north, northwestern, and western parts of the maps, and is spatially correlated with the Southern Carpathian. Absorption dominates in the Focsani Basin, crosses the Moesian Platform, and reaches the Southern part of the Scythian Platform southeast of Vrancea (see Figures 1 and 10).

The strong frequency-dependence of scattering attenuation for waves generated in the Vrancea subcrustal domain (Figures 4 and 5) correlates well with the results of Popa et al. (2005), who first remarked a difference in total attenuation depending on frequency content, and Oth et al. (2008), who found that attenuation variability strongly increases with increasing frequency. The last authors showed that, at high frequencies $(>4-5 \mathrm{~Hz})$, there is 
approximately one order of magnitude difference in total attenuation between the mountain range and the foreland, whereas at lower frequencies the attenuation characteristics are rather similar. The similarity between the attenuation characteristics above described and the behaviour of peak delay times in frequency (Figure 4) and space (Figure 5) implies that scattering is the main attenuation mechanism in the area, at least at the investigated frequencies. Possible physical explanations for these results involve the degree of coupling between the subducting slab and the overlying crust (Sperner et al., 2005), scattering phenomena within a subducted (Furumura and Kennett, 2005) or delaminated (Koulakov et al., 2010) lithospheric fragment. Strong temperature effects (Ismail-Zadeh et al., 2005) should rather produce relevant patterns in the frequency-dependent absorption imaging.

The high-scattering Southern Carpathians represent the region characterized by the highest velocity and density contrasts, coupled with strong time-dependent deformations (Schmid et al. 1998, Matenco and Bertotti, 2000, Cloetingh et al. 2005). According to Bocin et al. (2005), three main post-docking deformational stages were recognised in this region. During Palaeogene-Early Miocene times, the clockwise rotation of the Tisza-Dacia block (Balla, 1986) has caused NNE-SSW to ENE-WSW shortening in the internal Moldavides napes of the East Carpathians (Matenco and Bertotti, 2000), large scale transtension/extension to core-complex formation in the South Carpathians (e.g., Schmid et al. 1998), and final collision of the Balkans with Moesian Platform southwards (e.g., Doglioni et al. 1996). Collision with the stable foreland has occurred during the Middle and Late Miocene (Badenian-Sarmatian), leading to large-scale deformation characterised by EW shortening in the East Carpathians (e.g., Sandulescu, 1988; Matenco and Bertotti, 2000) and transpression/shortening in the South Carpathians (Matenco et al. 1997). The collision with the foreland culminated during Late Miocene (Sarmatian) times. This region dominated by scattering also corresponds to the contact between the South Carpathians and the hinterland, the South Apuseni Mountains units, where potentially large scale thrusting and transcurrent motions occurred during the late Alpine evolution (Cloetingh et al., 2005). Another possible cause of high scattering is the presence of the TTZ (Tornquist-Teisseyre Zone) in this region. Bocin et al. (2013) suggest that TTZ is situated in Romania beneath the South-Eastern Carpathians, further to the Southeast than assumed by previous studies. As such, the TTZ incorporates the Vrancea zone earthquake epicentres. In the Carpathians, Weidle (2004) have also shown that approximately $75 \%$ of the observed attenuation of teleseismic $P$-waves is induced by scattering, predominantly from complex boundaries and heterogeneities in the crust.

The area of highest geodynamical and seismotectonic complexity is thus the one marked by highest scattering attenuation. Regions that produce high scattering are located near the transition zone from low-velocities to high velocity ratios (Koulakov et al. 2010). This is in 
agreement with Takahashi et al. (2007), who obtain similar results in the Japanese crust, specifically under Quaternary volcanoes. The analogy suggests that the dimension of the strong heterogeneities ranges from a few hundred metres to a few kilometres and scattering in the area (including Ciumadul volcano) is influenced by volcanism. At the lowest frequency (Figures 8 and $10,3 \mathrm{~Hz}$ panel, in our assumption the frequency band sampling deepest Earth layers) absorption increases northwest and southeast of the epicentral area, crossing an area of average-to-strong scattering (Figure 5). This anomaly is spatially correlated with the location of the hypothesised asthenospheric upwelling beneath the Neogene volcanic arc (Figure 1), which migrated from NW to SE (Seghedi, 2005; Koulakov et al. 2010; Popa et al. 2011; Panaiotu et al. 2012). Comparing the NW and SE high-absorption features with the results of the tomography study of Koulakov et al. (2010), high absorption correlates with strong S-waves velocities perturbations at depths of 110-130 $\mathrm{km}$. The region characterized by high absorption (Figure 8) at higher frequencies (from $6 \mathrm{~Hz}$ to $18 \mathrm{~Hz}$ ) starts from the front of the Carpathian bend (Focsani Basin) and extends to the South and South-Eastern Moesian Platform within the southwestern part of Scythian Platform (compare Figures 1 and 8).. The results in the Focsani Basin confirm that sedimentary basins represent a primary cause of high absorption (see e.g. Calvet et al, 2013a for Pyrenees). Bocin et al (2005) model the Foscani Basin as containing up to $13 \mathrm{~km}$ of sediments, deposited in a foredeep type setting. This basin, according to Mocanu et al. (1996), is predominantly characterized by Neogene sedimentary rocks derived from the Carpathians, with significant contributions of detritus from the more external Moldavian and Moesian Platform. We also note that important crustal movements characterize areas of active subsidence (up to $3 \mathrm{~mm} \mathrm{yr}^{-1}$ ) in this region (Popescu and Dragoescu, 1987). The location of the high-absorption anomalies at higher frequencies (12 and $18 \mathrm{~Hz}$ ) in such stable regions (platforms), however, suggests that high-frequency absorption effects are generated by even shallower structures. The anomalies are in fact spatially correlated with zones of hydrocarbons, natural gas, and oil accumulation (Radulescu et al. 1976; Stefanescu et al. 1988; Stanica and Stanica, 1998; Matenco and Bertotti, 2000; Tarapoanca et al. 2003; Leever et al. 2006).

To better understand the meaning of the scattering/absorption contrasts at different frequencies (Figures 5 and 8), they are compared with the heat flow map displayed using the Global Heat Flow Database (http://www.heat flow.und.edu) (Figure 11, left). High scattering (represented in blue in Figure 5) corresponds mostly to average/low heat-flow values, while high absorption anomalies correlate spatially with high heat flow values. The highest heat flow, corresponding to the location of the Ciomadul volcanic field, is at the northwestern limit of the southeast-west trending absorption anomaly at $3 \mathrm{~Hz}$ (Figure $8,3 \mathrm{~Hz}$ ). A second 
507 http://bgi.omp.obs-mip.fr) reveals that the highest seismic scattering overlaps the lowest 508 Bouguer anomalies (lower densities - compare with Figure 5), while the south and southeastern high-absorption structures correlate with positive Bouguer anomalies.

510
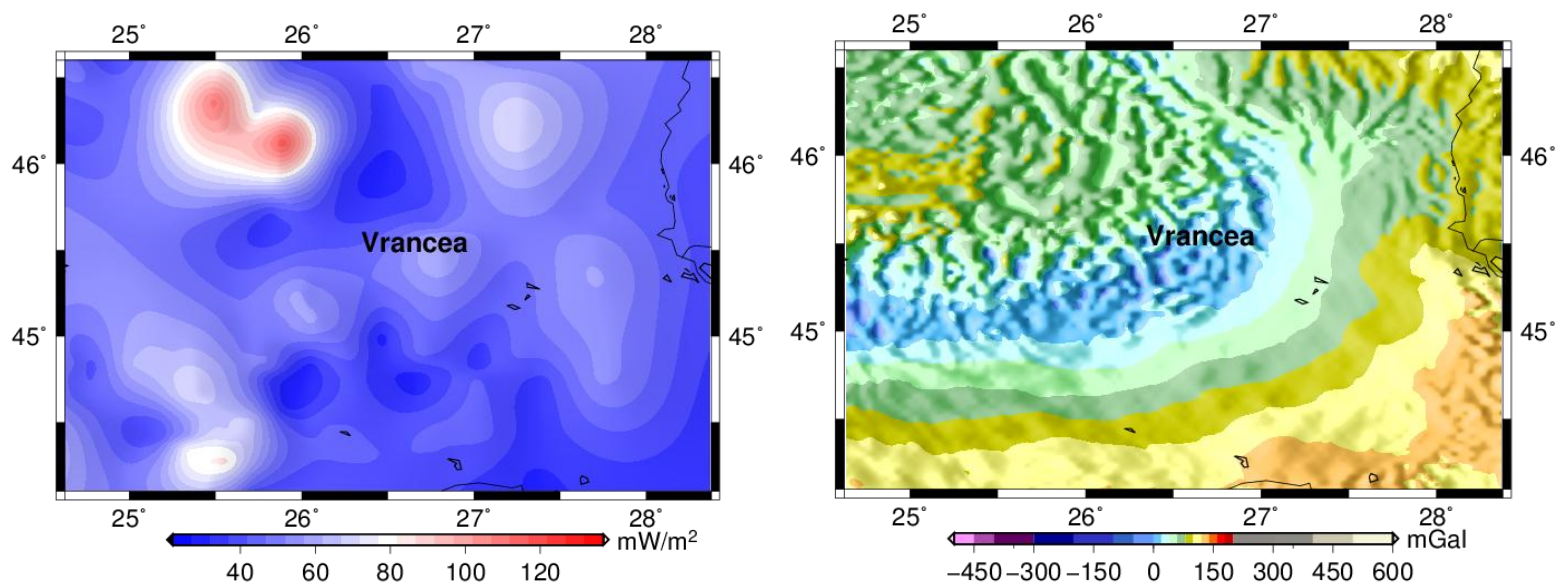

511

512

513

514

515

516

517

518

519

520

521

522

523

524

525

526

527

528

529

530

531

532

533

534

Figure 11 Maps showing heat flow distribution (left) and Bouguer anomaly (right). The high heat flow corresponds to the location of Ciomadul volcano.

The cluster analysis results (Figure 10) at low frequencies (3 Hz and $6 \mathrm{~Hz}$ ) quantify and map the absorption and effects of deep seismic structures. High-scattering structures (cyan) characterize the regions southwest and northeast of Vrancea, spreading along the Carpathians, whose high topography possibly influences measurements. Orange anomalies (high absorption) are distributed along a trend that is almost perpendicular, and crosses, the epicentral trend (NW-SE). The limit of the high-absorption pattern spatially corresponds to the Ciomadul volcanic region, situated just NNW of the Vrancea region (Seghedi, 2005; Popa et al. 2011; Panaiotu et al. 2012). Such an high-absorption trend has been observed under the Cascadian volcanoes and related to the effect of a deep magmatic arc (De Siena et al., 2016). Cluster analysis results at low frequencies thus depict a unique high-absorption structure extending from southeast of Vrancea, at the location of the mantle upwelling modelled by several studies (e.g. Popa et al., 2011), to northwest of Vrancea, feeding Ciomadul volcano (Koulakov et al., 2010).

At high frequencies (Figure 10,12 Hz and $18 \mathrm{~Hz}$ ), the NNE-SSW scattering/absorption contrast follows the epicentral trend. This observation is similar in space and nature to that of Takahashi et al. (2007) for the subducting Japanese crust, at least for the peak delay time, and consistent with the presence of a NNE-SSW-oriented sinking lithospheric fragment into the asthenosphere (Radulian et al. 2006). In this framework, considering the investigated frequencies and Bouguer anomalies, the high scattering following the epicentral trend and extending to the west (Figure $10,12 \mathrm{~Hz}$ and $18 \mathrm{~Hz}$ ) is feasibly caused by either coupling 
between a subducting slab and the overlying crust (Sperner et al., 2005) or small-scale scattering phenomena within the upper portion of a subducted (Furumura and Kennett, 2005) or detached (Seghedi, 2005; Koulakov et al. 2010; Popa et al. 2011; Panaiotu et al. 2012) lithospheric fragment, sinking into the asthenosphere.

\section{CONCLUSIONS}

We have mapped different seismic attenuation mechanisms in the Vrancea area and adjacent regions quantitatively using two integrated measurements, peak delay times and, late lapse-time coda quality factors $\left(Q_{c}\right)$, in four frequency bands. Using these techniques we were able to identify structures of different dimension and depth (different wavelength/frequency) responsible for seismic absorption and seismic scattering. The approach complements other geophysical and geodynamical results and provides a quantitative interpretation of deep Earth properties and tectonic structures. Peak-delay time values, interpreted as a measurement of scattering attenuation, show considerable variations at high frequencies, which suggests a strong effect of short-wavelength heterogeneities in the upper crust and strong differences in sampling at different frequencies. Once mapped, peak delay time differences grow (scattering increases) towards the Carpathians (north, northwest, and west of Vrancea) with the highest values in the southern Carpathians, the same region characterized by a minimum in Bouguer anomaly. $Q_{c}^{-1}$ is interpreted as a measurement of absorption, with patterns showing lower frequency dependence, but still progressively sampling shallower regions with increasing frequencies. High absorption is prevalent in the fore-arc region (SE of Vrancea): besides the Focsani Basin, which shows the highest absorption, the area includes the southeastern side of the Moesian Platform, in strong spatial correlation with hydrocarbon and natural gas reservoirs consistently depicted by seismic exploration studies.

Cluster analysis has been used to obtain a quantitative interpretation of the structures producing the scattering and absorption anomalies: the results are mainly influenced by deep tectonics structures. At high frequencies, we observe clear correlation of high scattering/absorption contrasts acting along the NW-SE trend crossing Vrancea, and feasibly produced by coupling or small-scale scattering phenomena produced at the top of either a subducting or detached slab sinking into the astenosphere. While at all frequencies the highest absorption still corresponds to the Focsani sedimentary basin. A unique lowfrequency high-absorption southeast-to-northwest trend marks areas of mantle upwelling, feeding deep Neogene volcanism and reaching the Ciomadul volcanic area, NNW of Vrancea. 
The present study was performed during a stay at the University of Münster financed by a grant awarded by the German Academic Exchange Service (DAAD) in 2014. Data used in the present study were provided by The National Institute for Earth Physics (Romania) and processed within the National Data Centre in Magurele. Seismic Analysis Code (SAC) (Goldstein and Snoke, 2005) and GMT (Wessel et al. 2013) codes were used. We thank the College of Physical Sciences (University of Aberdeen) and the Santander Mobility Award for providing travel grant to LDS to complete this manuscript.

582

Aki, K., and B. Chouet 1975, Origin of coda waves: Source, attenuation, and scattering 585 effects, J. Geophys. Res., 80, 3322-3342.

\section{REFERENCES}

Bala, A., Radulian, M., Popescu, E., 2003. Earthquakes distribution and their focal mechanism in correlation with the active tectonic zones of Romania. Journal of Geodynamics 36: 129-145

Balla, Z., 1986. Paleotectonic reconstruction of the central Alpine-Mediteranean belt for the Neogene. Tectonophysics 127, 213-243.

592

Bocin, A., Stephenson, R., Tryggvason, A., Panea, I., Mocanu, V., Hauser, F., Matenco, L., 2005. 2.5 D seismic velocity modelling in the south-eastern Romanian Carpathians Orogen and its foreland, Tectonophysics, Volume 410, 273-291

596

Bocin, A., Stephenson, R., Matenco, L., Mocanu, V., 2013 - Gravity and magnetic modelling in the Vrancea Zone, south-eastern Carpathians: Redefinition of the edge of the East European Cratonbeneath the south-eastern Carpathians; Journal of Geodynamics 71, 52-

Bureau Gravimetrique International -http://bgi.omp.obs-mip.fr

Calvet, M., M. Sylvander, L. Margerin, and A. Villaseñor, 2013a Spatial variations of seismic attenuation and heterogeneity in the Pyrenees: Coda $Q$ and peak delay time analysis, Tectonophysics, 608, 428-439. 
608

609

610

611

612

613

614

615

616

617

618

619

620

621

622

623

624

625

626

627

628

629

630

631

632

633

634

635

636

637

638

639

640

641

642

Calvet, M., and L. Margerin 2013b, Lapse-time dependence of coda Q: Anisotropic multiplescattering models and application to the Pyrenees, Bull. Seismol. Soc. Am., 103(3), 19932010.

Chalot-Prat, F., Girbacea, R., 2000. Partial delamination of continental mantle lithosphere, upliftrelated crust-mantle decoupling, volcanism and basin formation: a new model for the Pliocene-Quaternary evolution of the southern East-Carpathians, Romania. Tectonophysics $327,83-107$.

Cloetingh, S., Matenco, L., Bada, G., Dinu C., Mocanu V., 2005 The evolution of the Carpathians-Pannonian system: Interaction between neotectonics, deep structure, polyphase orogeny and sedimentary basins in a source to sink natural laboratory, Tectonophysics 410 (2005) 1-14

Cornea, I., Radulescu, F., Pompilian, A. and Sova, A., 1981. Deep seismic sounding in Romania. Pure Appl. Geophys., 119: 1144-1156

Cornish, 2007. Cluster Analysis. Mathematics Learning Support Chapter 3.1,http://www.quic kpdfs.com/read/217773/statistics-3-1-cluster-analysis-1-introduction-2-statstutor.htm

Csontos, L., 1995. Tertiary tectonic evolution of the Intra-Carpathian area: a review. Acta Vulcanol. 7, 1-13.

Del Pezzo, E., F. Bianco, S. Marzorati, P. Augliera, E. D'Alema, and M. Massa 2011, Depthdependent intrinsic and scattering seismic attenuation in north central Italy, Geophys. J. Int., 186, 373-381, doi:10.1111/j.1365-246X.2011.05053.x.

De Siena, L., E. Del Pezzo, and F. Bianco, 2011, A scattering image of Campi Flegrei from the autocorrelation functions of velocity tomograms, Geophysical Journal International, 184 (3), 1304-1310.

De Siena L., Thomas C., Waite G. P., Moran S. C., Klemme S., 2014, Attenuation and scattering tomography of the deep plumbing system of Mount St. Helens. J. Geophys.Res. Solid Earth, 119, 8223-8238, doi:10.1002/2014JB011372. 
De Siena L., Calvet M., Watson K. J., Jonkers A. R. T., Thomas C., 2016, Seismic scattering and absorption mapping of debris flows, feeding paths, and tectonic units at Mount St. Helens volcano. Earth and Planetary Science Letters 442 (2016): 21-31.

Doglioni, C., P. Harabaglia, G. Martinelli, F. Mongelli,and G. Zito 1996, A geodynamic model

Downes, H., Seghedi, I., Szakács, A., Dobosi, G., James, D.E., Vaselli, O., Rigby, I.J., 651 Ingram, G.A., Rex, D., Pécskay, Z., 1995, Petrology and geochemistry of late Tertiary/Quaternary mafic alkaline volcanism in Romania. Lithos 35, 65 - 81

Ellouz, N., and E. Roca 1994, Palinspastic reconstructions of the Carpathians and adjacent areas since the Cretaceous: A quantitative approach, in Peri Tethyan Platforms, edited by F.Roure,pp.51-78, Technip, Paris.

657

Furumura, T., and Kennett, B., 2005, Subduction zone guided waves and the heterogeneity 659 of the subducted plate: Intensity anomalies in northern Japan: Journal of Geophysical Research, v. 110, B10302, doi:10.1029/2004JB003486.

661

Galluzzo, D., La Rocca M., Margerin L., Del Pezzo E., and Scarpa R, 2015, Attenuation and 663 velocity structure from diffuse coda waves: Constraints from underground array data; Physics of the Earth and Planetary Interiors 240: 34-42.

665

Girbacea, R.A., 1997, The Pliocene to recent tectonic evolution of the Eastern Carpathians 667 (Romania). Tub. Geowiss. Arb., AGeol. Paläontol. Stratigr. 35 (136 pp.).

Global Heat Flow Database (http://www.heat flow.und.edu)

Goldstein, P., A. Snoke, 2005, "SAC Availability for the IRIS Community", Incorporated Institutions for Seismology Data Management Center Electronic Newsletter.

Hartigan, J.A., 1975, Clustering Algorithms, Wiley Series in Probability and Mathematical Statistics, John Wiley \& Sons, New York. 
681 Herrmann, R. B., 1980, Q estimates using the coda of local earthquakes, Bull. Seism. Soc. 682 Am.,70, 447-468,

Hippolyte, J.C., Badescu, D., Constantin, P., 1999, Evolution of the transport direction of the 685 Carpathian belt during its collision with the east European Platform. Tectonics 18, 1120 686 1138

687

Ivan M., 2007, Attenuation of P and pP waves in Vracea area - Romania, Journal of Seismology, Springer Verlag, http://dx.doi.org/10.1007/s10950-006-9038-7

Knopoff L 1964, Q. Rev Geophys 2:625-660

692

Koulakov, I., Zaharia, B., Enescu, B., Radulian, M., Popa, M., Parolai, S., and J. Zschau, 694 2010, Delamination or slab detachment beneath Vrancea? New arguments from local 695 earthquake tomography, Geochem. Geophys. Geosyst. (G3), 11, 3, Q03002, doi:10.1029/2009GC002811

697

Linzer H.-G., Frisch W., Zweigel P., Girbacea R., Hann H.-P., Moser F., 1998, Kinematic 699 evolution of the Romanian Carpathians, Tectonophysics 297, 133-156

700

Leever, K., L. Matenco, G. Bertotti, S. Cloetingh, K. G.Drijkoningen, and I. Vasiliev 2006,

Pliocene to Recent kinematics in the Focşani basin, Romania: New constraints from shallow seismic and paleo-magnetic data, Basin Res., 18 , 521-545, doi:10.1111/j.13652117.2006.00306.

Martin, M., Ritter, J.R.R., the CALIXTO working group 2005, High-resolution tele-seismic body-wave tomography beneath SE Romania - I. Implications forthree-dimensional versus one-dimensional crustal correction strategies witha new crustal velocity model. Geophys. J. Int. 162, 448-460.

Mason, P.R.D., Seghedi, I., Szakács, A., Downes, 1998, Magmatic constraints on geodynamic models of subduction in the East Carpathians, Romania. Tectonophysics 297, $157-176$. 
Matenco, L., Zoetemeijer, R., Cloetingh, S. and Dinu, C., 1997, Lateral variations in mechanical properties of the Romanian external Carpathians: inferences of flexure and gravity modelling. Tectonophysics, 282, 147-166.

Matenco L, Schmid St., 1999, Exhumation of the Danubian nappes system (South Carpathians) during Early Tertiary: inferences from kinematic and paleostress analysis at the Getic/Danubian nappes contact. Tectonophysics 314:401-42

Matenco, L., Bertotti, G., 2000, Tertiary tectonic evolution of the external East Carpathians (Romania). Tectonophysics 316, 255 - 286.

Mocanu, V., Dinu, C., Radulescu, F., Diaconescu M., 1996, Seismogeological features of the crust in Romania G. Wessely, W. Leibl (Eds.), Oil and Gas in Alpidic Thrustbets and Basins of Central and Eastern Europe, EAGE Sp. Publ. No. 5 (1996), pp. 289-29

Neagoe, C. and lonescu, C., 2009, Toward a dense real-time seismic network in Romania, Romanian Reports in Physics 61, 359-366.

Oancea V., Bazacliu O., Mihalache G., Dumitrascu A., 1989, Anomalies of coda waves parameters correlated with large Vrancea intermediate earthquake occurrence, Proc. Of the XXI Gen. Assembly of the ESC, Sofia, Bulgaria, 404 - 409

Oancea, V., Bazacliu, O., Mihalache, G. 1991, The estimation of the coda quality factor for the Romanian territory, Phys. Earth Planet. Inter., 67, 87-94

Obara, K., and Sato, H. 1995, Regional differences of random inhomogeneities around the volcanic front in the Kanto-Tokai area, Japan, revealed from the broadening of $S$ wave seismogram envelopes, J. Geophys. Res. 100, 2103- 2121.

Obermann, A., Planès, T., Larose, E., Sens-Schönfelder, C., \& Campillo, M., 2013, Depth sensitivity of seismic coda waves to velocity perturbations in an elastic heterogeneous medium, Geophysical Journal International, 194(1), 372-382.

Oncescu, M. C., and K. P. Bonjer, 1997, A note on the depth recurrence and strain release of large Vrancea earthquakes, Tectonophysics, 272, 291 - 302, doi:10.1016/S00401951(96)00263-6 
Oncescu, M. C., Marza, V, Rizescu, M. and Popa, M., 1999, The Romanian earthquakes catalogue between 984 and 1997. In:Vrancea Earthquakes: Tectonics, Hazard and Risk Mitigation, edited by F. Wenzel, and D. Lungu, Kluwer Academic Publishers, pp. 43-47.

Oth, A., D. Bindi, S. Parolai, and F. Wenzel 2008, S-wave attenuation characteristics beneath the Vrancea region in Romania: new insights from the inversion of ground-motion spectra, Bull. Seismol. Soc. Am. 98,no. 5, 2482-2497, doi: 10.1785/0120080106.

Petukhin, A.G., Gusev, A.A., 2003, The duration-distance relationship and average envelope shapes of small Kamchatka earthquakes. Pure Appl. Geophys. 160, 171-1743.

Popa, M, Radulian, M, Grecu, B, Popescu, E. and Placinta, A. O., 2005, Attenuation in Southeastern Carpathians area: Result of upper mantle inhomogeneity. Tectonophysics 410 , 235-249.

Popa, M, Radulian M, Ghica D., Neagoe C., Nastase E., 2015, Romanian Seismic Network Since 1980 to the Present, Nonlinear Mathematical Physics and Natural Hazards Volume 163 of the series Springer Proceedings in Physics pp 117-131

Panaiotu, C.G., Vişan, M., Tugui, A., Seghedi, I.,Panaiotu, A.G., 2012, Palaeomagnetism of the South Harghita volcanic rocks of the East Carpathians: implications for tectonic rotations and palaeosecular variation in the past 5Ma , Geophys. J .Int., doi: 10.1111/j.1365246X.2012.05394

Popa, M., Grecu, B., Popescu, E., Placinta, A., Radulian, M., 2003, Asymmetric distribution of seismic motion across Southeastern Carpathians (Romania) and its implications. Rom. Rep. Phys. 55, 521-534

Popa, M., Radulian, M., Szakacs, A., Seghedi, I. \& Zaharia, B., 2011, New Seismic and Tomography Data in the Southern Part of the Harghita Mountains (Romania, Southeastern Carpathians): connection with Recent Volcanic Activity, Pure appl. Geophys., September 2012, Volume 169, Issue 9, pp 1557-1573

Popescu, M.N., Dragoescu, I., 1987, Maps of recent vertical crustal movements in Romania: similarities an differences. J. Geodyn. 8, 123-136. 
Prudencio, J., Ibáñez, J. M., García-Yeguas, A., Del Pezzo, E., Posadas, A. M., 2013, Spatial distribution of intrinsic and scattering seismic attenuation in active volcanic islands-II: Deception Island images. Geoph. J. Int., 195(3), 1957-1969.

Radulian M., Mandrescu N., Panza G.F., Popescu E., Utale A., 2000, Characterization of seismogenic zones of Romania, Pure appl. geophys., 157, 57-77.

Radulian, M., Panza, G.F., Grecu, B. 2006, Seismic wave attenuation for Vrancea events revisited J. Earthquake Engineering, 10, 3, 411-427

Raileanu,V., Diaconescu,C.,Radulescu,F., 1994, Characteristicsof Romanian lithosphere from deep seismic reflection profiling. Tectonophysics 239, 165-185.

Raileanu, V. \& Diaconescu, C., 1998, Seismic signature in Romanian crust, Tectonophysics, 288, 127-136.

Raileanu V., Dinu C., Ardeleanu L., Diaconescu V., Popescu E., Bala A., Crustal seismicity and associated fault systems in Romania, Procedings of the 27th ECGS Workshop: Seismicity Patterns in the Euro-Med Region, Luxembourg, 17-19 Nov. 2008, in "Cahiers du Centre Europeen de Geodynamique et de Seismologie”, 153 - 159, 2009 (ISBN 9.7829-1989702-5).

Raileanu V., Tataru D., Grecu B., 2012 Crustal Models in Romania - I. Moesian Platform, Romanian Reports in Physics, Vol. 64, No. 2, P. 539 - 554

Radulescu, D., Cornea, I., Sandulescu, M., Constantinescu, P., Radulescu, F. and Pompilian, A., 1976, Structure de la croute terrestre en Roumanie. Essai d'interprétation des études séismiques profondes, An. Inst. Geol. Geofiz, 50, 5-36

Rautian, T. G., and V. I. Khalturin 1978. The use of the coda for determination of the earthquake source spectrum, Bull. Seismol. Soc. Am. 68, 923-948.

Russo, R.M, Mocanu, V., Radulian, M., 2005. Seismic attenuation in the Carpathian bend zone and surroundings. Earth and Planetary Science Letters, 237 (3-4): 695-709.

Sandulescu, M. 1984, Geotectonics of Romania. Ed. Tehnica, Bucharest, p 334 (in Romanian) 
Sandulescu, M., Visarion, M., 1988,. La structures des plateformes situées dans l'avant-pays et audessous des nappes du flysch des Carpathes Orientales, Stud. Teh. Econ. - Inst. Geol.,

827 Ser. D Prospect. Geofiz. 15, pp. 61-68.

828

Sandulescu, M., 1988. Cenozoic tectonic history of the Carpathians. In: Royden, L.H., Horvath, F. (Eds.), The Pannonian Basin, A Study in Basin Evolution. AAPG memoir, pp. 17 -25 .

Saito, T., Sato, H., Ohtake, M., 2002. Envelope broadening of spherically outgoing waves in three-dimensional random media having power law spectra. J. Geophys. Res. 107 (B5). http://dx.doi.org/10.1029/2001JB000264.

Saito, T., Sato, H., Ohtake, M., Obara, K., 2005. Unified explanation of envelope broadening and maximum-amplitude decay of high-frequency seismograms based on the envelope simulation using the Markov approximation: forearc side of the volcanic front in northeastern Honshu, Japan. J. Geophys. Res. 110. http://dx.doi.org/10.1029/2004JB003225 (B01304).

Sato, H., 1977, Energy propagation including scattering effects: single isotropic scattering approximation, J. Phys. Earth, 25, 27-41.

Sato, H. 1989, Broadening of seismogram envelopes in the randomly inhomogeneous lithosphere based on the parabolic approximation: Southeastern Honshu, Japan, J. Geophys. Res. 94, 17735-7747.

Sato, H., Fehler, M.C. \& Maeda, T., 2012, Seismic Wave Propagation and Scattering in the heterogeneous Earth: Second Edition, Springer

Schmid, S.M., Berza, T., Diaconescu, V., Froitzheim, N., Fuegenschuh, B., 1998, Orogenparallel extension in the South Carpathians during the Paleogene. Tectonophysics 297, 209 $854-228$.

Schwartz, G., 1978, Estimating the dimension of a model, Ann. Stat., 6(2), 461-464.

Seghedi, I. and Szakacs, A., 1994, Upper Pliocene to Quaternary basaltic volcanism in the 
Seghedi, I., Balintoni, I. and Szakacs, A., 1998, Interplay of tectonics and Neogene postcollisional magmatism in the intracarpathian area. Lithos 45, 483- 499.

Seghedi, I., Downes, H., Harangi, S., Mason, P.R.D. and Pecskay, Z., 2005, Geochemical response of magmas to Neogene-Quaternary continental collision in the CarpathianPannonian region: a review. Tectonophysics 410: 485-499.

Shearer, P. M. \& Earle, P. S., 2004, The global short-period wavefield modelled with a Monte Carlo seismic phonon method, Geophysical Journal, Volume 158, Issue 3, pp. 11031117

Sperner, B.the CRC 461 Team, 2005, Monitoring of slab detachment in the Carpathians, in Perspectives in Modern Seismology , F. Wenzel (Editor), Lecture Notes in Earth Sciences, Vol. 105 , Springer Verlag, Berlin

Sudhaus H., Ritter J.R.R. , 2005,. High-resolution measurement of the seismic attenuation across the Vrancea region, Romania, Geophys. Res. Lett., 32, 10301

Stanica, D., Stanica, M., 1998, 2D modelling of the geoelectric structure in the area of the deep-focus Vrancea earthquakes. CERGOP "South Carpathians" monograph, vol. 7 (37), pp. 193 -203. Warszawa.

Ştefanescu, M., et al. 1988, Geological cross sections at scale 1:200,000, Map A9-14, Inst. Geol. Geofiz,.Bucharest

Szakács A., Seghedi I., Pécskay Z., 1993, Pecularities of South Harghita Mts. as terminal segment of the Carpathian Neogene to Quaternary volcanic chain. Rev. Roum. de Géologie $37,21-36$

Takahashi, T., H. Sato, T. Nishimura, and K. Obara, 2007, Strong inhomogeneity beneath quaternary volcanoes revealed from the peak delay analysis of S-wave seismograms of microearthquakes in northeastern Japan, Geophysical Journal International, 168 (1), 90-99

Takahashi, T., Sato, H., Nishimura, T., Obara, K., 2009, Tomographic inversion of the peak delay times to reveal random velocity fluctuations in the lithosphere: method and application to northeastern Japan. Geophys. J. Int. 178 (3), 1437-1455 
899 Tarapoanca, M., Bertotti, G., Matenco, L., Dinu, C., Cloetingh, S., 2003, Architecture of the 900 Focsani Depression: a $13 \mathrm{~km}$ deep basin in the Carpathians Bend Zone (Romania).

901 Tectonics 22, 1074.doi:10.1029/2002TC001486

902

903 Tripathi, J. N., M. Sato, and M. Yamamoto, 2010, Envelope broadening characteristics of 904 crustal earthquakes in northeastern Honshu, Japan, Geophysical Journal International, 182 905 (2), 988-1000

906

907 Weidle, C., 2004, Velocity and Attenuation Structure beneath the South eastern 908 Carpathians, American Geophysical Union, Fall Meeting 2004, abstract \#T33A-1341

910 Wessel, P., W. H. F. Smith, R. Scharroo, J. F. Luis, and F. Wobbe, 2013, Generic Mapping 911 Tools: Improved version released, EOS Trans. AGU, 94, 409-410.

912

913 Wortel, M.J.R., and Spakman, W., 2000, Subduction and Slab Detachment in the 914 Mediteranean-Carpathian Region: Science, v. 290, p. 1910-1917.

916 Zadeh, I. A.T., Mueller, B. and Schubert, G., 2005, Three dimensional numerical modeling of 917 contemporary mantle flow and tectonic stress beneath the earthquake-prone southeastern 918 Carpathians based on integrated analysis of seismic, heat flow, and gravity data, Physics of 919 the Earth and Planetary Interiors 149, 81-98. 


\title{
Seismic scattering and absorption mapping from intermediate-depth earthquakes reveals complex tectonic interactions acting in the Vrancea region and surroundings (Romania)
}

\author{
F. Borleanu ${ }^{(1,2)}$, L. De Siena ${ }^{(1,3)}$, C. Thomas ${ }^{(1)}$, M. Popa $^{(2)}$, M. Radulian ${ }^{(2)}$ \\ ${ }^{1}$ Institute for Geophysics, University of Munster (Germany); ${ }^{2}$ National Institute for Earth Physics (Romania); ${ }^{3}$ School of \\ Geosciences, University of Aberdeen (Scotland)
}

\section{Abstract}

The Vrancea region, located at the southeastern edge of the Carpathians arc bend, is a region of intense seismicity, whose major earthquakes produce hazard in southeastern Europe. Despite the consequent focus of the geophysical and geological community on providing accurate structural and dynamical models of Vrancea, these are still subject to numerous controversies and debates. In the present study, we use intermediate-depth seismicity recorded by the broadband stations of the Romanian Seismic Network between 2009 and 2011 to measure S-wave peak delay times and late-time coda quality factors. After mapping these two quantities in space, a cluster analysis provides a quantitative structural interpretation of the region in terms of different attenuation mechanisms affecting the seismic wave field, i.e. seismic scattering and seismic absorption. The results show that scattering is higher west and northwest of Vrancea, while absorption dominates in the Focsani Basin, located in the forearc region. In general, we obtain higher absorption in stable regions, with patterns emphasized at high-frequency affected by the presence of hydrocarbons and natural gas reservoirs in the upper crustal layers. Regions characterized by active seismicity and structural heterogeneity show higher scattering, spatially correlated with the highest velocity contrasts and the lowest density. The high-frequency scattering/absorption contrasts obtained using the cluster analysis depict a southwest-to-northeast lithospheric contrast, following the epicentral trend of Vrancea earthquakes, and characteristic of either lithospheric subduction or delamination. Low-frequency cluster analysis results, sampling deeper Earth layers, mark a unique high-absorption trend perpendicular to the epicentral trend, feasibly linked to Neogene volcanism, and induced by the back-arc mantle upwelling. Its most recent expression is Ciomadul volcano, located at the northwestern limit of the absorption trend.

Key words: Seismic attenuation, Vrancea region, intermediate depth earthquakes, peak delay times, coda quality factor, cluster analysis 


\section{INTRODUCTION}

The Vrancea region, located at the southeastern edge of the Carpathians arc bend in Romania (Figure 1a), represents one of the most seismically-active areas in Europe. Crustal- and intermediate-depth earthquakes overlay within the area. The intermediate-depth earthquakes are located in a small lithospheric volume going down in the mantle and cause important seismic hazard over large distances. Up to 4 - 5 events per century with magnitudes up to 7.9 (according to the Romplus catalog, Oncescu et al. 1999) are generated here. The earthquakes occurred in the shallower crust are characterized by moderate magnitudes (below 6) and spread over an extended area.

The competing effects of absorption, scattering, and geometrical spreading in 3-D structures cause the loss of seismic wave energy while travelling through the Earth. The study and 2D mapping of (1) anelastic absorption, related to temperature, chemical composition, melt or fluid content and (2) scattering of seismic waves on heterogeneities affecting different frequency ranges is an ideal complement to velocity tomography measurements, improving hazard assessment for regions exposed to strong ground motion. Nevertheless, the complex pattern of seismic radiation generated by an earthquake generally corrupts both the estimation of total seismic attenuation and the separation of specific attenuation mechanisms using direct waves (Del Pezzo et al. 2011). Subcrustal earthquakes in the Vrancea region near the Carpathians Arc in Romania (Figure 1) exhibit such complex ground motion patterns, with significant differences between the areas inside and outside of the Carpathians Arc. These differences are mainly attributed to attenuation properties (Popa et al. 2005; Russo et al. 2005; Oth et al. 2008) and the region is thus an ideal setting to apply methodologies that separate and map different attenuation mechanisms, in particular seismic scattering from seismic absorption (Takahashi et al. 2007; Calvet et al. 2013a). Oancea et al. (1991) were the first to measure $Q$ values of the order of $700-800$ for the region of maximum seismicity using Vrancea intermediate-depth earthquakes and coda wave analysis. Spatial variations of the attenuation patterns have been obtained by the comparison of waveforms produced by small- and moderate-magnitude Vrancea subcrustal earthquakes (Popa et al. 2003; 2005). Seismic amplitudes decrease by a factor of 10 to 100 for events occurring at the back-side part with respect to those occurring at the fore-side part. Sudhaus et al. (2005) used teleseismic waveforms from a seismic refraction experiment (VRANCEA99) to study seismic attenuation, and found relatively high-attenuation anomalies in the Carpathian Mountains as well as in the sedimentary basins. Russo et al. (2005) estimated S-wave quality factors for intermediate-depth earthquakes; their results show low attenuation east and north of Vrancea (Figure 1) and high attenuation in both the epicentral area and the Transylvanian Basin. Similar results were obtained by Ivan (2007) from 
teleseismic recordings of $\mathrm{P}$ and $\mathrm{pP}$ waves, while Radulian et al. (2006) show that attenuation is strongly frequency-dependent especially toward NW of Vrancea, at least with respect to SE. Oth et al. (2008) analysed the attenuation characteristics of $S$-wave spectra and found that attenuation is roughly homogeneous in the low frequency range $(<4-5 \mathrm{~Hz})$ for any propagation path, while at higher frequencies the attenuation in the Carpathian Mountains arc is over ten times stronger than that in the foreland area. The authors attribute this difference to the intrusion of hot asthenosphere beneath the Carpathians back-arc region. An overview of these studies is given in Table 1 and shown schematically in Figure $1 \mathrm{~b}$. While all these studies focus on seismic attenuation in the region, they do not distinguish between two different attenuation mechanisms, namely scattering attenuation and absorption.

Table 1. An overview of the attenuation effects for Vrancea subcrustal earthquakes within Romania according to various studies

\begin{tabular}{|c|c|c|}
\hline Study & low-attenuation & high-attenuation \\
\hline Oancea et al. (1991) & $\begin{array}{l}\text { High Qc (700- } 800) \text { within } \\
\text { the Carpathians bend }\end{array}$ & - \\
\hline Sudhaus et al. (2005) & & $\begin{array}{l}\text { Revealed in the Carpathian Mountains as well } \\
\text { as in the sedimentary basins }\end{array}$ \\
\hline Russo et al. (2005) & $\begin{array}{l}\text { Pointed out high Qs (low } \\
\text { attenuation) in Platform } \\
\text { regions and stable } \\
\text { Precambrian craton areas }\end{array}$ & $\begin{array}{l}\text { In tectonically active regions - especially } \\
\text { where asthenosphere lies at shallow levels }\end{array}$ \\
\hline $\begin{array}{l}\text { Popa et al. (2003; } \\
2005)\end{array}$ & $\begin{array}{l}\text { Shown in the foreland } \\
\text { platform }\end{array}$ & $\begin{array}{l}\text { Affects mostly high frequencies; the } \\
\text { amplitudes are reduced by a factor of } 20 \text { in } \\
\text { the Transylvanian Basin and the Eastern } \\
\text { Carpathians }\end{array}$ \\
\hline Radulian et al. (2006) & $\begin{array}{l}\text { Low attenuation in the } \\
\text { extra-Carpathians areas }\end{array}$ & $\begin{array}{l}\text { Strong attenuation at high frequencies } \\
\text { explains the low damage to structures in the } \\
\text { intra-arc region }\end{array}$ \\
\hline Ivan (2007) & $\begin{array}{l}\text { The volume is limited to } \\
\text { the East by the } 26^{\circ} 30^{\prime} \\
\text { meridian }\end{array}$ & $\begin{array}{l}\text { Has been observed for stations located in the } \\
\text { northwestern part of the Vrancea seismogenic } \\
\text { volume; no clear spatial correlation exists } \\
\text { between attenuation values and shallow } \\
\text { geological settings }\end{array}$ \\
\hline Oth et al. (2008) & $\begin{array}{l}\text { Was shown in the } \\
\text { foreland, variability } \\
\text { strongly increases with } \\
\text { increasing frequency }\end{array}$ & $\begin{array}{l}\text { Characterizes the Vrancea area; and the inner } \\
\text { sideof the mountain arc in the Transylvanian } \\
\text { Basin }\end{array}$ \\
\hline
\end{tabular}

87

The goal of the present study is to measure and map these two mechanisms in the Vrancea region and adjacent areas, i.e., to interpret them in terms of crustal and mantle structures and tectonic processes. We apply a set of techniques, namely peak delay time and coda quality factor mapping and 2D K-means cluster analysis, which have been widely used to 
image the heterogeneous crust in regions such as Japan (Sato, 1989; Obara and Sato, 1995; Petukhin and Gusev, 2003; Saito et al. 2002, 2005; Takahashi et al. 2007, 2009; Tripathi et al. 2010), the Pyrenean range (Calvet et al. 2013a), and local volcanoes (De Siena et al. 2011; Prudencio et al. 2013; De Siena et al. 2016). After presenting both the data used in our analysis and the limitations of the methods in terms of effective sensitivity of seismic waves to Earth structures, we discuss the results focusing on the novel insight they provide on the main seismo-tectonics and geological structures in the region.

\section{SEISMOTECTONIC OVERVIEW}

The SE Carpathian arc formation is related to the Alpine orogeny as a result of the collision of the Tisza-Dacia microplate in the West, the stable cratonic East European Platform in the East (Sandulescu, 1984, 1988) and Moesian Platform in the southeast. Many studies showed that the Carpathian unit collided with the W-SW part of Moesia in Mid-Cretaceous times, rotated subsequently around its corner and since the Paleogene moved towards their present position (Săndulescu, 1988; Schmid et al. 1998; Hippolyte et al. 1999; Maţenco and Schmid, 1999). During the Tertiary, an oceanic or thinned continental lithosphere was subducted below the East-Carpathians (e.g. Săndulescu, 1988; Wortel and Spakman, 2000). The active shortening process stopped during the late Oligocene-Early Miocene periods (about 20 MA) when all the oceanic-type basins were closed (Ellouz and Roca, 1994; Linzer et al. 1998). Different studies explained the time difference between the end of the shortening process and lithospheric subduction and the beginning of the volcanic activity in the Eastern Transylvanian Basin characterized by calc-alkaline and alkali basaltic eruptions of magmas (Szakacs, 1993; Seghedi and Szakacs, 1994; Downes et al. 1995; Seghedi et al. 1998) by various geodynamic processes like roll-back, detachment and/or break-off of the subducted lithospheric slab (Csontos, 1995; Mason et al. 1998; Seghedi et al. 1998; Linzer et al. 1998), or delamination of the lower part of the lithospheric mantle from the lower plate (Gîrbacea, 1997; Gîrbacea and Frisch, 1998; Chalot-Prat and Gîrbacea, 2000).

In this setting the Vrancea region, located at the limit of the SE Carpathian arc (Figure 1) is a region with notable crustal- and intermediate-depth seismicity with magnitudes up to 7.9, which can be used to illuminate the entire area. Earthquakes are generally located beneath the external thin-skinned thrust belt of the SE Carpathians at depths down to $220 \mathrm{~km}$ (Oncescu and Bonjer, 1997; Bala et al. 2003). Martin et al. (2005) have shown that the SE Carpathians area has a complex lithospheric structure because of its young and intense tectonic evolution. At least three distinct lithospheric blocks are in contact and responsible for the seismicity in Vrancea (Figure 1): (1) toward NE the East European Platform, (2) the Transylvanian Basin, located on the Tisza-Dacia block toward NW, and the Moesian 

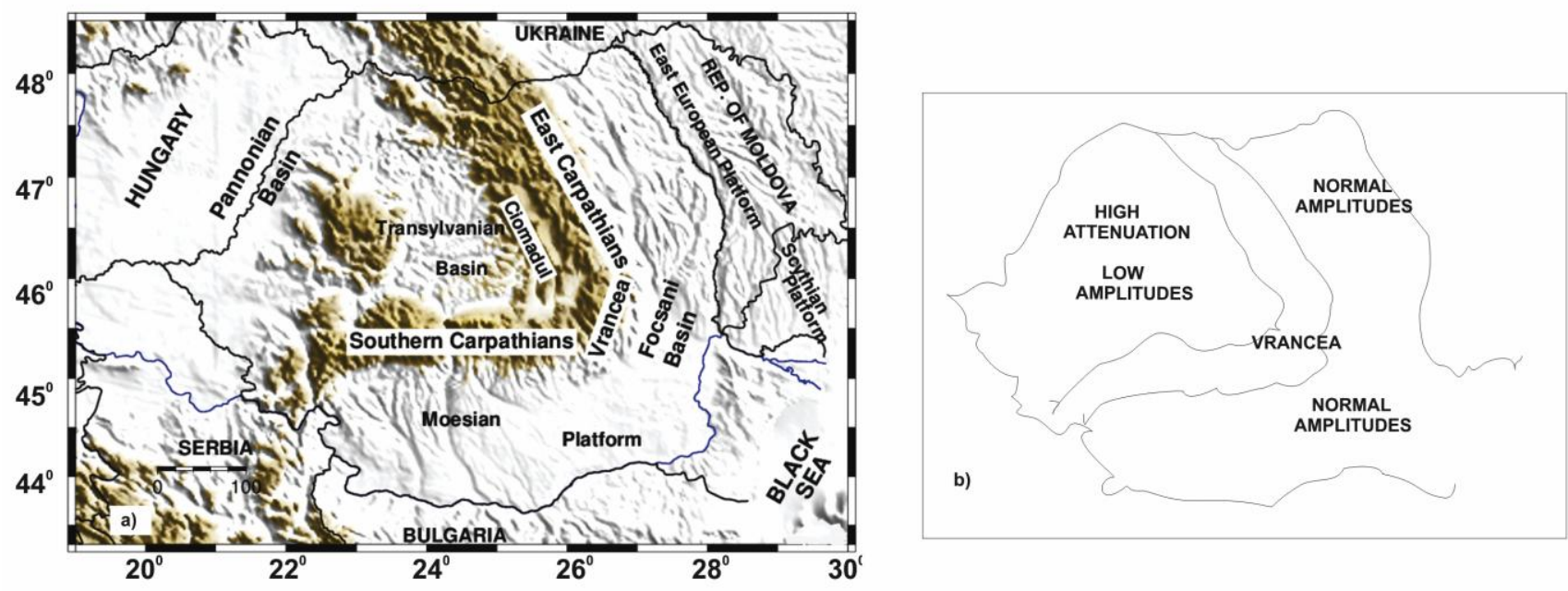

Figure 1 Simplified tectonic map of Romania (a) and sketch representing the attenuation mechanism (b) for the study area according to researches given in Table 1.

\section{DATA}

137 Velocity waveforms of local earthquakes in the Vrancea region recorded by 3-component broadband stations belonging to Romanian Seismic Network (RSN) of the National Institute for Earth Physics (NIEP) were used in the present study. The hypocentral distance of the selected earthquakes is in the range of 100 to $250 \mathrm{~km}$. The study region is characterised by good ray coverage due to the excellent aperture and station spacing of RSN, which has been constantly growing during the last decade (Neagoe and lonescu, 2009, Popa et al. 2015). A data set of 204 intermediate-depth earthquakes between 50 and $168 \mathrm{~km}$ (50 $\leq$ $\mathrm{h}(\mathrm{km})<100-39$ events; $100 \leq \mathrm{h}(\mathrm{km})<150-125$ events; $\mathrm{h}(\mathrm{km}) \geq 150-40$ events) occurring mostly between 2009 and 2011 with magnitudes ranging from 2.8 to $5.0(\mathrm{M}<3.0$ 67 events; $3 \leq M<4-109$ events $M \geq 4$ - 28 events) was selected for the analysis. The Romanian Data Centre (RONDC) of NIEP (Romplus catalogue, Oncescu et al. 1999, which is constantly updated) provided earthquake parameters as well as P- and S-wave travel times. The distribution of hypocentres, the seismic station coverage, and the ray density are shown in Figure 2. 

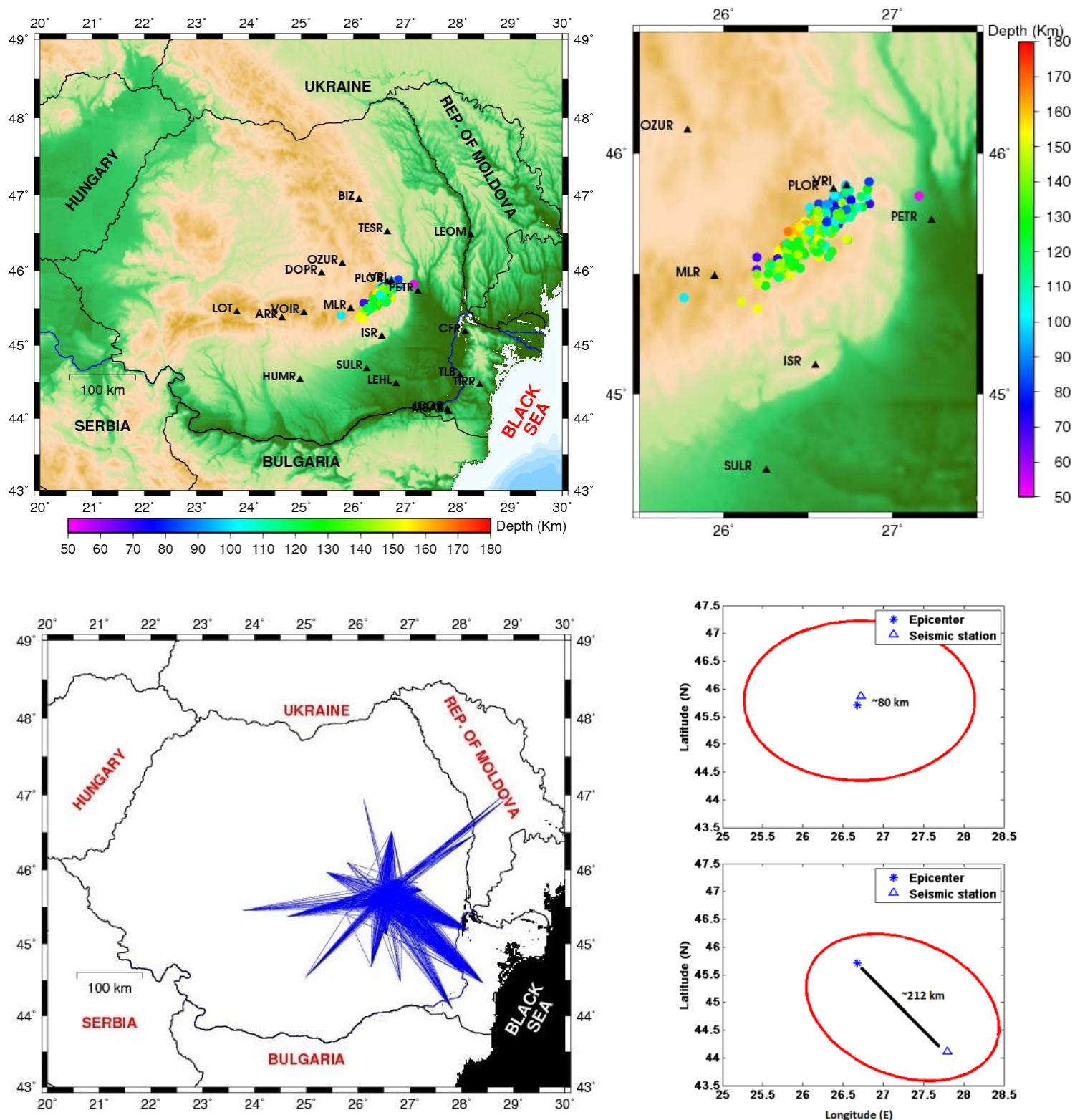

Figure 2 Epicenters (colored dots show depth) and stations distribution (black triangles) used in this study (top-left); a zoom on the seismicity, located in a SSW-NNE-trending vertical volume (top-right); the seismic ray paths density (bottom left); scattering ellipses for two source-station configurations, corresponding to $\sim 80 \mathrm{~km}$ distance (bottorm right - up) and 212 -bottom km distance (bottom right-down).

After the deconvolution of the instrument response, a fourth-order Butterworth bandpass filter was applied to each seismogram in forward and backward directions to obtain waveforms in 4 frequency bands $(2-4 \mathrm{~Hz}, 4-8 \mathrm{~Hz}, 8-16 \mathrm{~Hz}$ and 12-24 Hz). Envelopes for each frequency band were then computed as the root-mean-square (RMS - a direct measurement of seismic intensity) of each horizontal velocity seismograms (Figure 3). Finally, we applied smoothing using a moving time window whose typical duration is twice the central period of each frequency band. 


\section{METHODS}

\subsection{PEAK DELAY TIME (SCATTERING) MAPPING}

The peak delay time (Tpd) is defined as the time-difference between the S-wave onset and the maximum amplitude of the envelope, a well-known measurement of forward scattering (Takahashi et al. 2007, 2009; Tripathy et al. 2010; Calvet et al. 2013a). For each frequency band (central frequencies $3 \mathrm{~Hz}, 6 \mathrm{~Hz}, 12 \mathrm{~Hz}$, and $18 \mathrm{~Hz}$ ) the maximum was picked on the EW and NS components at each station in a time-window of $30 \mathrm{~s}$ duration, starting at the Swave onset. After averaging the two component measurements, we obtain $1540 \mathrm{Tpd}$ measurements for each frequency band. Figure 3 shows the data processing for two station recordings of the same earthquake $(25 / 02 / 2010,15: 51: 28, M w=4.3$, depth $h=110 \mathrm{~km})$.
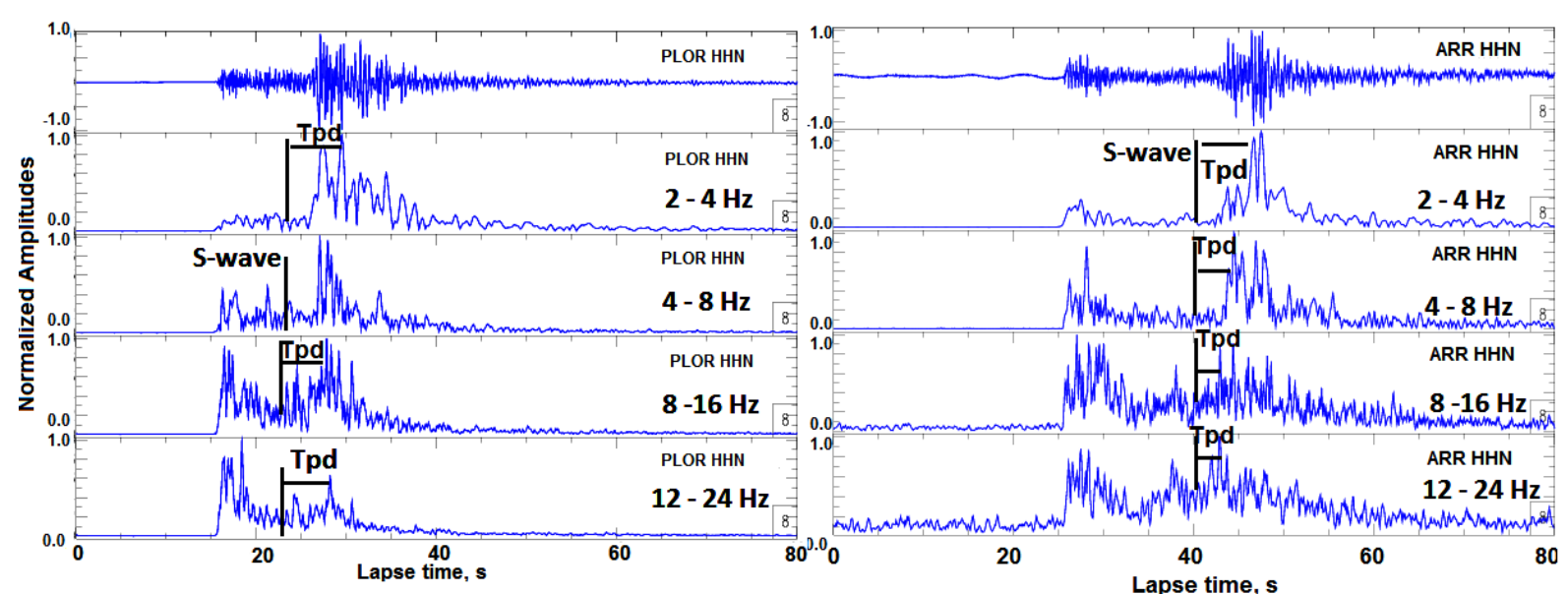

Figure 3 Examples of observed seismograms and their filtered envelopes at two stations: (left) PLOR situated around $140 \mathrm{~km}$ hypocentral distance and (right) ARR situated around $250 \mathrm{~km}$ (west relative to Vrancea) hypocentral distance. Top to bottom: velocity seismograms recorded by NS-components, filtered between 1 and $50 \mathrm{~Hz}$ after the deconvolution of the recording system response, and root mean square (RMS) envelopes in the 2-4 Hz, 4-8 Hz, 8-16 Hz, and $12-24 \mathrm{~Hz}$ frequency bands. The amplitudes were normalized to the maximum amplitude of each trace. The arrival of the S-wave and measurements of Tpd are shown in each panel.

\section{Correction of travel distance and frequency dependence of peak delay times}

We follow the selection criteria for distance of Sato (1989) and Takahashi et al. (2007) and consider source-station hypocentral distances in the range of 100 to $250 \mathrm{~km}$. These criteria ensure that the dependence of the envelope broadening on distance has the same characteristics across the entire hypocentral range. The linear dependence of the logarithm of peak-delay times against hypocentral distances is shown in Figure 4 (red lines) and is 
characteristic for the selected frequency ranges at lithospheric scale (Takahashi et al. 2007; Tripathi et al. 2010). The linear fit corresponds to the following equation and is used to correct for the hypocentral distance $(\mathrm{R})$ dependence:

$$
\log _{10} T p d(f)=A_{r}(f)+B_{r}(f) \log _{10} R
$$

Both the regression coefficients $\left(A_{r}\right.$ and $\left.B_{r}\right)$ and the root mean square errors (RMSE) are given in Table 2.

Table 2. Estimated coefficients from peak delay time distance corrections, obtained by leastsquare regression for each frequency band. The right hand column shows the root mean square values (RMSE)

\begin{tabular}{|l|l|l|l|}
\hline Frequency (HZ) & Ar & Br & RMSE \\
\hline $\mathbf{2}-\mathbf{4 ~ H z}$ & 0.9803 & -0.1976 & 0.0875 \\
\hline $\mathbf{4 - 8} \mathbf{~ H z}$ & 0.4018 & -0.0327 & 0.1250 \\
\hline $\mathbf{8}-\mathbf{1 6 ~ H z}$ & -0.0835 & 0.1490 & 0.1577 \\
\hline $\mathbf{1 2}-\mathbf{2 4 ~ H z}$ & -0.5725 & 0.3526 & 0.1747 \\
\hline
\end{tabular}

Figure 4 reveals three important features of the regression trends with increasing frequency: (i) the slope of the regression trends increases, (ii) measurements are increasingly spread around the regression trend, and (iii) the slopes change from negative (3-6 Hz) to positive $(12-18 \mathrm{~Hz})$. Feature (i) is typical of upper-crustal measurements, especially at $3 \mathrm{~Hz}$, while features (ii) and (iii) are different with respect to what is generally observed at lithospheric scale (Takahashi et al. 2007; Calvet et al. 2013a).

Several studies (Popa et al. 2005; Oth et al. 2008) have previously highlighted that attenuation is frequency-dependent, with attenuation variability strongly increasing with increasing frequency. In particular, Oth et al. (2008) have shown that, at high frequencies (> 4-5 Hz), there is approximately one order of magnitude difference in attenuation between the recordings in the Carpathians and the foreland areas, whereas, at lower frequencies, the attenuation characteristics in both regions are similar. Possible physical explanations for this frequency-dependent behaviour of attenuation involve the degree of coupling between the slab and the overlying crust (Sperner et al. 2005), strong temperature effects (Zadeh et al. 2005), as well as scattering phenomena within the subducted lithosphere (Furumura and Kennett, 2005). We rely on the results of Saito et al. (2002), who showed that envelope broadening strongly increases with frequency if the content of short-wavelength (strong velocity fluctuations) in random media increases. This and the aforementioned results all agree with higher variation of high-frequency peak-delay measurements and indicate a dominance of small-scale heterogeneities in Vrancea and surrounding areas (feature ii). 
233 It has been shown by several authors that coda-waves at $3 \mathrm{~Hz}$ comprise surface waves 234 (Obermann et al. 2013; Popelliers et al. 2014; Galluzzo et al. 2015; De Siena et al. 2015). 235 Nevertheless, while surface-wave components could affect Qc measurements, this is no feasible explanation for the lowering of the peak-delay times with hypocentral distance at low frequencies (feature iii, Figure 4): if we would pick surface waves instead of S-waves we would observe a time dispersion, i.e., peak-delays increasing with hypocentral distance. Takahashi et al. (2007), who analysed data in a similar depth range but with a more extended lateral coverage, did not observe noticeable changes in the behaviour of the linear hypocentral-correction fit among different frequency ranges. Calvet et al. (2013a) noticed changes of the slope of the regression line for different frequencies using seismicity located in the upper crustal layers with less extended network coverage. However, they did not measure a negative slope. Our preferred explanation for feature (iii) is thus related (a) to the particular geometry of the hypocenters in our dataset and (b) to the different sensitivity of peak-delay measurements to depth in different frequencies. Seismic events are clustered inside a relatively-small lithospheric volume with respect to the extension of the seismic network. At larger hypocentral distances, $3 \mathrm{~Hz}$ and $6 \mathrm{~Hz}$ waves progressively sample deeper, more-compact/lower-scattering Earth layers, thus consistently showing a decrease in peak-delay time with distance. $12 \mathrm{~Hz}$ and $18 \mathrm{~Hz}$ waves sample instead shallower and more inhomogeneous layers, presenting stronger scattering that increases peak-delay times at larger hypocentral distances. This difference in sensitivity is the main cause for the lowfrequency negative slopes in the peak-delay times. If our interpretation is correct, we can safely assume that (1) the linear dependence of peak delay times versus distance and (2) the increase of peak-delay slopes versus distance with increasing frequency (Figure 4) are sufficient to ensure the validity of the linear peak-delay time distance correction.
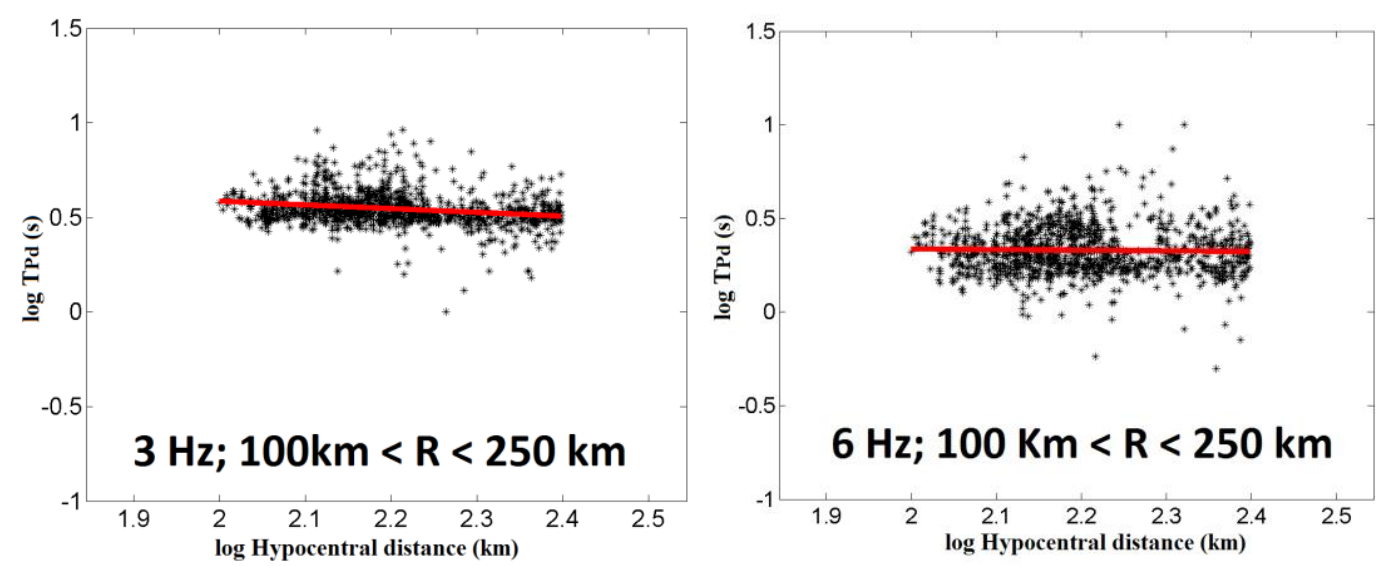

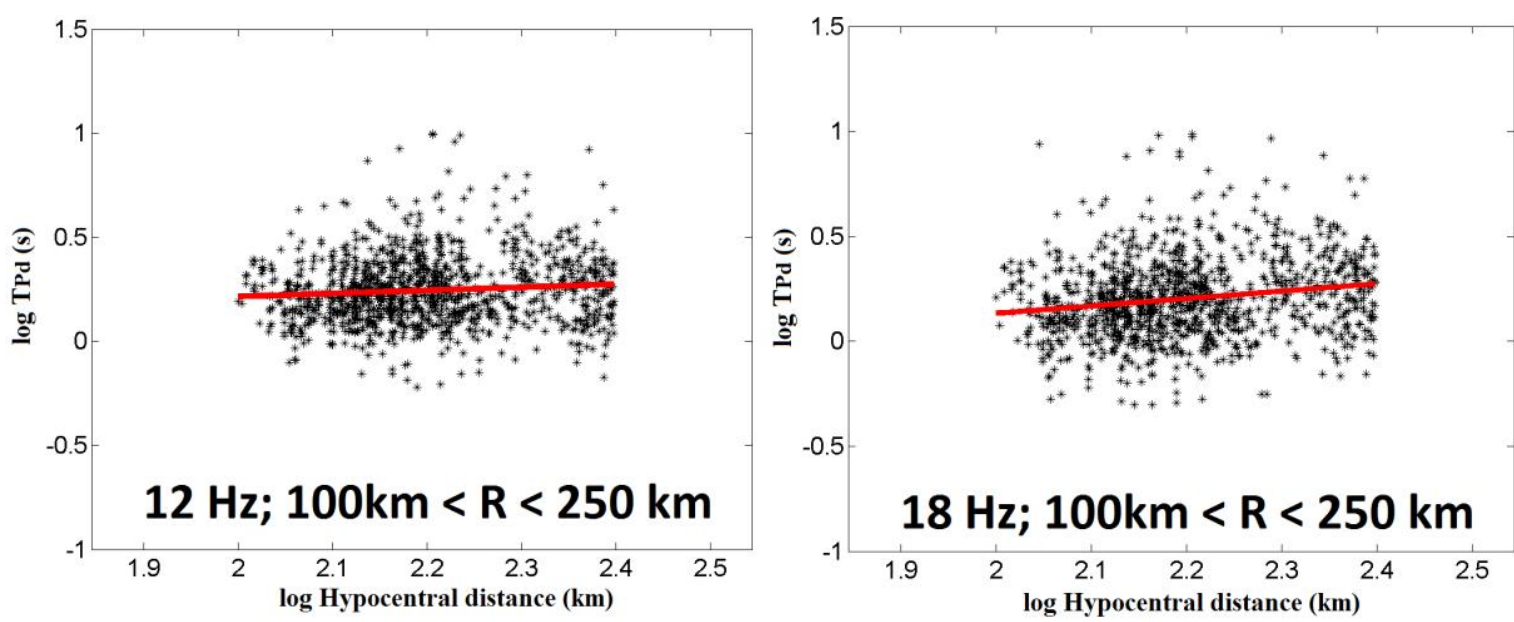

Figure 4 The logarithm of peak delay times (Tpd) against the logarithm of the hypocentral distance. Central frequency and distance range $(R)$ are shown in each panel.

\section{Spatial distribution of peak delay times in the Vrancea region and adjacent areas}

The 2-D spatial distribution of peak delay times (Tpd) was obtained following the approach of Takahashi et al. (2007) and Calvet et al. (2013a). The hypocentral distance dependence was removed for each frequency range computing Tpd differences following the equation:

$$
\Delta \log _{10} T_{p d}=\log _{10} T_{p d}(f)-\left(A_{r}(f)+B_{r}(f) \log _{10} R\right)
$$

where $\Delta \log _{10} T_{p d}$ are the mapped measurements and represent, in our interpretation, the strength of the scattering due to heterogeneities along the source-station path. The study region has been divided into squares of $0.25^{\circ} \times 0.25^{0}$. The average value of $\Delta \log { }_{10} T_{p d}$ from all rays crossing the square is allocated in space to the centre of the square and results are then interpolated. Figure 5 shows the $\Delta \log _{10} T_{p d}$, maps in the four frequency bands. We took into account only squares crossed by a minimum of 4 rays. Red regions are characterized by low $\Delta \log _{10} T_{p d}$ values (low scattering), while blue regions are characterized by high $\Delta \log _{10} T_{p d}$ values (strong scattering). 

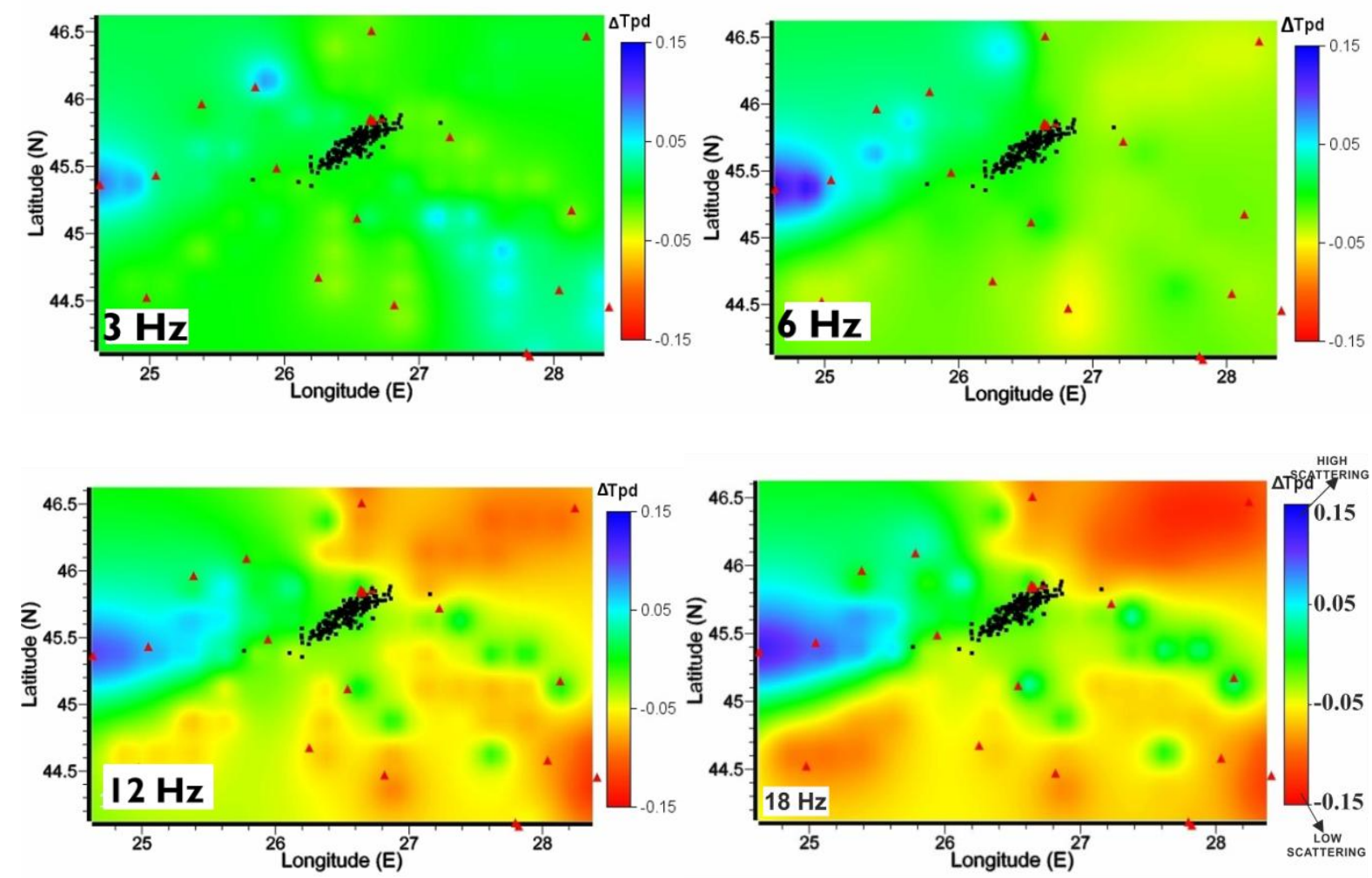

Figure 5 Maps of logarithmic peak delay times differences for the selected frequency ranges. Red triangles represent seismic stations and black dots earthquake epicenters. Blue regions are characterized by strong scattering; red denotes areas of low scattering.

Standard deviations maps for peak delay time differences for the selected frequency ranges are shown in Figure 6. Main variations are, as expected, in the source region and close to the lithospheric slab beneath the Vrancea region.
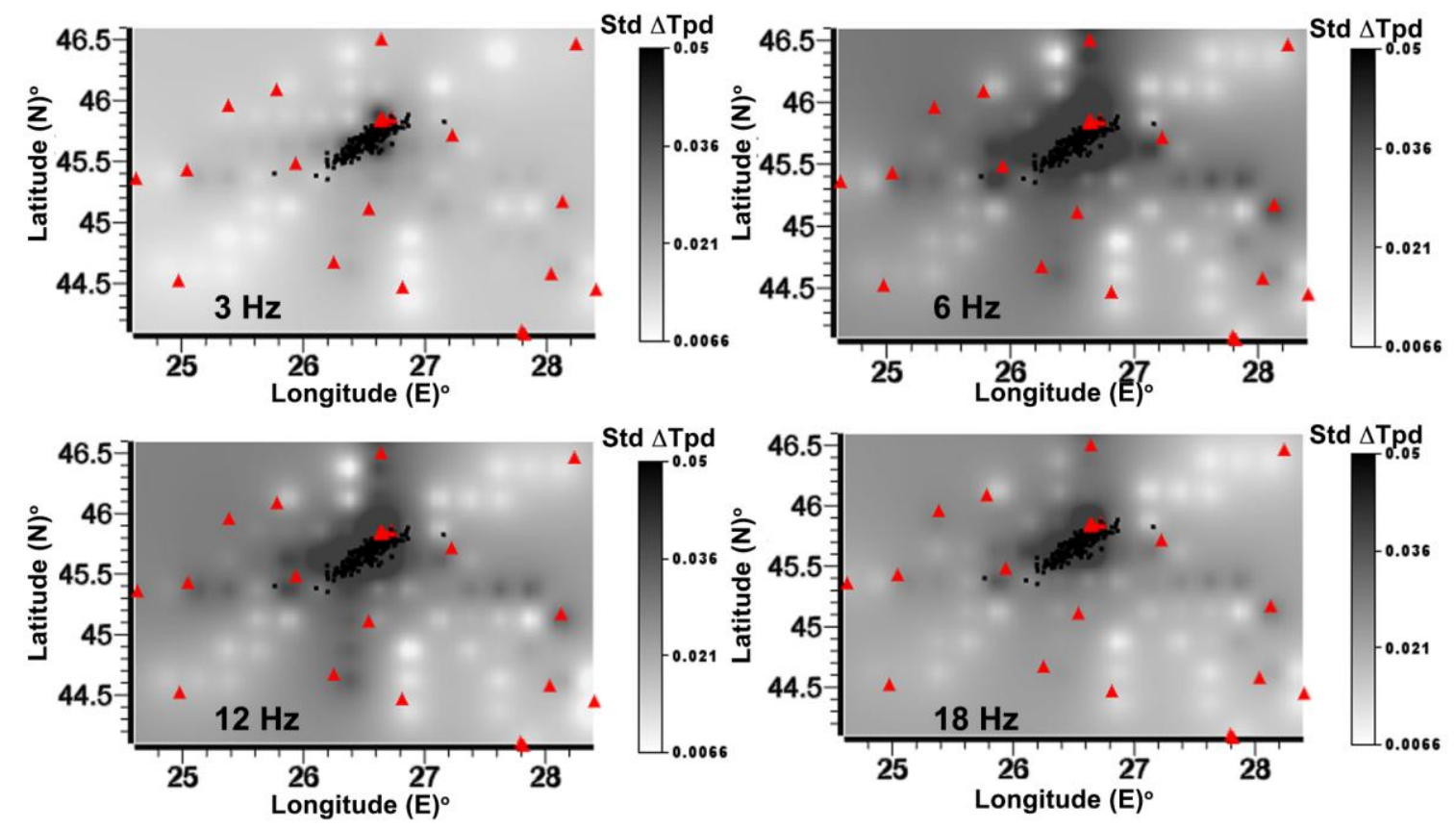

Figure 6 Maps showing the standard deviation of peak delay time differences for the selected frequency ranges. Red triangles represent seismic stations and black dots earthquake epicenters. 
303 From a smooth spatial distribution of scattering heterogeneity at low frequencies $(3 \mathrm{~Hz})$ we pass to strongly variable scattering strengths for higher frequencies (18 Hz). Anomalies in the high-frequency range show spatial correlation with the S-waves seismic velocity patterns obtained by Ren et al. (2013) from ambient noise tomography at a depth of $4 \mathrm{~km}$ (Figure 7). These are also associated with the three major tectonic units, intersecting in the Vrancea region.

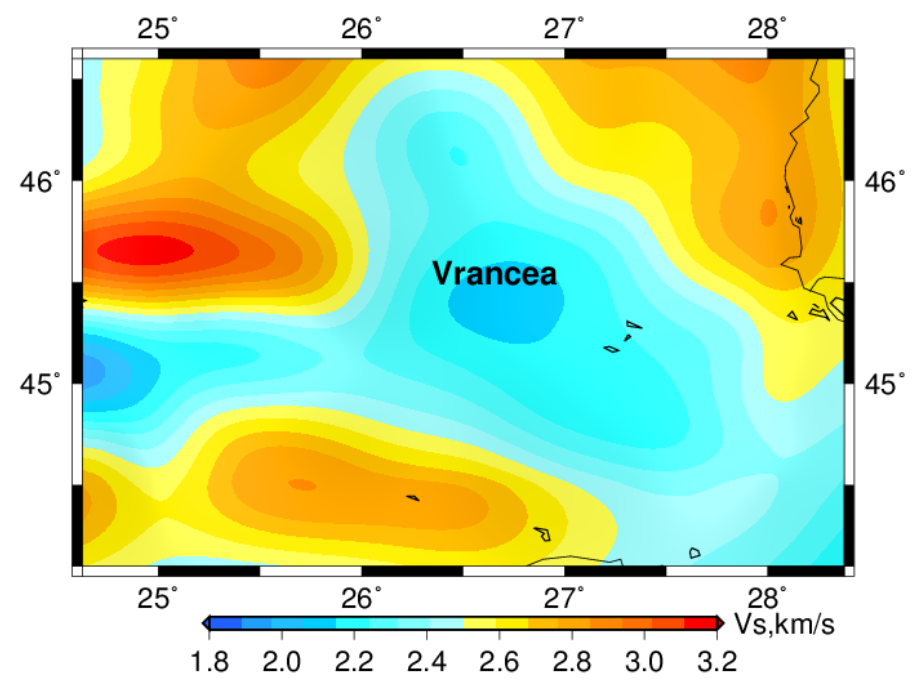

Figure 7 Horizontal section of $S$-waves velocity at a depth of $4 \mathrm{~km}$ according to Ren et al. 2013.

In particular, the highest peak-delay time differences are distributed $\mathrm{W}$ and NW relative to the Vrancea region, in the Transylvanian Basin, and are associated with the Carpathian Mountains roots, while the transition to the East European Platform to the Moesian Platform, east and northeast of Vrancea, produces low-/average-scattering anomalies (compare with Figure 1).

\subsection{CODA QUALITY FACTOR (ABSORPTION) MAPPING}

The quality factor $(Q)$ is a non-dimensional parameter (Knopoff, 1964) measuring the decrease in amplitude of a seismic wave travelling through a heterogeneous medium, thus used to quantify different media characteristics. The inverse coda quality factor $\left(Q_{c}^{-1}\right.$, also called the coda attenuation factor) represents a direct measurement of seismic attenuation. According to Sato et al. (2012), $Q_{c}^{-1}$ is a linear combination of the inverse intrinsic quality factor $Q_{i}^{-1}$ (measuring intrinsic absorption) and the inverse scattering quality factor $Q_{s}^{-1}$ (measuring the energy scattered by the medium that can be recovered in seismic coda). Starting from Aki (1969), the $Q c^{-1}$ dependence from scattering and absorption as well as its 
connection to tectonic stress has been the focus of several studies (e.g. Aki and Chouet 1975; Sato, 1977; Rautian and Khalturin, 1978; Hermann, 1980; Oancea et al. 1989b, 1991; Calvet et al. 2013a, b). In the present study, the single backscattering approach proposed first by Aki and Chouet (1975) is applied. It measures the coda attenuation factor from the decay of the energy envelope as a function of time $t$, according to the following equation:

$$
A(f, t)=A_{0}(f) t^{-\alpha} e^{-2 \pi f t / Q c}
$$

where $A(f, t)$ represents the power spectral density, $A_{0}(f)$ is a source-dependent term, $t$ is the lapse time from the earthquake origin time, $f$ is the frequency, and $\alpha$ is the positive exponent (assumed equal to 1.5 following Calvet et al. 2013a). $Q_{c}{ }^{-1}$ for a single station component was computed by a least-squares linear fit of $\log \left(A(f, t) t^{1.5}\right)$ versus $t$ in the four frequency bands used to measure peak delay times. The average over the two components was then taken as the source-station $Q_{c}^{-1}$. The envelope decay was measured (i) using a time window starting at the highest possible lapse-time from the origin of the earthquake, (ii) selecting those seismograms who had a signal-to-noise ratio higher than 1.5 and (iii) for which the correlation coefficient $(\mathrm{CC})$ of the linear regression was greater than 0.5 . The $\mathrm{CC}$ value was chosen after several trial tests. Increasing the CC threshold, we lose data and, consequently, lower resolution. A CC of 0.5 is similar to that used by De Siena et al., 2014 (0.6) and reduces uncertainties in the results while preserving a sufficient number of data for the chosen resolution. We obtain 1540 measurements for each frequency band. Figure 8 shows example-measurements for two different source-station pairs, using the same earthquake described in Figure 3.

According to Calvet et al. (2013a, 2013b), the highest achievable lapse-time is selected (70 s), so that the $Q_{c}{ }^{-1}$ dependence on anisotropy and scattering attenuation is low, and the quantity can be considered a direct measurement of absorption. This assumption is not valid for shorter lapse times and higher levels of heterogeneity, where topography and different coherent effects might still affect the coda waves (Saito, 2010; Calvet et al. 2013a; De Siena et al. 2014). The signal-to-noise ratio after $90 \mathrm{~s}$ always drops below 1.5 for most sourcestation recordings, thus the coda time window $\left(t_{w}\right)$ is set at $20 \mathrm{~s}$. Recent advances in coda wave imaging have shown a complex sensitivity of coda waves to Earth heterogeneities (e.g. Mayor et al. 2014). Despite this, coda wave lateral- and in-depth sensitivities can be estimated by computing the surface area and average depth of a scattering ellipsoid (Sato, 1978), dependent on the average lapse-time (80 s), the average S-wave velocity $(4 \mathrm{~km})$ for either a short $(100 \mathrm{~km})$ and long $(250 \mathrm{~km})$ hypocentral distances. Figure 2 (bottom right panel) shows the two scattering ellipses for these two source-station configurations. The 
average dimension of the volume producing the coda is $171 \mathrm{~km}$, estimated by considering an average depth of the seismicity of $100 \mathrm{~km}$.
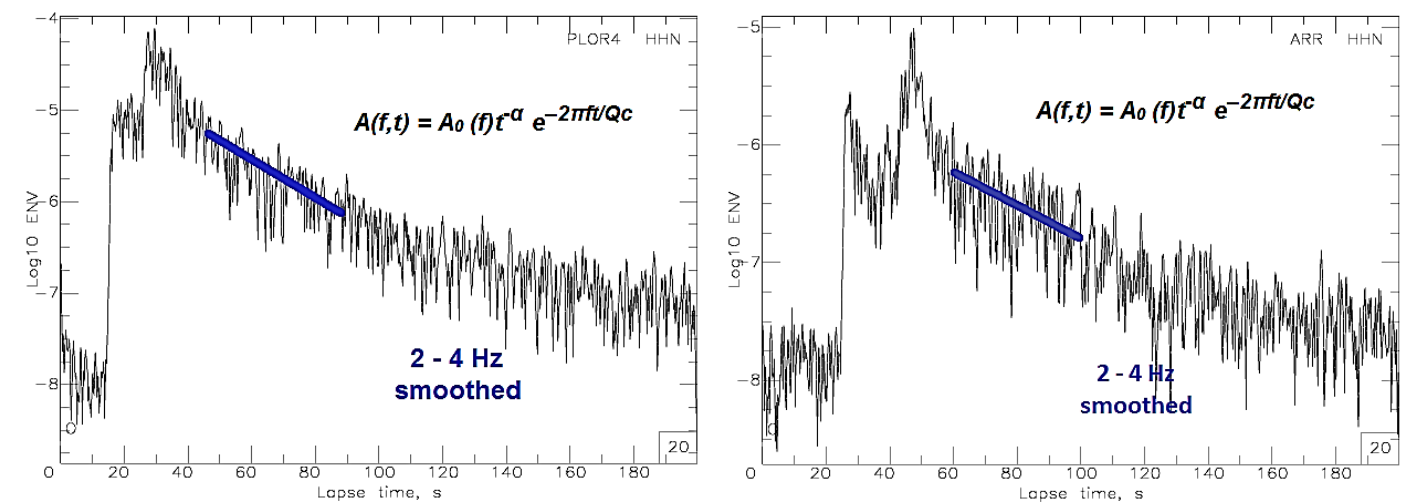

Figure 8 Examples of observed envelopes obtained from the NS components filtered between 2 and $4 \mathrm{~Hz}$ for station PLOR (left) situated at $140 \mathrm{~km}$ hypocentral distance and (right) for station ARR with a $250 \mathrm{~km}$ hypocentral distance. The two stations show different slopes for the envelope decay.

\section{Spatial distribution of Qc in the Vrancea region and adjacent areas}

We adopt the same mapping strategy for both peak-delay times and coda quality factors, dividing the region into squares of $0.25^{0} \times 0.25^{\circ}$, allocating the average over ray values of $Q_{c}^{-1}$ to the centre of each square, keeping only those crossed by at least 4 rays and interpolate the results. The scattering and absorptions maps (Figures 5 and 10) were obtained in Voxler 2.0 (c) through the inverse distant weighting (IDW) interpolation method, with weighting power equal to 2 . This assumes that distance weights each interpolated point. Data are weighted during interpolation such that the influence of one point relative to another declines with distance from the grid node. Weighting is assigned to data through the use of a weighting power that controls how the weighting factors drop off as distance from a grid node increases. The greater the weighting power, the less effect points far from the grid node has during interpolation. As the power increases, the grid node value approaches the value of the nearest point. For a smaller power, the weights are more evenly distributed among the neighboring data points.

In order to give a better insight on the quality results we represented in Figure 9 the chessboards maps for the Qc computed for $3 \mathrm{~Hz}$. This measurement is the one with the lowest number of blocks solved according to our 4-rays threshold. The chessboard test shows sufficient illumination in the areas interpreted. 


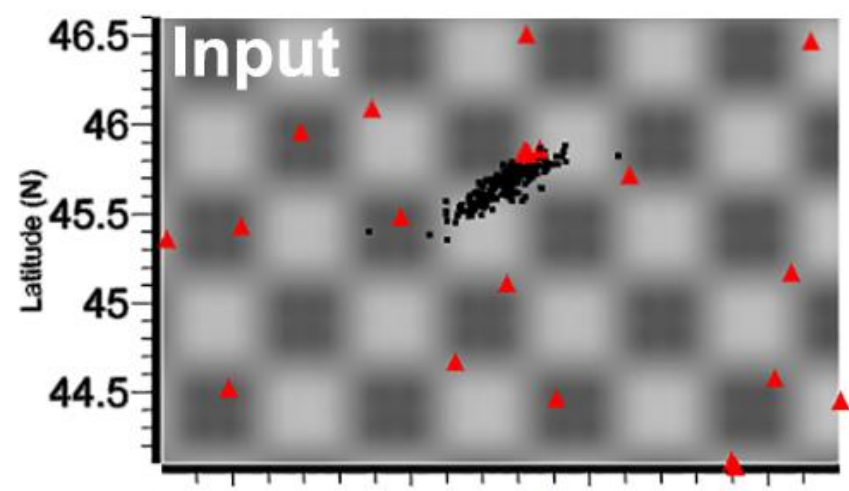

\section{Qc $^{-1}$}
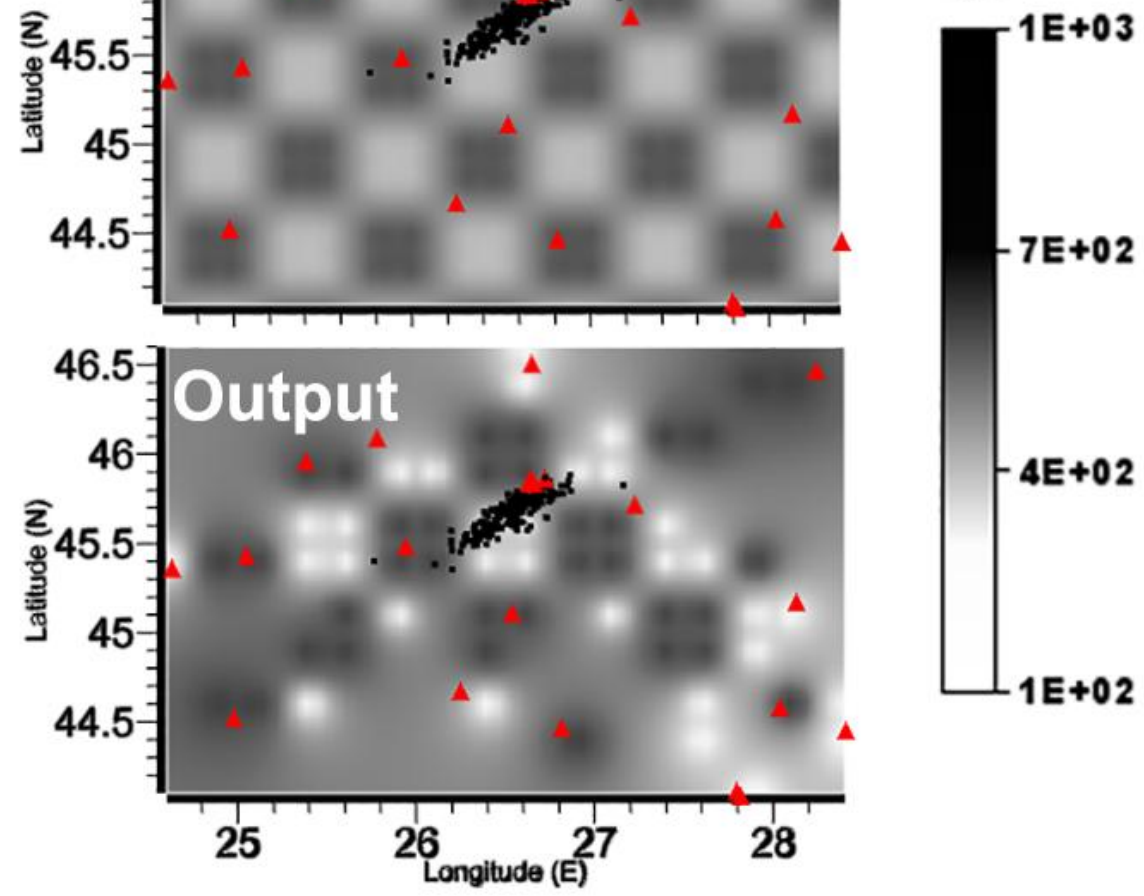

7E+02

$-4 E+02$

$1 E+02$

Figure 9 The chessboards maps computed for the Qc at the central frequency of $3 \mathrm{~Hz}$

The ray-dependent $Q_{c}{ }^{-1}$ values were finally divided by the average $Q_{c}{ }^{-1}$ over the entire dataset $\left(Q_{m}{ }^{-1}\right)$, to show attenuation variations. $Q_{m}{ }^{-1}$ can be correlated to the tectonic setting of the area; it is thus computed at each frequency and with the corresponding uncertainties by using a least square approach: $(\mathrm{Qm}(3 \mathrm{~Hz}))^{-1}=0.0025 \pm 0.010 ;(\mathrm{Qm}(6 \mathrm{~Hz}))^{-1}=0.0014 \pm 0.007$; $(\mathrm{Qm}(12 \mathrm{~Hz}))^{-1}=0.0007 \pm 0.0004 ;(\mathrm{Qm}(18 \mathrm{~Hz}))^{-1}=0.0004 \pm 0.0003$. Uncertainties are estimated computing the $95 \%$ confidence interval, using the covariance matrix. Ideally, also the absolute values of Qc after mapping could be related to tectonics; however, as evidenced by the chessboard test (Figure 9) ray geometries and selection criteria have important effect on absolute Qc values, while contrasts are generally preserved. We thus prefer a more careful approach and divide $\mathrm{Qc}^{-1}$ by $\mathrm{Qm}^{-1}$ to show attenuation variations only. In Figure 10, red regions are associated with low $Q_{c}$ values (high absorption) whereas blue colors correspond to high $Q_{c}$ values (low absorption). No clear correlation exists between the absorption maps and the three main tectonic units of the area. On the other hand, the absorption measurements are frequency dependent, with contrasts in absorption properties clearly enhanced at higher frequencies (Figure 10). At $3 \mathrm{~Hz}$, we observe secondary highabsorption anomalies crossing Vrancea from west to southeast, while at higher frequencies we observe a south-to-northeast absorption contrast, located between the outer and inner Carpathians, dominates the maps. 

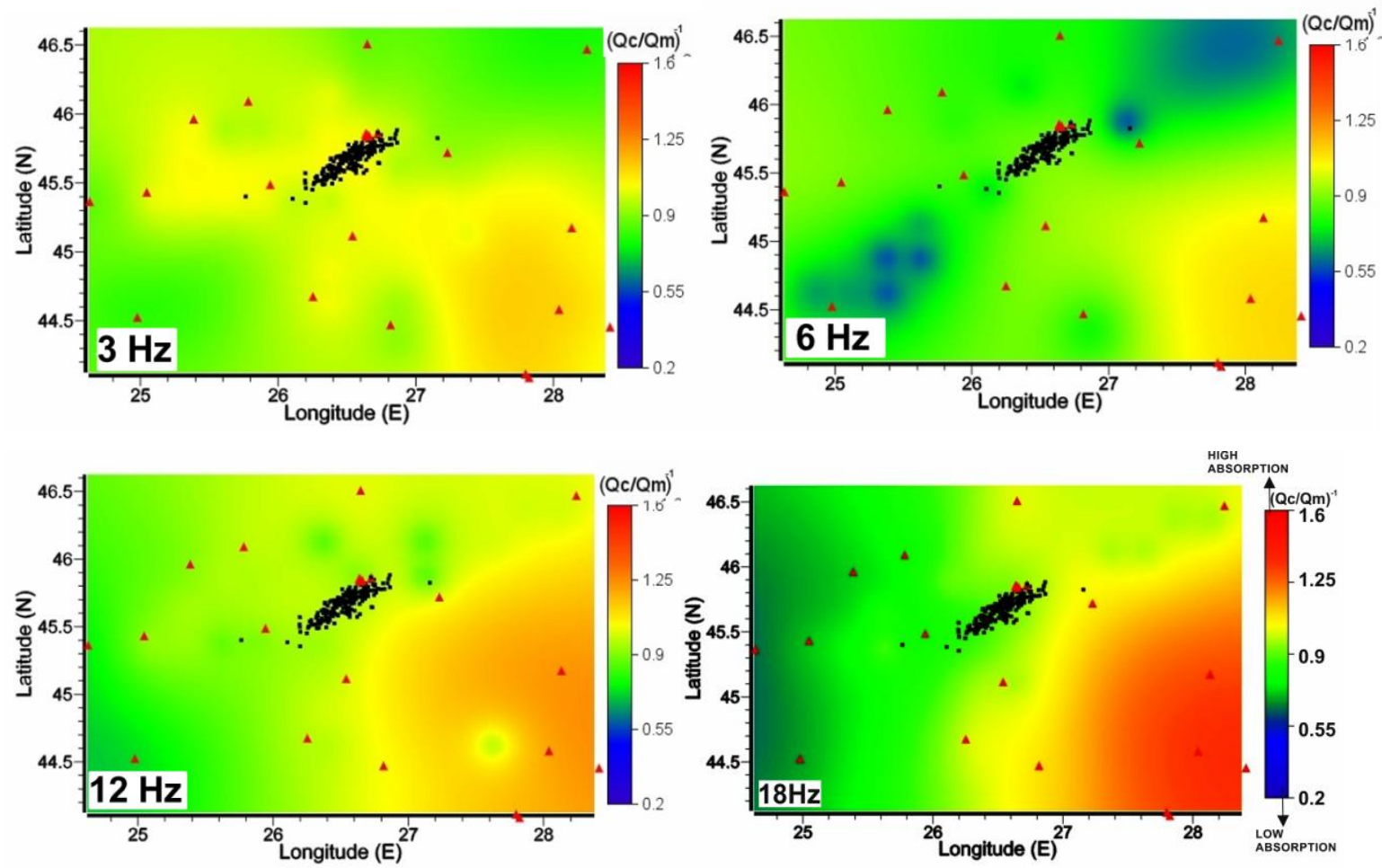

Figure 10 Maps of inverse coda quality factor divided by the mean of all measurements $\left(Q_{d} Q_{m}\right)^{-1}$ for the selected frequency ranges. Red triangles represent seismic stations and black dots earthquake epicenters. Red colours show high absorption, blue colours low absorption.

Standard deviations maps of $\left(Q_{d} / Q_{m}\right)^{-1}$ for the selected frequency ranges are shown in Figure 11. The variations reduce with increasing frequency, as expected. The areas with the largest uncertainties are those NW and South of the source (Vrancea) area.
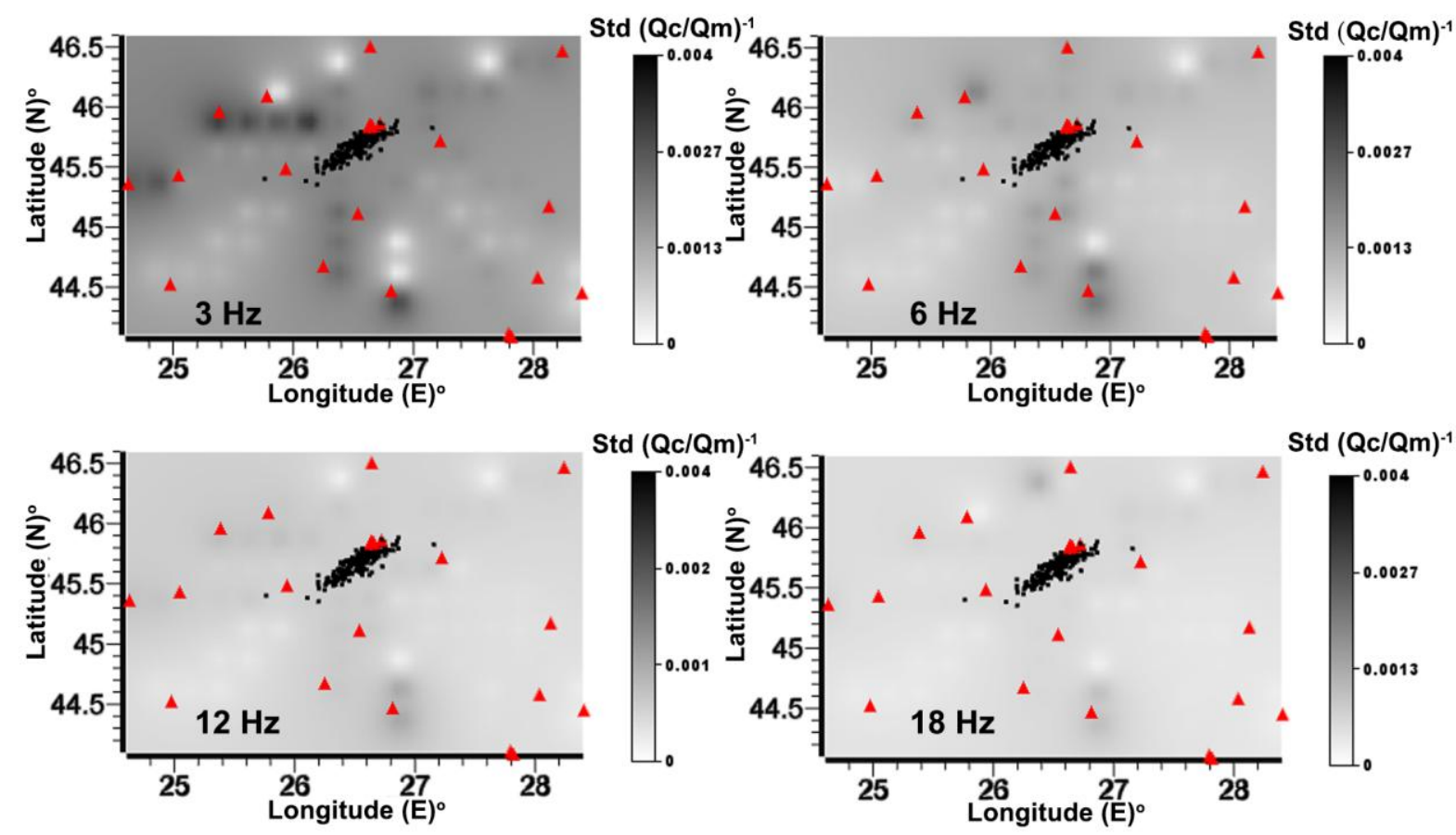

$\operatorname{Std}(Q c / Q m)^{-1}$
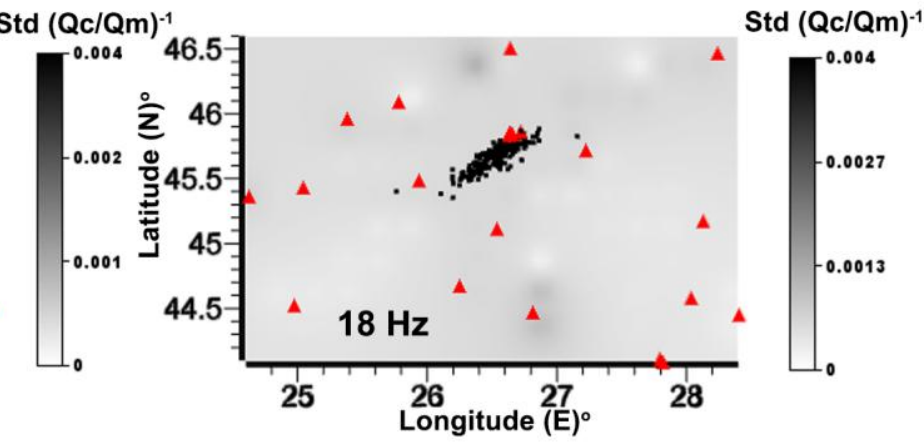

Figure 11 Maps showing the standard deviation of $\left(Q_{c} / Q_{m}\right)^{-1}$ for the selected frequency ranges. Red triangles represent seismic stations and black dots earthquake epicenters. 
Although the exact frequency-dependent sensitivity of coda waves to depth is still debated (e.g. Aki and Chouet, 1975; Shearer and Earle, 2004), it has been theoretically and experimentally shown that $3 \mathrm{~Hz}$ coda measurements are consisting of surface waves, making them particularly sensitive to surface structures (Calvet et al 2013a, Obermann et al. 2013; Mayor et al. 2014; Galluzzo et al. 2015; De Siena et al. 2016). Attenuation by absorption is more important in the upper crust than in the upper mantle (Sato et al. 2012). In a volcanic medium, the high heterogeneity and quick onset of the diffusion regime makes $Q_{c}$ particularly sensitive to shallow volcanic structures, as debris flows (Popelliers et al. 2015; De Siena et al. 2016). In a lithospheric setting however, different frequency-dependent behaviours are suggested by other studies (Calvet et al. 2013a, De Siena et al. 2014), with $Q_{c}$ measurements sampling deeper structures at lower frequencies: the results of the mapping at Vrancea agrees with this last interpretation, as higher spatial correlation with superficial lithospheric structures is found at higher frequencies.

\subsection{CLUSTER ANALYSIS}

To separate scattering and absorption patterns quantitatively using the maps of $\Delta \log _{10} T p d$ (Figure 5) and (Qc/Qm) ${ }^{-1}$ (Figure 10) obtained in previous sections we have applied a nonhierarchical selection analysis known as K-means clustering (Hartigan, 1975) with Euclidean distance. This method associates measures to a number of clusters $(K)$ independently defined in order to maximize the clusters separation. The distance between clusters is Euclidean. Cluster analysis is a widely used method to separate data into groups depending on their physical characteristics. The main challenge this method presents is the estimation of an optimal number of clusters $(\mathrm{K})$, each cluster comprising objects with similar characteristics. According to Cornish (2007), the main disadvantage of cluster analysis is that there is no mechanism to differentiate between relevant and irrelevant variables when choosing the number of clusters. Therefore, the choice of variables included in a cluster analysis must be underpinned by conceptual considerations.

Our dataset comprises couples of peak-delay and $(\mathrm{Qc} / \mathrm{Qm})^{-1}$ measurements, each couple corresponding to the centre of a square in space (De Siena et al. 2011). To compute the optimal number of clusters, we used the elbow method (Hartigan, 1975 - Figure 12 shows the curve obtained at $3 \mathrm{~Hz}$ ) and the Bayesian Information criterion (BIC - Schwartz, 1978). The "elbow" method runs K-means clustering on the selected dataset for a range of integers $\mathrm{K}$, computing the percent of variance reduction due to separation in $\mathrm{K}$ clusters. The percent of variance reduction on $\mathrm{K}$ values (Figure 12) is a qualitative way to define the best number of clusters: when the line deviates from the linear increase (the "elbow) and following values 
reach an approximate plateau, increasing the number of clusters only increase complexity 465 without adding a relevant percent reduction. At all frequencies the number of clusters selected is two (see De Siena et al. 2011 for a similar analysis). A 2-mean cluster analysis was thus performed separately for all frequency ranges, with results (Figure 13) showing areas of either stronger absorption (orange) or stronger scattering (cyan). At all frequencies, absorption dominates southeast of Vrancea while scattering attenuation is stronger north and northwest of Vrancea.

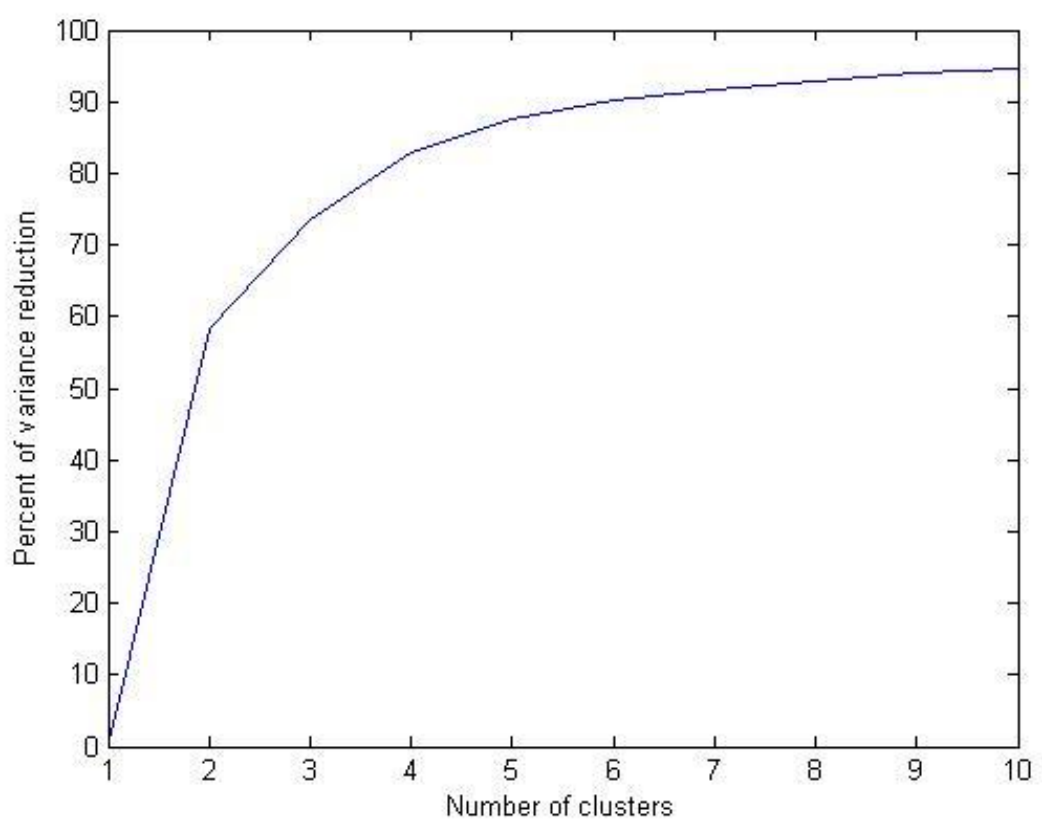

471

472 Figure 12 The percentage of variance reduction versus the number of clusters at $3 \mathrm{~Hz}$. The 473 number of cluster chosen is 2 .

474
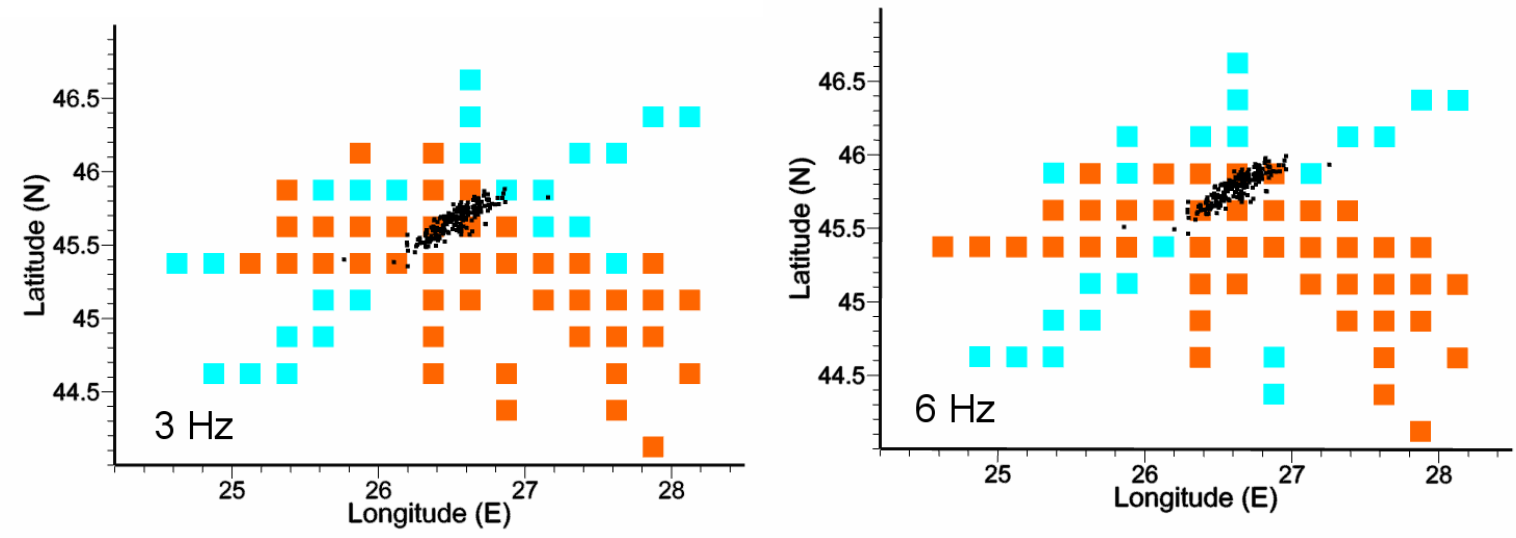

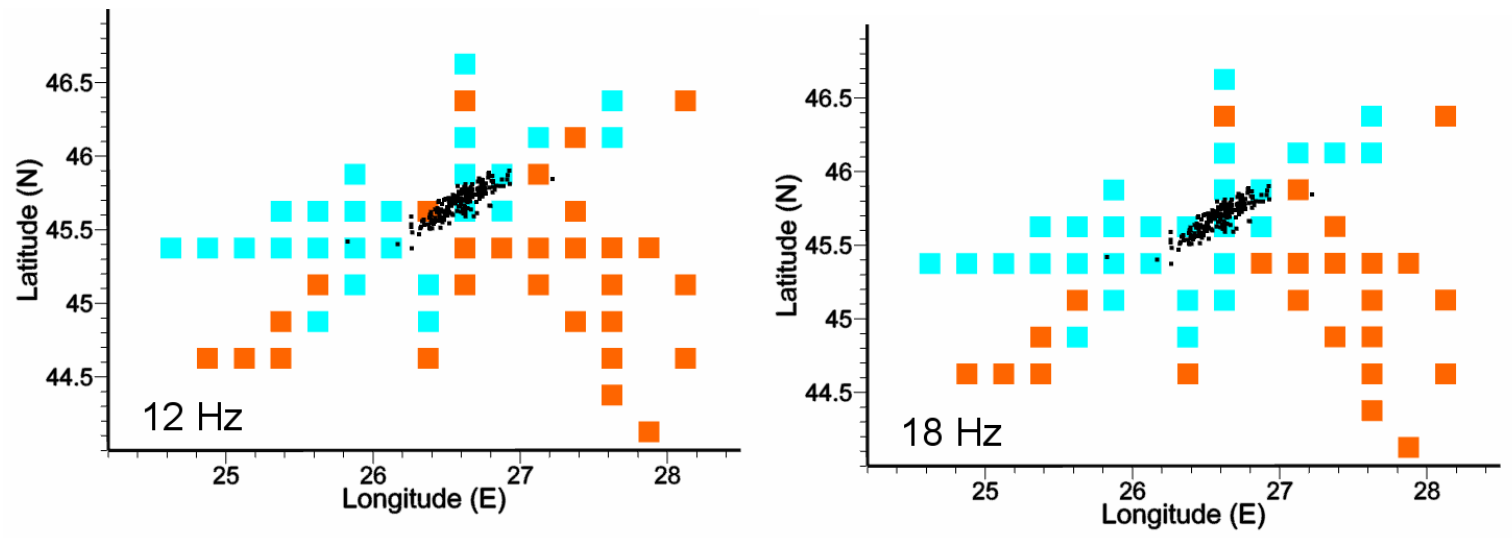

476

477

478

479

480

481

482

483

484

485

486

487

488

489

490

491

492

493

494

495

496

497

498

499

500

501

502

503

504

505

Figure 13 Maps showing results of cluster analysis obtained using the $\Delta \log _{10} T p d$ and the inverse of $\left(Q_{d} / Q_{m}\right)^{-1}$ spatial measurements. Black dots represent earthquake epicentres. Orange squares denote higher absorption while cyan squares represent higher scattering

\section{DISCUSSION}

The goals of the present study are (1) to investigate the two mechanisms producing seismic wave attenuation in the Vrancea region and adjacent areas and (2) to interpret the patterns in terms of seismotectonic structures. In this section, we take into account the interdisciplinary literature relative to the geophysical and geodynamical characteristics of the area, and discuss the limitations of the methodology. Scattering is dominant in the north, northwestern, and western parts of the maps, and is spatially correlated with the Southern Carpathian. Absorption dominates in the Focsani Basin, crosses the Moesian Platform, and reaches the Southern part of the Scythian Platform southeast of Vrancea (see Figures 1 and 13).

The strong frequency-dependence of scattering attenuation for waves generated in the Vrancea subcrustal domain (Figures 4 and 5) correlates well with the results of Popa et al. (2005), who first remarked a difference in total attenuation depending on frequency content, and Oth et al. (2008), who found that attenuation variability strongly increases with increasing frequency. The last authors showed that, at high frequencies (> 4-5 Hz), there is approximately one order of magnitude difference in total attenuation between the mountain range and the foreland, whereas at lower frequencies the attenuation characteristics are rather similar. The similarity between the attenuation characteristics above described and the behaviour of peak delay times in frequency (Figure 4) and space (Figure 5) implies that scattering is the main attenuation mechanism in the area, at least at the investigated frequencies. Possible physical explanations for these results involve the degree of coupling between the subducting slab and the overlying crust (Sperner et al. 2005), scattering phenomena within a subducted (Furumura and Kennett, 2005) or delaminated (Koulakov et 
al. 2010) lithospheric fragment. Strong temperature effects (Ismail-Zadeh et al. 2005) should rather produce relevant patterns in the frequency-dependent absorption imaging. The high-scattering Southern Carpathians represent the region characterized by the highest velocity and density contrasts, coupled with strong time-dependent deformations (Schmid et al. 1998, Matenco and Bertotti, 2000, Cloetingh et al. 2005). According to Bocin et al. (2005), three main post-docking deformational stages were recognised in this region. During Palaeogene-Early Miocene times, the clockwise rotation of the Tisza-Dacia block (Balla, 1986) has caused NNE-SSW to ENE-WSW shortening in the internal Moldavides napes of the East Carpathians (Matenco and Bertotti, 2000), large scale transtension/extension to core-complex formation in the South Carpathians (e.g., Schmid et al. 1998), and final collision of the Balkans with Moesian Platform southwards (e.g., Doglioni et al. 1996). Collision with the stable foreland has occurred during the Middle and Late Miocene (Badenian-Sarmatian), leading to large-scale deformation characterised by EW shortening in the East Carpathians (e.g., Sandulescu, 1988; Matenco and Bertotti, 2000) and transpression/shortening in the South Carpathians (Matenco et al. 1997). The collision with the foreland culminated during Late Miocene (Sarmatian) times. This region dominated by scattering also corresponds to the contact between the South Carpathians and the hinterland, the South Apuseni Mountains units, where potentially large scale thrusting and transcurrent motions occurred during the late Alpine evolution (Cloetingh et al. 2005). Another possible cause of high scattering is the presence of the TTZ (Tornquist-Teisseyre Zone) in this region. Bocin et al. (2013) suggest that TTZ is situated in Romania beneath the South-Eastern Carpathians, further to the southeast than assumed by previous studies. As such, the TTZ incorporates the Vrancea zone earthquake epicentres. In the Carpathians, Weidle (2004) have also shown that approximately $75 \%$ of the observed attenuation of teleseismic $\mathrm{P}$-waves is induced by scattering, predominantly from complex boundaries and heterogeneities in the crust.

532 The area of highest geodynamical and seismotectonic complexity is thus the one marked by 533 highest scattering attenuation. Regions that produce high scattering are located near the transition zone from low-velocities to high velocity ratios (Koulakov et al. 2010). This is in agreement with Takahashi et al. (2007), who obtain similar results in the Japanese crust, specifically under Quaternary volcanoes. The analogy suggests that the dimension of the strong heterogeneities ranges from a few hundred metres to a few kilometres and scattering in the area (including Ciomadul volcano) is influenced by volcanism. At the lowest frequency (Figures 10 and 13, $3 \mathrm{~Hz}$ panel, in our assumption the frequency band sampling deepest Earth layers) absorption increases northwest and southeast of the epicentral area, crossing an area of average-to-strong scattering (Figure 5). This anomaly is spatially correlated with the location of the hypothesised asthenospheric upwelling beneath 
543 the Neogene volcanic arc (Figure 1), which migrated from NW to SE (Seghedi, 2005; 544 Koulakov et al. 2010; Popa et al. 2011; Panaiotu et al. 2012). Comparing the NW and SE 545 high-absorption features with the results of the tomography study of Koulakov et al. (2010), 546 high absorption correlates with strong S-waves velocities perturbations at depths of 110-130 $547 \mathrm{~km}$. The region characterized by high absorption (Figure 10) at higher frequencies (from 6 to $54818 \mathrm{~Hz}$ ) starts from the front of the Carpathian bend (Focsani Basin) and extends to the South 549 and South-Eastern Moesian Platform within the southwestern part of Scythian Platform 550 (compare Figures 1 and 10). The results in the Focsani Basin confirm that sedimentary 551 basins represent a primary cause of high absorption (see e.g. Calvet et al, 2013a for 552 Pyrenees). Bocin et al (2005) model the Foscani Basin as containing up to $13 \mathrm{~km}$ of 553 sediments, deposited in a foredeep type setting. This basin, according to Mocanu et al. 554 (1996), is predominantly characterized by Neogene sedimentary rocks derived from the 555 Carpathians, with significant contributions of detritus from the more external Moldavian and 556 Moesian Platform. We also note that important crustal movements characterize areas of 557 active subsidence (up to $3 \mathrm{~mm} \mathrm{yr}^{-1}$ ) in this region (Popescu and Dragoescu, 1987). The 558 location of the high-absorption anomalies at higher frequencies (12 and $18 \mathrm{~Hz}$ ) in such 559 stable regions (platforms), however, suggests that high-frequency absorption effects are 560 generated by even shallower structures. The anomalies are in fact spatially correlated with 561 zones of hydrocarbons, natural gas, and oil accumulation (Radulescu et al. 1976; 562 Stefanescu et al. 1988; Stanica and Stanica, 1998; Matenco and Bertotti, 2000; Tarapoanca 563 et al. 2003; Leever et al. 2006).

564 To better understand the meaning of the scattering/absorption contrasts at different 565 frequencies (Figures 5 and 10), they are compared with the heat flow map displayed using 566 the Global Heat Flow Database (http://www.heat flow.und.edu) (Figure 14, left). High 567 scattering (represented in blue in Figure 5) corresponds mostly to average/low heat-flow 568 values, while high absorption anomalies correlate spatially with high heat flow values. The 569 highest heat flow, corresponding to the location of the Ciomadul volcanic field, is at the 570 northwestern limit of the southeast-west trending absorption anomaly at $3 \mathrm{~Hz}$ (Figure 10, 3 $571 \mathrm{~Hz}$ ). A second comparisons of our results with the Bouguer anomaly (Figure 14, right) shown 572 using the grid provided by Bureau Gravimetrique International (Bureau Gravimétrique 573 International; http://bgi.omp.obs-mip.fr) reveals that the highest seismic scattering overlaps 574 the lowest Bouguer anomalies (lower densities - compare with Figure 5), while the south 575 and southeastern high-absorption structures correlate with positive Bouguer anomalies. 

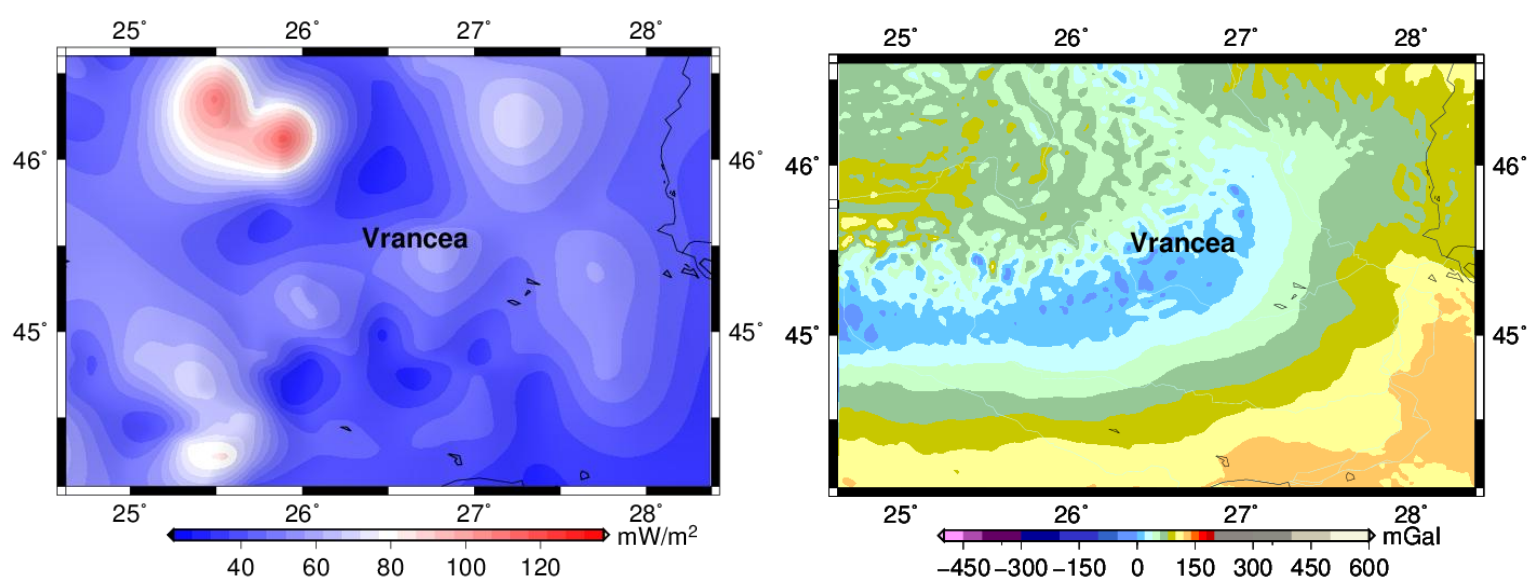

Figure 14 Maps showing heat flow distribution (left) and Bouguer anomaly (right). The high heat flow corresponds to the location of Ciomadul volcano.

The cluster analysis results (Figure 13) at low frequencies (3 Hz and $6 \mathrm{~Hz}$ ) quantify and map the absorption and effects of deep seismic structures. High-scattering structures (cyan) characterize the regions southwest and northeast of Vrancea, spreading along the Carpathians, whose high topography possibly influences measurements. Orange anomalies (high absorption) are distributed along a trend that is almost perpendicular, and crosses, the epicentral trend (NW-SE). The limit of the high-absorption pattern spatially corresponds to the Ciomadul volcanic region, situated just NNW of the Vrancea region (Seghedi, 2005; Popa et al. 2011; Panaiotu et al. 2012). Such a high-absorption trend has been observed under the Cascadian volcanoes and related to the effect of a deep magmatic arc (De Siena et al. 2016). Cluster analysis results at low frequencies thus depict a unique high-absorption structure extending from southeast of Vrancea, at the location of the mantle upwelling modelled by several studies (e.g. Popa et al. 2011), to northwest of Vrancea, feeding Ciomadul volcano (Koulakov et al. 2010).

At high frequencies (Figure 13,12 Hz and $18 \mathrm{~Hz}$ ), the NNE-SSW scattering/absorption contrast follows the epicentral trend. This observation is similar in space and nature to that of Takahashi et al. (2007) for the subducting Japanese crust, at least for the peak delay time, and consistent with the presence of a NNE-SSW-oriented sinking lithospheric fragment into the asthenosphere (Radulian et al. 2006). In this framework, considering the investigated frequencies and Bouguer anomalies, the high scattering following the epicentral trend and extending to the west (Figure $13,12 \mathrm{~Hz}$ and $18 \mathrm{~Hz}$ ) is feasibly caused by either coupling between a subducting slab and the overlying crust (Sperner et al. 2005) or small-scale scattering phenomena within the upper portion of a subducted (Furumura and Kennett, 2005) or detached (Seghedi, 2005; Koulakov et al. 2010; Popa et al. 2011; Panaiotu et al. 2012) lithospheric fragment, sinking into the asthenosphere. 


\section{CONCLUSIONS}

607

We have mapped different seismic attenuation mechanisms in the Vrancea area and adjacent regions quantitatively using two integrated measurements, peak delay times and late lapse-time coda quality factors $\left(Q_{c}\right)$, in four frequency bands. Using these techniques we were able to identify structures of different dimension and depth (different wavelength/frequency) responsible for seismic absorption and seismic scattering. The approach complements other geophysical and geodynamical results and provides a quantitative interpretation of deep Earth properties and tectonic structures. Peak-delay time values, interpreted as a measurement of scattering attenuation, show considerable variations at high frequencies, which suggests a strong effect of short-wavelength heterogeneities in the upper crust and strong differences in sampling at different frequencies. Once mapped, peak delay time differences grow (scattering increases) towards the Carpathians (north, northwest, and west of Vrancea) with the highest values in the southern Carpathians, the same region characterized by a minimum in Bouguer anomaly. $Q_{c}^{-1}$ is interpreted as a measurement of absorption, with patterns showing lower frequency dependence, but still progressively sampling shallower regions with increasing frequencies. High absorption is prevalent in the fore-arc region (SE of Vrancea): besides the Focsani Basin, which shows the highest absorption, the area includes the southeastern side of the Moesian Platform, in strong spatial correlation with hydrocarbon and natural gas reservoirs consistently depicted by seismic exploration studies. Cluster analysis has been used to obtain a quantitative interpretation of the structures producing the scattering and absorption anomalies: the results are mainly influenced by deep tectonics structures. At high frequencies, we observe clear correlation of high scattering/absorption contrasts acting along the NW-SE trend crossing Vrancea, and feasibly produced by coupling or small-scale scattering phenomena produced at the top of either a subducting or detached slab sinking into the astenosphere. While at all frequencies the highest absorption still corresponds to the Focsani sedimentary basin. A unique lowfrequency high-absorption southeast-to-northwest trend marks areas of mantle upwelling, feeding deep Neogene volcanism and reaching the Ciomadul volcanic area, NNW of Vrancea.

\section{ACKNOWLEDGMENTS}



Seismic Analysis Code (SAC) (Goldstein and Snoke, 2005) and GMT (Wessel et al. 2013) codes were used. We thank the College of Physical Sciences (University of Aberdeen) and the Santander Mobility Award for providing travel grant to LDS to complete this manuscript. We are grateful as well to the anonymous reviewer for his useful remarks which helped us to improve the paper.

\section{REFERENCES}

649

Aki, K., and B. Chouet 1975, Origin of coda waves: Source, attenuation, and scattering effects, J. Geophys. Res., 80, 3322-3342.

652

Bala, A., Radulian, M., Popescu, E., 2003. Earthquakes distribution and their focal 654 mechanism in correlation with the active tectonic zones of Romania. Journal of Geodynamics 36: 129-145

656

Balla, Z., 1986. Paleotectonic reconstruction of the central Alpine-Mediteranean belt for the Neogene. Tectonophysics 127, 213-243.

659

Bocin, A., Stephenson, R., Tryggvason, A., Panea, I., Mocanu, V., Hauser, F., Matenco, L., 661 2005. 2.5 D seismic velocity modelling in the south-eastern Romanian Carpathians Orogen and its foreland, Tectonophysics, Volume 410, 273-291

663

Bocin, A., Stephenson, R., Matenco, L., Mocanu, V., 2013 - Gravity and magnetic modelling 665 in the Vrancea Zone, south-eastern Carpathians: Redefinition of the edge of the East European Cratonbeneath the south-eastern Carpathians; Journal of Geodynamics 71, 5264

Bureau Gravimetrique International -http://bgi.omp.obs-mip.fr

Calvet, M., M. Sylvander, L. Margerin, and A. Villaseñor, 2013a Spatial variations of seismic attenuation and heterogeneity in the Pyrenees: Coda $Q$ and peak delay time analysis, Tectonophysics, 608, 428-439.

675 Calvet, M., and L. Margerin 2013b, Lapse-time dependence of coda Q: Anisotropic multiple676 scattering models and application to the Pyrenees, Bull. Seismol. Soc. Am., 103(3), 1993677 2010. 
679 Chalot-Prat, F., Girbacea, R., 2000. Partial delamination of continental mantle lithosphere, 680 upliftrelated crust-mantle decoupling, volcanism and basin formation: a new model for the 681 Pliocene-Quaternary evolution of the southern East-Carpathians, Romania. Tectonophysics $327,83-107$.

683

684 Cloetingh, S., Matenco, L., Bada, G., Dinu C., Mocanu V., 2005 The evolution of the 685 Carpathians-Pannonian system: Interaction between neotectonics, deep structure, 686 polyphase orogeny and sedimentary basins in a source to sink natural laboratory, 687 Tectonophysics 410 (2005) 1-14

688

689

Cornea, I., Radulescu, F., Pompilian, A. and Sova, A., 1981. Deep seismic sounding in 690 Romania. Pure Appl. Geophys., 119: 1144-1156

691

692

Cornish, 2007. Cluster Analysis. Mathematics Learning Support Chapter 3.1,http://www.quic 693 kpdfs.com/read/217773/statistics-3-1-cluster-analysis-1-introduction-2-statstutor.htm

694

695

Csontos, L., 1995 Tertiary tectonic evolution of the Intra-Carpathian area: a review. Acta 696 Vulcanol. 7, 1-13.

697

Del Pezzo, E., F. Bianco, S. Marzorati, P. Augliera, E. D'Alema, and M. Massa 2011, Depth699 dependent intrinsic and scattering seismic attenuation in north central Italy, Geophys. J. Int., 186, 373-381, doi:10.1111/j.1365-246X.2011.05053.x.

701

De Siena, L., E. Del Pezzo, and F. Bianco, 2011, A scattering image of Campi Flegrei from 703 the autocorrelation functions of velocity tomograms, Geophysical Journal International, 184 (3), 1304-1310.

De Siena L., Thomas C., Waite G. P., Moran S. C., Klemme S., 2014, Attenuation and scattering tomography of the deep plumbing system of Mount St. Helens. J. Geophys.Res. Solid Earth, 119, 8223-8238, doi:10.1002/2014JB011372.

De Siena L., Calvet M., Watson K. J., Jonkers A. R. T., Thomas C., 2016, Seismic scattering and absorption mapping of debris flows, feeding paths, and tectonic units at Mount St. Helens volcano. Earth and Planetary Science Letters 442 (2016): 21-31. 
Doglioni, C., P. Harabaglia, G. Martinelli, F. Mongelli,and G. Zito 1996, A geodynamic model of the southern Apennines accretionary prism, Terra Nova, 8, 540-547

Downes, H., Seghedi, I., Szakács, A., Dobosi, G., James, D.E., Vaselli, O., Rigby, I.J., Ingram, G.A., Rex, D., Pécskay, Z., 1995, Petrology and geochemistry of late Tertiary/Quaternary mafic alkaline volcanism in Romania. Lithos 35, 65 - 81

Ellouz, N., and E. Roca 1994, Palinspastic reconstructions of the Carpathians and adjacent areas since the Cretaceous: A quantitative approach, in Peri Tethyan Platforms, edited by F.Roure,pp.51-78, Technip, Paris.

Furumura, T., and Kennett, B., 2005, Subduction zone guided waves and the heterogeneity of the subducted plate: Intensity anomalies in northern Japan: Journal of Geophysical Research, v. 110, B10302, doi:10.1029/2004JB003486.

Galluzzo, D., La Rocca M., Margerin L., Del Pezzo E., and Scarpa R, 2015, Attenuation and velocity structure from diffuse coda waves: Constraints from underground array data; Physics of the Earth and Planetary Interiors 240: 34-42.

Gırbacea, R.A., 1997, The Pliocene to recent tectonic evolution of the Eastern Carpathians (Romania). Tub. Geowiss. Arb., AGeol. Paläontol. Stratigr. 35 (136 pp.).

Girbacea, R., and Frisch, W., 1998, Slab in the wrong place: Lower lithospheric mantle delamination in the last stage of the Eastern Carpathians subduction retreat: Geology, v. 26, p. 611-614.

Global Heat Flow Database (http://www.heat flow.und.edu)

Goldstein, P., A. Snoke, 2005, "SAC Availability for the IRIS Community", Incorporated Institutions for Seismology Data Management Center Electronic Newsletter.

Hartigan, J.A., 1975, Clustering Algorithms, Wiley Series in Probability and Mathematical Statistics, John Wiley \& Sons, New York.

Herrmann, R. B., 1980, Q estimates using the coda of local earthquakes, Bull. Seism. Soc. Am.,70, 447-468, 
751 Hippolyte, J.C., Badescu, D., Constantin, P., 1999, Evolution of the transport direction of the

752 Carpathian belt during its collision with the east European Platform. Tectonics 18, 1120 1138

754

755

Ivan M., 2007, Attenuation of P and pP waves in Vracea area - Romania, Journal of

Knopoff L 1964, Q. Rev Geophys 2:625-660

Koulakov, I., Zaharia, B., Enescu, B., Radulian, M., Popa, M., Parolai, S., and J. Zschau, 2010, Delamination or slab detachment beneath Vrancea? New arguments from local earthquake tomography, Geochem. Geophys. Geosyst. (G3), 11, 3, Q03002, doi:10.1029/2009GC002811

Linzer H.-G., Frisch W., Zweigel P., Girbacea R., Hann H.-P., Moser F., 1998, Kinematic evolution of the Romanian Carpathians, Tectonophysics 297, 133-156

Leever, K., L. Matenco, G. Bertotti, S. Cloetingh, K. G.Drijkoningen, and I. Vasiliev 2006, Pliocene to Recent kinematics in the Focşani basin, Romania: New constraints from shallow seismic and paleo-magnetic data, Basin Res., 18 , 521-545, doi:10.1111/j.13652117.2006.00306.

772

Martin, M., Ritter, J.R.R., the CALIXTO working group 2005, High-resolution tele-seismic body-wave tomography beneath SE Romania - I. Implications forthree-dimensional versus one-dimensional crustal correction strategies witha new crustal velocity model. Geophys. J. Int. 162, 448-460.

Mason, P.R.D., Seghedi, I., Szakács, A., Downes, 1998, Magmatic constraints on 780 geodynamic models of subduction in the East Carpathians, Romania. Tectonophysics 297, $157-176$.

Matenco, L., Zoetemeijer, R., Cloetingh, S. and Dinu, C., 1997, Lateral variations in mechanical properties of the Romanian external Carpathians: inferences of flexure and gravity modelling. Tectonophysics, 282, 147-166. 
Matenco L, Schmid St., 1999, Exhumation of the Danubian nappes system (South Carpathians) during Early Tertiary: inferences from kinematic and paleostress analysis at the Getic/Danubian nappes contact. Tectonophysics 314:401-42

Matenco, L., Bertotti, G., 2000, Tertiary tectonic evolution of the external East Carpathians (Romania). Tectonophysics 316, 255 - 286.

Mayor, J., Margerin, L., \& Calvet, M., 2014. Sensitivity of coda waves to spatial variations of absorption and scattering: radiative transfer theory and 2-D examples, Geophysical Journal International, 197, 1117-1137.

Mocanu, V., Dinu, C., Radulescu, F., Diaconescu M., 1996, Seismogeological features of the crust in Romania G. Wessely, W. Leibl (Eds.), Oil and Gas in Alpidic Thrustbets and Basins of Central and Eastern Europe, EAGE Sp. Publ. No. 5 (1996), pp. 289-29

Neagoe, C. and lonescu, C., 2009, Toward a dense real-time seismic network in Romania, Romanian Reports in Physics 61, 359-366.

Oancea V., Bazacliu O., Mihalache G., Dumitrascu A., 1989, Anomalies of coda waves parameters correlated with large Vrancea intermediate earthquake occurrence, Proc. Of the XXI Gen. Assembly of the ESC, Sofia, Bulgaria, 404 - 409

Oancea, V., Bazacliu, O., Mihalache, G. 1991, The estimation of the coda quality factor for the Romanian territory, Phys. Earth Planet. Inter., 67, 87-94

Obara, K., and Sato, H. 1995, Regional differences of random inhomogeneities around the volcanic front in the Kanto-Tokai area, Japan, revealed from the broadening of $S$ wave seismogram envelopes, J. Geophys. Res. 100, 2103- 2121.

Obermann, A., Planès, T., Larose, E., Sens-Schönfelder, C., \& Campillo, M., 2013, Depth sensitivity of seismic coda waves to velocity perturbations in an elastic heterogeneous medium, Geophysical Journal International, 194(1), 372-382.

Oncescu, M. C., and K. P. Bonjer, 1997, A note on the depth recurrence and strain release of large Vrancea earthquakes, Tectonophysics, 272, 291 - 302, doi:10.1016/S00401951(96)00263-6 
823 Oncescu, M. C., Marza, V, Rizescu, M. and Popa, M., 1999, The Romanian earthquakes 824 catalogue between 984 and 1997. In:Vrancea Earthquakes: Tectonics, Hazard and Risk Mitigation, edited by F. Wenzel, and D. Lungu, Kluwer Academic Publishers, pp. 43-47.

Oth, A., D. Bindi, S. Parolai, and F. Wenzel 2008, S-wave attenuation characteristics beneath the Vrancea region in Romania: new insights from the inversion of ground-motion spectra, Bull. Seismol. Soc. Am. 98,no. 5, 2482-2497, doi: 10.1785/0120080106.

Petukhin, A.G., Gusev, A.A., 2003, The duration-distance relationship and average 833 envelope shapes of small Kamchatka earthquakes. Pure Appl. Geophys. 160, 171-1743.

Popa, M, Radulian, M, Grecu, B, Popescu, E. and Placinta, A. O., 2005, Attenuation in Southeastern Carpathians area: Result of upper mantle inhomogeneity. Tectonophysics 410, 235-249.

837

Popa, M, Radulian M, Ghica D., Neagoe C., Nastase E., 2015, Romanian Seismic Network Since 1980 to the Present, Nonlinear Mathematical Physics and Natural Hazards Volume 163 of the series Springer Proceedings in Physics pp 117-131

Panaiotu, C.G., Vişan, M., Tugui, A., Seghedi, I.,Panaiotu, A.G., 2012, Palaeomagnetism of the South Harghita volcanic rocks of the East Carpathians: implications for tectonic rotations and palaeosecular variation in the past 5Ma , Geophys. J .Int., doi: 10.1111/j.1365246X.2012.05394

Popa, M., Grecu, B., Popescu, E., Placinta, A., Radulian, M., 2003, Asymmetric distribution of seismic motion across Southeastern Carpathians (Romania) and its implications. Rom. Rep. Phys. 55, 521-534 Tomography Data in the Southern Part of the Harghita Mountains (Romania, Southeastern Carpathians): connection with Recent Volcanic Activity, Pure appl. Geophys., September 2012, Volume 169, Issue 9, pp 1557-1573

Popescu, M.N., Dragoescu, I., 1987, Maps of recent vertical crustal movements in Romania: similarities an differences. J. Geodyn. 8, 123-136. 
859 Prudencio, J., Ibáñez, J. M., García-Yeguas, A., Del Pezzo, E., Posadas, A. M., 2013, 860 Spatial distribution of intrinsic and scattering seismic attenuation in active volcanic islands-II:

861 Deception Island images. Geoph. J. Int., 195(3), 1957-1969.

862

863

Radulian M., Mandrescu N., Panza G.F., Popescu E., Utale A., 2000, Characterization of 864 seismogenic zones of Romania, Pure appl. geophys., 157, 57-77.

865

866

Radulian, M., Panza, G.F., Grecu, B. 2006, Seismic wave attenuation for Vrancea events 868 revisited J. Earthquake Engineering, 10, 3, 411-427

Raileanu,V., Diaconescu,C.,Radulescu,F., 1994, Characteristicsof Romanian lithosphere from deep seismic reflection profiling. Tectonophysics 239, 165 - 185.

871

Raileanu, V. \& Diaconescu, C., 1998, Seismic signature in Romanian crust, Tectonophysics, $288,127-136$.

Raileanu V., Dinu C., Ardeleanu L., Diaconescu V., Popescu E., Bala A., Crustal seismicity and associated fault systems in Romania, Procedings of the 27th ECGS Workshop: Seismicity Patterns in the Euro-Med Region, Luxembourg, 17-19 Nov. 2008, in "Cahiers du Centre Europeen de Geodynamique et de Seismologie", 153 - 159, 2009 (ISBN 9.7829-1989702-5).

880

Raileanu V., Tataru D., Grecu B., 2012 Crustal Models in Romania - I. Moesian Platform, Romanian Reports in Physics, Vol. 64, No. 2, P. 539 - 554

Radulescu, D., Cornea, I., Sandulescu, M., Constantinescu, P., Radulescu, F. and Pompilian, A., 1976, Structure de la croute terrestre en Roumanie. Essai d'interprétation des études séismiques profondes, An. Inst. Geol. Geofiz, 50, 5-36

Rautian, T. G., and V. I. Khalturin 1978. The use of the coda for determination of the earthquake source spectrum, Bull. Seismol. Soc. Am. 68, 923-948.

Russo, R.M, Mocanu, V., Radulian, M., 2005. Seismic attenuation in the Carpathian bend zone and surroundings. Earth and Planetary Science Letters, 237 (3-4): 695-709. Romanian) 
896

897

898

899

900

901

902

903

904

905

906

907

908

909

910

911

912

913

914

915

916

917

918

919

920

921

922

923

924

925

926

927

928

929

930

931

Sandulescu, M., Visarion, M., 1988,. La structures des plateformes situées dans l'avant-pays et audessous des nappes du flysch des Carpathes Orientales, Stud. Teh. Econ. - Inst. Geol., Ser. D Prospect. Geofiz. 15, pp. 61-68.

Sandulescu, M., 1988. Cenozoic tectonic history of the Carpathians. In: Royden, L.H., Horvath, F. (Eds.), The Pannonian Basin, A Study in Basin Evolution. AAPG memoir, pp. 17 -25 .

Saito, T., Sato, H., Ohtake, M., 2002. Envelope broadening of spherically outgoing waves in three-dimensional random media having power law spectra. J. Geophys. Res. 107 (B5). http://dx.doi.org/10.1029/2001JB000264.

Saito, T., Sato, H., Ohtake, M., Obara, K., 2005, Unified explanation of envelope broadening and maximum-amplitude decay of high-frequency seismograms based on the envelope simulation using the Markov approximation: forearc side of the volcanic front in northeastern Honshu, Japan. J. Geophys. Res. 110. http://dx.doi.org/10.1029/2004JB003225 (B01304).

Sato, H., 1977, Energy propagation including scattering effects: single isotropic scattering approximation, J. Phys. Earth, 25, 27-41.

Sato, H., 1978, Mean free path of S-waves under the Kanto district of Japan, J. Phys. Earth, 26, 185-198

Sato, H. 1989, Broadening of seismogram envelopes in the randomly inhomogeneous lithosphere based on the parabolic approximation: Southeastern Honshu, Japan, J. Geophys. Res. 94, 17735-7747.

Sato, H., Fehler, M.C. \& Maeda, T., 2012, Seismic Wave Propagation and Scattering in the heterogeneous Earth: Second Edition, Springer

Schmid, S.M., Berza, T., Diaconescu, V., Froitzheim, N., Fuegenschuh, B., 1998, Orogenparallel extension in the South Carpathians during the Paleogene. Tectonophysics 297, 209 $-228$.

Schwartz, G., 1978, Estimating the dimension of a model, Ann. Stat., 6(2), 461-464. 
Seghedi, I. and Szakacs, A., 1994, Upper Pliocene to Quaternary basaltic volcanism in the

Persani Mountains. Romanian J. Pet., 76, 101-107.

934

935

936

937

938

939

940

941

942

943

944

945

946

947

948

949

950

951

952

953

954

955

956

957

958

959

960

961

962

963

964

965

966

967

968

Seghedi, I., Balintoni, I. and Szakacs, A., 1998, Interplay of tectonics and Neogene postcollisional magmatism in the intracarpathian area. Lithos 45, 483- 499.

Seghedi, I., Downes, H., Harangi, S., Mason, P.R.D. and Pecskay, Z., 2005, Geochemical response of magmas to Neogene-Quaternary continental collision in the CarpathianPannonian region: a review. Tectonophysics 410: 485-499.

Shearer, P. M. \& Earle, P. S., 2004, The global short-period wavefield modelled with a Monte Carlo seismic phonon method, Geophysical Journal, Volume 158, Issue 3, pp. 11031117

Sperner, B.the CRC 461 Team, 2005, Monitoring of slab detachment in the Carpathians, in Perspectives in Modern Seismology , F. Wenzel (Editor), Lecture Notes in Earth Sciences, Vol. 105 , Springer Verlag, Berlin

Sudhaus H., Ritter J.R.R. , 2005, High-resolution measurement of the seismic attenuation across the Vrancea region, Romania, Geophys. Res. Lett., 32, 10301

Stanica, D., Stanica, M., 1998, 2D modelling of the geoelectric structure in the area of the deep-focus Vrancea earthquakes. CERGOP "South Carpathians" monograph, vol. 7 (37), pp. 193 -203. Warszawa.

Ştefanescu, M., et al. 1988, Geological cross sections at scale 1:200,000, Map A9-14, Inst. Geol. Geofiz,.Bucharest

Szakács A., Seghedi I., Pécskay Z., 1993, Pecularities of South Harghita Mts. as terminal segment of the Carpathian Neogene to Quaternary volcanic chain. Rev. Roum. de Géologie $37,21-36$

Takahashi, T., H. Sato, T. Nishimura, and K. Obara, 2007, Strong inhomogeneity beneath quaternary volcanoes revealed from the peak delay analysis of S-wave seismograms of microearthquakes in northeastern Japan, Geophysical Journal International, 168 (1), 90-99 
969 Takahashi, T., Sato, H., Nishimura, T., Obara, K., 2009, Tomographic inversion of the peak

970 delay times to reveal random velocity fluctuations in the lithosphere: method and application

971 to northeastern Japan. Geophys. J. Int. 178 (3), 1437-1455

972

973 Tarapoanca, M., Bertotti, G., Matenco, L., Dinu, C., Cloetingh, S., 2003, Architecture of the

974 Focsani Depression: a $13 \mathrm{~km}$ deep basin in the Carpathians Bend Zone (Romania).

975 Tectonics 22, 1074.doi:10.1029/2002TC001486

976

977 Tripathi, J. N., M. Sato, and M. Yamamoto, 2010, Envelope broadening characteristics of

978 crustal earthquakes in northeastern Honshu, Japan, Geophysical Journal International, 182

979 (2), 988-1000

980

981 Weidle, C., 2004, Velocity and Attenuation Structure beneath the South eastern

982 Carpathians, American Geophysical Union, Fall Meeting 2004, abstract \#T33A-1341

983

984 Wessel, P., W. H. F. Smith, R. Scharroo, J. F. Luis, and F. Wobbe, 2013, Generic Mapping

985 Tools: Improved version released, EOS Trans. AGU, 94, 409-410.

986

987 Wortel, M.J.R., and Spakman, W., 2000, Subduction and Slab Detachment in the 988 Mediteranean-Carpathian Region: Science, v. 290, p. 1910-1917.

989

990 Zadeh, I. A.T., Mueller, B. and Schubert, G., 2005, Three dimensional numerical modeling of 991 contemporary mantle flow and tectonic stress beneath the earthquake-prone southeastern 992 Carpathians based on integrated analysis of seismic, heat flow, and gravity data, Physics of 993 the Earth and Planetary Interiors 149, 81-98. 